Universidade de Brasília - UnB

Faculdade de Tecnologia

Departamento de Engenharia Elétrica

André H S Castro e Victor S C Teichmann

\title{
Análise de Desempenho da Transmissão de Sinais OFDM em Banda Base sobre Fibras Multimodo de Perfil Degrau
}

Trabalho apresentado ao Programa de Graduação do Departamento de Engenharia Elétrica da Universidade de Brasília - UnB como requisito parcial para obtenção do grau de Bacharel em Engenharia de Redes de Comunicação.

Orientador: Prof. Dr. Darli A. A. Mello

Co-orientador: Prof. Dr. Adolfo Cartaxo

Campus Darcy Ribeiro - Asa Norte - Brasília

02 de Setembro de 2010 


\section{Resumo}

Multiplexação por divisão em frequências ortogonais (orthogonal frequency division multiplexing - OFDM) é uma técnica de modulação que é bastante difundida nos sistemas de comunicação sem fio. A sua robustez contra os efeitos de multi-percurso e interferência inter-simbólica causadas por um canal dispersivo faz com que taxas de transmissão mais elevadas dos que as utilizadas anteriormente sejam possíveis nesses sistemas. Recentemente, estudos que visam a aplicar essa técnica em sistemas ópticos têm sido desenvolvidos. Esta monografia visa aplicar a técnica de modulação OFDM em fibras multimodo (multimode fiber - MMF), para avaliar o comportamento do sinal perante a dispersão modal da fibra. Esse estudo inclui a análise de diversas condições de lançamento da luz em uma fibra, bem como para diferentes comprimentos da fibra. O conhecimento dos modos de acoplamento na fibra é fundamental para a otimização do sistema, permitindo assim buscar a maximização do produto banda-comprimento de fibra (BxL). O estudo que esta tese desenvolve foi motivado pelo baixo custo de implementação de fibras multimodo em redes de curta distância.

Palavras-chave: Comunicações ópticas, dispersão modal, fibra multimodo (multimode fiber - MMF), multiplexação por divisão em frequências ortogonais (orthogonal frequency division multiplexing - OFDM). 

Dedicamos este trabalho a todos os nossos amigos, professores e familiares que nos apoiaram nesse projeto em toda a sua trajetória. 



\section{Agradecimentos}

Agradecemos a todos os nossos amigos, professores e familiares que nos apoiaram nesse projeto em toda a sua trajetória. 

O louco que persiste em sua loucura, se torna sábio.

—ALBERT EINSTEIN (1908) 




\section{Sumário}

1 Introdução 1

1.1 Fibras multimodo 1

1.2 OFDM 2

1.3 Revisão bibliográfica 2

1.4 Objetivos desta monografia 4

2 Derivação Matemática da Resposta Impulsional da MMF 5

2.1 Cálculo dos coeficientes de acoplamento 5

$\begin{array}{ll}2.2 \text { Modos de propagação da fibra } & 10\end{array}$

2.3 Definição das amplitudes modais 11

2.4 Condições de lançamento $\quad 14$

2.5 Resposta impulsional da fibra 16

3 Transmissão DD-OFDM 17

$\begin{array}{lll}3.1 & \text { Transmissor } & 17\end{array}$

$\begin{array}{lll}3.2 & \text { Canal } & 22\end{array}$

3.3 Receptor 23

4 Resultados de Simulação para uma Fibra Multimodo com Perfil Degrau 25

4.1 Resultados de simulação dos campos da fibra multimodo 25

4.2 Função de transferência para diversas condições de lançamento 32

4.3 Resultados para diferentes raios da SMF

5 Resultados de Simulação para o Sistema OFDM 53

5.1 Estimador de canal e equalizador $\quad 53$

5.2 Métodos de avaliação de desempenho 55

5.3 Resultados e discussões 56

$\begin{array}{lll}6 & \text { Conclusões } & 77\end{array}$

A Sistema de Coordenadas $\quad 79$

$\begin{array}{lll}\text { B Implementação } & 83\end{array}$ 



\section{Lista de Figuras}

2.1 Representação das funções de Bessel de primeiro e segundo tipo.

2.2 Representação das funções de Bessel modificadas de primeiro e segundo tipo. 8

2.3 Função de Hankell do primeiro tipo. 9

$\begin{array}{lll}2.4 & \text { Sistema de coordenadas } & 14\end{array}$

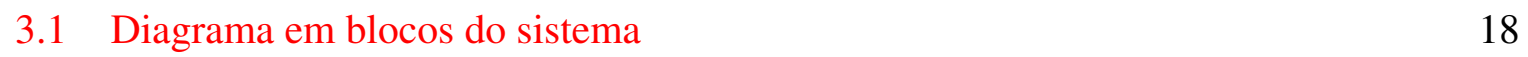

3.2 Diagrama em blocos do transmissor $\quad 18$

3.3 Diagrama em blocos do receptor 19

3.4 Potência de saída do modulador Mach-Zehnder em função da tensão em seus braços para $V_{\pi}=0.5 \mathrm{~V}$ e $P_{I N}=1 \mathrm{~mW} \quad 20$

3.5 Potência de saída do modulador Mach-Zehnder em função da tensão em seus braços para $V_{\pi}=1 \mathrm{~V}$ e $P_{I N}=1 \mathrm{~mW} \quad 21$

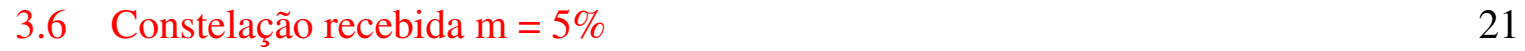

3.7 Constelação recebida $\mathrm{m}=15 \%$

$\begin{array}{lll}4.1 & \text { LP01 } & 26\end{array}$

$\begin{array}{lll}4.2 & \text { LP02 } & 26\end{array}$

$\begin{array}{lll}4.3 & \text { LP11 } & 27\end{array}$

$\begin{array}{lll}4.4 & \text { LP12 } & 27\end{array}$

$\begin{array}{lll}4.5 & \text { LP21 } 28 & 28\end{array}$

$\begin{array}{lll}4.6 & \text { LP22 } & 28\end{array}$

$\begin{array}{lll}4.7 & \text { LP31 } & 29\end{array}$

$\begin{array}{lll}4.8 & \text { LP32 } & 29\end{array}$

$\begin{array}{lll}4.9 & \text { LP41 } & 30\end{array}$

$\begin{array}{lll}4.10 \mathrm{LP} 42 & 30\end{array}$

4.11 Campo da fibra monomodo. $R_{\text {offset }}=0$ e $\theta_{\text {offset }}=0$ radiano $\quad 32$

4.12 Resposta impulsional da fibra multimodo. $R_{\text {offset }}=0$ e $\theta_{\text {offset }}=0$ radiano $\quad 33$

4.13 Distribuição da parcela de potência por modo. $R_{\text {offset }}=0$ e $\theta_{\text {offset }}=0$ radiano 33

4.14 Resposta em amplitude da fibra multimodo. $R_{\text {offset }}=0$ e $\theta_{\text {offset }}=0$ radiano $\quad 33$

4.15 Atraso de grupo da fibra multimodo. $R_{\text {offset }}=0$ e $\theta_{\text {offset }}=0$ radiano $\quad 34$

4.16 Campo da fibra monomodo. $R_{\text {offset }}=5 \mu \mathrm{m}$ e $\theta_{\text {offset }}=0$ radiano $\quad 35$

4.17 Resposta impulsional da fibra multimodo. $R_{\text {offset }}=5 \mu \mathrm{m}$ e $\theta_{\text {offset }}=0$ radiano $\quad 35$

4.18 Distribuição da parcela de potência por modo. $R_{\text {offset }}=5 \mu \mathrm{m}$ e $\theta_{\text {offset }}=0$ radiano.

4.19 Resposta em amplitude da fibra multimodo. $R_{\text {offset }}=5 \mu \mathrm{m}$ e $\theta_{\text {offset }}=0$ radiano 36 4.20 Atraso de grupo da fibra multimodo. $R_{\text {offset }}=5 \mu \mathrm{m}$ e $\theta_{\text {offset }}=0$ radiano. $\quad 36$ 
4.21 Campo da fibra monomodo. $R_{\text {offset }}=5 \mu \mathrm{m}$ e $\theta_{\text {offset }}=\pi / 4$ radianos.

4.22 Resposta impulsional da fibra multimodo. $R_{\text {offset }}=5 \mu \mathrm{m}$ e $\theta_{\text {offset }}=\pi / 4$ radianos.

4.23 Distribuição da parcela de potência por modo. $R_{\text {offset }}=5 \mu \mathrm{m}$ e $\theta_{\text {offset }}=\pi / 4$ radianos.

4.24 Resposta em amplitude da fibra multimodo. $R_{\text {offset }}=5 \mu \mathrm{m}$ e $\theta_{\text {offset }}=\pi / 4$ radianos.

4.25 Atraso de grupo da fibra multimodo. $R_{\text {offset }}=5 \mu \mathrm{m}$ e $\theta_{\text {offset }}=\pi / 4$ radianos.

4.26 Campo da fibra monomodo. $R_{\text {offset }}=5 \mu \mathrm{m}$ e $\theta_{\text {offset }}=\pi / 2$ radianos.

4.27 Resposta impulsional da fibra multimodo. $R_{\text {offset }}=5 \mu \mathrm{m}$ e $\theta_{\text {offset }}=\pi / 2$ radianos.

4.28 Distribuição da parcela de potência por modo. $R_{\text {offset }}=5 \mu \mathrm{m}$ e $\theta_{\text {offset }}=\pi / 2$ radianos.

4.29 Resposta em amplitude da fibra multimodo. $R_{\text {offset }}=5 \mu \mathrm{m}$ e $\theta_{\text {offset }}=\pi / 2$ radianos.

4.30 Atraso de grupo da fibra multimodo. $R_{\text {offset }}=5 \mu \mathrm{m}$ e $\theta_{\text {offset }}=\pi / 2$ radianos.

4.31 Campo da fibra monomodo. $R_{\text {offset }}=12.5 \mu \mathrm{m}$ e $\theta_{\text {offset }}=0$ radiano.

4.32 Resposta impulsional da fibra multimodo. $R_{\text {offset }}=12.5 \mu \mathrm{m}$ e $\theta_{\text {offset }}=0$ radiano.

4.33 Distribuição da parcela de potência por modo. $R_{\text {offset }}=12.5 \mu \mathrm{m}$ e $\theta_{\text {offset }}=0$ radiano.

4.34 Resposta em amplitude da fibra multimodo. $R_{\text {offset }}=12.5 \mu \mathrm{m}$ e $\theta_{\text {offset }}=0$ radiano.

4.35 Atraso de grupo da fibra multimodo. $R_{\text {offset }}=12.5 \mu \mathrm{m}$ e $\theta_{\text {off } f \text { set }}=0$ radiano.

4.36 Campo da fibra monomodo. $R_{\text {offset }}=12.5 \mu \mathrm{m}$ e $\theta_{\text {offset }}=\pi / 2$ radianos.

4.37 Resposta impulsional da fibra multimodo. $R_{\text {offset }}=12.5 \mu \mathrm{m}$ e $\theta_{\text {offset }}=\pi / 2$ radianos.

4.38 Distribuição da parcela de potência por modo. $R_{\text {offset }}=12.5 \mu \mathrm{m}$ e $\theta_{\text {offset }}=$ $\pi / 2$ radianos.

4.39 Resposta em amplitude da fibra multimodo. $R_{\text {offset }}=12.5 \mu \mathrm{m}$ e $\theta_{\text {offset }}=\pi / 2$ radianos.

4.40 Atraso de grupo da fibra multimodo. $R_{\text {offset }}=12.5 \mu \mathrm{m}$ e $\theta_{\text {offset }}=\pi / 2$ radianos. 46

4.41 Campo da fibra monomodo. $R_{\text {offset }}=20 \mu \mathrm{m}$ e $\theta_{\text {offset }}=0$ radiano.

4.42 Resposta impulsional da fibra multimodo. $R_{\text {offset }}=20 \mu \mathrm{m}$ e $\theta_{\text {offset }}=0$ radiano. 47

4.43 Distribuição da parcela de potência por modo. $R_{\text {offset }}=20 \mu \mathrm{m}$ e $\theta_{\text {offset }}=0$ radiano.

4.44 Resposta em amplitude da fibra multimodo. $R_{\text {offset }}=20 \mu \mathrm{m}$ e $\theta_{\text {offset }}=0$ radiano. 47

4.45 Atraso de grupo da fibra multimodo. $R_{\text {offset }}=20 \mu \mathrm{m}$ e $\theta_{\text {offset }}=0$ radiano. $\quad 48$

4.46 Campo da fibra monomodo. $R_{\text {offset }}=30 \mu \mathrm{m}$ e $\theta_{\text {offset }}=0$ radiano. $\quad 49$

4.47 Resposta impulsional da fibra multimodo. $R_{\text {offset }}=30 \mu \mathrm{m}$ e $\theta_{\text {offset }}=0$ radiano. 49

4.48 Distribuição da parcela de potência por modo. $R_{\text {offset }}=30 \mu \mathrm{m}$ e $\theta_{\text {offset }}=0$ radiano.

4.49 Resposta em amplitude da fibra multimodo. $R_{\text {offset }}=30 \mu \mathrm{m}$ e $\theta_{\text {offset }}=0$ radiano. 50 
4.50 Atraso de grupo da fibra multimodo. $R_{\text {offset }}=30 \mu \mathrm{m}$ e $\theta_{\text {offset }}=0$ radiano.

4.51 Distribuição de potência por modos para uma fibra monomodo de $2 \mu \mathrm{m}$ de raio do núcleo, para um lançamento centrado.

4.52 Distribuição de potência por modos para uma fibra monomodo de $3 \mu \mathrm{m}$ de raio do núcleo, para um lançamento centrado.

4.53 Distribuição de potência por modos para uma fibra monomodo de $4 \mu \mathrm{m}$ de raio do núcleo, para um lançamento centrado.

5.1 BER x $R_{\text {offset }}$ para $\theta_{\text {offset }}=0$ radiano.

5.2 BER x $\theta_{\text {offset }}$ para $R_{\text {offset }}=2.5 \mu \mathrm{m}$.

5.3 BER x $\theta_{\text {offset }}$ para $R_{\text {offset }}=12.5 \mu \mathrm{m}$.

5.4 BER x $\theta_{\text {offset }}$ para $R_{\text {offset }}=25 \mu \mathrm{m}$.

5.5 Espectro de amplitude do sinal OFDM após diodo PIN.

5.6 Espectro de amplitude do sinal OFDM após diodo PIN com adição de ruído.

5.7 Espectro de amplitude do sinal OFDM filtrado após diodo PIN com adição de ruído e após filtragem.

5.8 BER por MC versus erros na pior sub-portadora.

5.9 BER versus número de amostras por sub-portadora para $\frac{E_{b}}{N 0}=2 \mathrm{~dB} \quad 62$

5.10 BER versus número de amostras por sub-portadora para $\frac{E_{b}}{N 0}=6 \mathrm{~dB} \quad 63$

5.11 Variação relativa da BER versus número de amostras por sub-portadora para $\frac{E_{b}}{N 0}=2 \mathrm{~dB}$

5.12 Variação relativa da BER versus número de amostras por sub-portadora para $\frac{E_{b}}{N 0}=6 \mathrm{~dB}$

5.13 BER versus $\frac{E_{b}}{N 0}$

5.14 Taxa de transmissão versus número de sub-portadoras piloto 65

5.15 BER em função do comprimento da fibra multimodo 66

5.16 Resposta de amplitude do sistema e do equalizador para $280 \mathrm{~m}$ de fibra multimodo 66

5.17 Resposta ao atraso do sistema e do equalizador para $280 \mathrm{~m}$ de fibra multimodo 67

5.18 Resposta ao impulso do sistema para $280 \mathrm{~m}$ de fibra multimodo 67

5.19 Resposta de amplitude do sistema e do equalizador para $300 \mathrm{~m}$ de fibra multimodo 67

5.20 Resposta ao atraso do sistema e do equalizador para $300 \mathrm{~m}$ de fibra multimodo $\quad 68$

5.21 Resposta ao impulso do sistema para $300 \mathrm{~m}$ de fibra multimodo 68

5.22 Resposta de amplitude do sistema e do equalizador para 66 sub-portadoras piloto, $500 \mathrm{~m}$ de fibra multimodo e polinômio interpolador de ordem 4

5.23 Resposta ao atraso do sistema e do equalizador para 66 sub-portadoras piloto, $500 \mathrm{~m}$ de fibra multimodo e polinômio interpolador de ordem 4

5.24 Resposta de amplitude do sistema e do equalizador para 128 sub-portadoras piloto, $500 \mathrm{~m}$ de fibra multimodo e polinômio interpolador de ordem 4

5.25 Resposta ao atraso do sistema e do equalizador para 128 sub-portadoras piloto, $500 \mathrm{~m}$ de fibra multimodo e polinômio interpolador de ordem 4

5.26 Resposta de amplitude do sistema e do equalizador para 66 sub-portadoras piloto, $500 \mathrm{~m}$ de fibra multimodo e polinômio interpolador de ordem 1 
5.27 Resposta ao atraso do sistema e do equalizador para 66 sub-portadoras piloto, $500 \mathrm{~m}$ de fibra multimodo e polinômio interpolador de ordem 1

5.28 Resposta de amplitude do sistema e do equalizador para 26 sub-portadoras piloto, $100 \mathrm{~m}$ de fibra multimodo e polinômio interpolador de ordem 3

5.29 Resposta ao atraso do sistema e do equalizador para 26 sub-portadoras piloto, $100 \mathrm{~m}$ de fibra multimodo e polinômio interpolador de ordem 3

5.30 $E V M_{R M S}$ versus grau do polinômio interpolador para diferentes números de sub-portadoras piloto e comprimento de MMF

5.31 Constelação recebida antes da equalização para 500 m de MMF, 66 sub-portadoras piloto e polinômio interpolador de grau 4

5.32 Constelação recebida após equalização para 500 m de MMF, 66 sub-portadoras piloto e polinômio interpolador de grau 4

5.33 Constelação recebida antes da equalização para 500 m de MMF, 128 subportadoras piloto e polinômio interpolador de grau 4

5.34 Constelação recebida após equalização para 500 m de MMF, 128 sub-portadoras piloto e polinômio interpolador de grau 4

5.35 Constelação recebida antes da equalização para 100 m de MMF, 26 sub-portadoras piloto e polinômio interpolador de grau 3

5.36 Constelação recebida após equalização para 100 m de MMF, 26 sub-portadoras piloto e polinômio interpolador de grau 3

A.1 Mapeamento do eixo de coordenadas em matriz.

A.2 Matrizes sobrepostas com lançamento centralizado.

80

A.3 Matrizes sobrepostas com lançamento deslocado no raio e ângulo. 


\section{Lista de Tabelas}

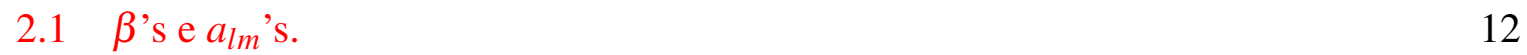

4.1 $N_{l m}$ 's e $h_{l m}$ 's. 31

4.2 Variações para a resposta em amplitude e ao atraso para diversas condições de lançamento.

5.1 Resumo dos resultados do capítulo 



\section{CAPÍTULO 1 \\ Introdução}

Com a migração de tecnologias de rede para protocolos de taxa de transmissão da ordem de gigabits por segundo (Gigabit Ethernet, 10 Gigabit Ethernet e 100 Gigabit Ethernet [1]), passouse a difundir mais o uso de fibras ópticas para aplicações de rede local (local area network LAN). Fibras monomodo têm sido utilizadas em sistemas de longo alcance e a dispersão modal inexistente nessas fibras faz com que elas sejam uma boa escolha para esse tipo de aplicação. Mas o seu alto custo de implementação e a sua grande sensibilidade a curvaturas dificultam a sua utilização em redes locais. Diante dessas circunstâncias a fibra multimodo se torna uma boa opção, mas ainda limitada pela dispersão modal, que implica um alargamento dos pulsos, o que pode levar a uma maior probabilidade de erro de bit.

\subsection{Fibras multimodo}

Fibras multimodo têm sido cada vez mais utilizadas em sistema ópticos e, dessa forma, diversos estudos vêm sendo feitos visando aumentar o desempenho desses sistemas. O fato de elas possuírem um diâmetro do núcleo maior do que as fibras monomodo faz com que o seu custo seja menor, devido à sua menor complexidade de acoplamento com a fonte. Outra vantagem é a maior facilidade de manipulação da fibra. Mas quanto maior o núcleo da fibra, mais modos são excitados, o que aumenta a dispersão modal. A sua larga utilização tem sido em redes locais e redes domésticas, ou seja, em redes de pequeno alcance.

Para garantir um bom desempenho em redes Gigabit Ethernet, deve-se amenizar os efeitos da dispersão modal, razão principal da limitação do produto BxL (banda de transmissão x comprimento) da fibra multimodo. A dispersão modal acontece devido às diferentes constantes de propagação dos modos excitados na fibra. Devido a este fenômeno, diversas técnicas têm sido estudadas e implementadas nas fibras multimodo, sempre visando mitigar a dispersão modal. Entre elas, a condição de lançamento na fibra é uma técnica importante, pois os parâmetros ópticos dos campos de propagação da fibra dependem do campo incidente [2] [3]. Neste caso, o laser de bombeio é posicionado com um deslocamento radial e/ou angular em relação ao centro da fibra multimodo, visando excitar modos pré-determinados, para amenizar a diferença entre as suas constantes de propagação. O nível de compreensão dos vários fenômenos existentes no sistema é importante para o seu correto funcionamento. Dessa forma, o conhecimento detalhado de como os modos são excitados é relevante para o controle do sistema e para definir a precisão da condição de lançamento.

Em redes locais típicas, o comprimento das fibras multimodo utilizadas é menor do que 300 metros [4]. Com a possibilidade de se controlar os modos excitados por meio das condições 
de lançamento, estudos têm apontado a possibilidade de se fazer um sistema multicanal ou MIMO (técnica de transmissão de múltiplas entradas e múltiplas saídas) [5], utilizando-se apenas uma fibra multimodo. Para avaliar as melhores condições de lançamento, necessitase de uma definição da distribuição dos coeficientes de acoplamento de potência dos modos. Realizam-se essa derivação e a análise de algumas possibilidades de lançamento nessa monografia.

\subsection{OFDM}

Técnicas OFDM têm sido utilizadas em sistemas sem fio devido à sua grande robustez em relação à interferência inter-simbólica (intersymbol interference - ISI) causada em um meio dispersivo. Uma vantagem para os transmissores e receptores é que através da transformada rápida de Fourier (fast Fourier transform - FFT) e da transformada rápida de Fourier inversa (inverse fast Fourier transform - IFFT) pode-se trabalhar no domínio digital, facilitando a sua implementação.

O fato de o sinal OFDM ser definido a partir de componentes em frequência (sub-portadoras) muito bem definidas faz com que o espectro do sinal OFDM também seja muito bem definido. Isso facilita a implementação e a utilização de filtros na transmissão e recepção. Essas vantagens, entre outras, fizeram com que o OFDM fosse cogitado como formato de modulação em sistemas ópticos. Nessa monografia, realizamos a análise através de simulações de um sinal OFDM em banda base sendo transmitido ao longo de uma fibra multimodo de perfil degrau. Análises de desempenho através do cálculo da taxa de erro de bit (bit error rate - BER) também foram feitas. Estimamos a BER por simulações de Monte-Carlo (MC) e pelo método magnitude do vetor erro (error vector magnitude - EVM), para diversos parâmetros do sistema.

\subsection{Revisão bibliográfica}

Diversas técnicas têm sido estudadas e implementadas visando ao aumento do produto BxL no âmbito de altas taxas de transmissão, uma vez que um dos focos de operação das fibras multimodo são as redes locais, domésticas e data centers, em que a ligação dos mesmos é feita utilizando fibras multimodo. A referência [6] estuda o método de casamento do campo do modo fundamental de uma fibra monomodo com o campo do modo fundamental de uma fibra multimodo. Tal técnica se baseia em concentrar o sinal transmitido no modo fundamental (LP01) da fibra multimodo, reduzindo drasticamente os efeitos da dispersão modal. Faz-se uma emenda por fusão, em que aumenta-se o núcleo da fibra monomodo gradativamente até atingir o ponto ideal de casamento dos campos. O artigo realiza um estudo para diferentes condições da variação do núcleo da fibra monomodo, observando sempre o acoplamento modal na fibra multimodo. Analisam-se as perturbações na fibra, bem como pequenos deslocamentos no momento da fusão.

A forma do campo de lançamento também exerce influência na excitação dos modos e consequentemente na dispersão modal, como pode ser visto em [7]. Esta monografia faz a análise para algumas condições de lançamento, bem como para diferentes áreas de inserção do 
campo incidente na fibra multimodo. Fazem-se também análises de perfil Gaussiano e perfil em anel para o campo de lançamento, bem como a variação do diâmetro do anel. Realiza-se ainda uma análise da BER com o método de equalização por realimentação, para diferentes distâncias.

A referência [8] faz uma abordagem completa da transmissão de altas taxas em fibras multimodo. Realiza-se uma derivação dos modos de propagação da MMF e seus respectivos atrasos, bem como a análise para diferentes índices de refração para um perfil degrau. É possível observar o comportamento dos atrasos para cada perfil em relação ao modo fundamental. Posteriormente, faz-se uma avaliação de como os modos são excitados quando se muda a condição de lançamento. Obtém-se o resultado esperado, em que os modos de maior ordem são excitados à medida que se afasta o campo de lançamento da região central da fibra multimodo. Realiza-se também uma comparação do tipo de dispositivo usado para gerar a luz no emissor. O artigo analisa diversas características da fibra, bem como diferentes tipos de modulação e diferentes comprimentos de fibra. Introduz-se também uma abordagem de possíveis técnicas de otimização do sistema. Entre elas, técnicas especiais de lançamento, equalização baseada no transmissor, compensação de dispersão eletrônica, multiplexação por divisão no comprimento de onda (wavelength division multiplexing - WDM) e modulação adaptativa para sub-portadoras em sinais OFDM.

Uma derivação das expressões analíticas para os coeficientes de acoplamento para condições de lançamento arbitrárias pode ser vista em [4], para fibras multimodo com perfil gradual. Nesta referência, faz-se uma análise dos campos elétricos e magnéticos, bem como os campos híbridos. Demonstra-se também todas as derivações e validações das expressões obtidas para os campos e acoplamentos modais e a conservação de potência. Fazem-se todas as derivações para um índice do perfil gradual igual a 2, e posteriormente expandidas para uma faixa de 1,8 a 2,2 .

Cogita-se também a utilização da fibra multimodo para sistemas de longo alcance devido ao seu baixo custo quando comparado ao da fibra monomodo, conforme visto em [9]. Obtém-se experimentalmente altas taxas de transmissão para fibras multimodo com o comprimento de 100km, utilizando sinais OFDM.

Uma vez definidos os fatores relacionados à fibra multimodo, deve-se analisar e definir os fatores relacionados aos sinais OFDM. Existem algumas categorias de sinais OFDM, entre elas o OFDM de banda ultra larga (OFDM Ultra-Wideband - OFDM-UWB), que é um sinal alocado em uma banda entre 3.1 e $10.6 \mathrm{GHz}$. Afere-se a degradação de desempenho do OFDM-UWB causada por canais dispersivos em uma fibra monomodo em [10], tanto numericamente quanto teoricamente. $\mathrm{O}$ artigo utiliza binary phase shift keying (BPSK) como formato de modulação das sub-portadoras de dados e avalia a BER por sub-portadora utilizando o método de abordagem Gaussiana semi-analítica (semianalytical Gaussian approach - GA), sendo feita uma comparação deste com o Monte Carlo. Os resultados mostram que o GA obtém uma boa estimativa da BER, com discrepâncias não maiores que metade de uma ordem de grandeza. A referência citada então deriva uma expressão para a variação da OSNR (optical signal-to-noise ratio) para compensar os efeitos de redução da potência do sinal elétrico causada pela dispersão.

Apresenta-se um estudo sobre a transmissão do OFDM-UWB bidirecional em fibras multimodo em [11], exibindo resultados de desempenho para este sistema através da taxa de erro de 
pacotes (packet error rate - PER) e confirmações (acknowledgements) recebidos.

Tendo em vista que a tecnologia OFDM óptico coerente (Coherent Optical OFDM - COOFDM) pode utilizar as regiões em banda passante de alta frequência e pode carregar altas taxas de informação, mas tem seu desempenho degradado pelas regiões de desvanecimento profundo da fibra multimodo, propõe-se um algoritmo de modulação adaptativa em [12]. Após exibir os resultados experimentais, conclui-se que esta técnica reduz em $2 \mathrm{~dB}$ a OSNR requerida para uma transmissão de $21.4 \mathrm{~Gb} / \mathrm{s}$ em $200 \mathrm{~km}$ de fibra multimodo.

\subsection{Objetivos desta monografia}

Tendo em vista que vários trabalhos recentes sugerem que o OFDM vem se mostrando uma tecnologia promissora para comunicações ópticas, esta monografia tem o objetivo de analisar o desempenho da transmissão desta técnica de modulação em uma fibra multimodo de perfil degrau, investigando principalmente a capacidade de amenizar os efeitos da interferência intersimbólica (intersymbol interference - ISI) causada pela dispersão modal.

Outro objetivo é a derivação matemática dos coeficientes de acoplamento de potência em cada modo, o que é fundamental para a modelagem da fibra multimodo, pois estes são utilizados no cálculo da resposta impulsional da MMF.

Realiza-se um estudo das condições de lançamento da luz na fibra com o intuito de decidir qual o caso que gera menos erros na recepção. Também coloca-se o sistema à prova para várias intensidades de ruído, comprimentos de fibra e número de sub-portadoras piloto, sendo que em cada caso faz-se uma avaliação rigorosa de desempenho através da taxa de erro de bit (BER). Estima-se esta última utilizando duas técnicas: EVM e simulação de Monte Carlo, com o objetivo de realizar uma comparação entre as duas, concluir qual delas se aplica melhor em cada caso e as vantagens e desvantagens de cada uma. 


\section{CAPÍtUlo 2 \\ Derivação Matemática da Resposta Impulsional da MMF}

Este capítulo desenvolve matematicamente a resposta impulsional da fibra multimodo, para uma posterior simulação e análise de resultados para diversas condições do sistema nos próximos capítulos. Fazem-se derivações para os campos de propagação dos modos presentes na fibra, bem como a definição de seus coeficientes de acoplamento de potência.

Dessa forma, faz-se a análise das amplitudes modais na saída da fibra, dependendo das possíveis condições de lançamento do campo elétrico em sua entrada. Assim, determina-se a função de transferência da fibra multimodo, em função de seus parâmetros físicos e das possíveis condições de lançamento.

\subsection{Cálculo dos coeficientes de acoplamento}

De acordo com [13], tem-se a expressão para o campo total guiado na fibra multimodo:

$$
\frac{d^{2} \Psi(r, \phi)}{d r^{2}}+\frac{1}{r} \frac{d \Psi(r, \phi)}{d r}+\frac{1}{r^{2}} \frac{d^{2} \Psi(r, \phi)}{d \phi^{2}}+\left(k^{2} n^{2}-\beta^{2}\right) \Psi(r, \phi)=0,
$$

em que $\Psi(r, \phi)$ representa o campo na fibra em coordenadas cilíndricas, $n$ representa o índice de refração, $\beta$ é a constante de propagação, e $k=2 \pi / \lambda_{0}$, em que $\lambda_{0}$ é o comprimento de onda de operação. Utilizando o método de separação de variáveis:

$$
\Psi(r, \phi) \equiv R(r) \Phi(\phi),
$$

em que $R(r)$ representa a componente de $\Psi(r, \phi)$ que varia com o raio e $\Phi(\phi)$ a componente que varia com o ângulo. Nesse caso:

$$
\begin{gathered}
\frac{d^{2} R_{v} r}{d r^{2}}+\frac{1}{R} \frac{d R_{v}(r)}{d r}+\left[k^{2} n^{2}-\beta^{2}-\frac{v^{2}}{r^{2}}\right] R_{v}(r)=0, \\
\frac{d^{2} \Phi_{v}(\phi)}{d \phi^{2}}+v^{2} \Phi_{v}(\phi)=0 .
\end{gathered}
$$

Na equação 2.4, verifica-se que o valor de $v$ deve ser inteiro positivo ou negativo, incluindo o zero, para que satisfaça corretamente os ciclos periódicos de $2 \pi$ das possíveis soluções apresentadas: 


$$
v=0, \pm 1, \pm 2, \pm 3, \ldots
$$

Para um dado $v$, divide-se a solução em duas, para $\kappa>0$ e $\kappa<0$, em que

$$
\left|\kappa^{2}\right| \equiv k^{2} n^{2}-\beta^{2}
$$

No primeiro caso, representando a solução no núcleo, tem-se a solução a partir da combinação das funções de Bessel de primeiro e segundo tipo, ambas com o argumento $\kappa r$ :

$$
R_{v}(r)=A J_{v}(\kappa r)+A^{\prime} Y_{v}(\kappa r), r<a
$$

em que $A$ e $A^{\prime}$ são constantes e $a$ representa o raio do núcleo.

Já para o segundo caso, tem-se a solução para a casca, também dada pelas funções de Bessel de primeiro e segundo tipo, ambas com argumento $|\kappa| r$ :

$$
R_{v}(r)=C K_{v}(|\kappa| r)+C^{\prime} I_{v}(|\kappa| r), r>a
$$

em que $C$ e $C^{\prime}$ são constantes.

A constante de fase $\beta$ para cada modo segue a seguinte regra:

$$
k n_{2}<\beta<k n_{1},
$$

em que $n_{1}$ e $n_{2}$ são os índices de refração do núcleo e da casca, respectivamente. A definição da equação 2.9 ocorre a partir da equação 2.6 , e assumindo $\kappa^{2}>0$ para o núcleo e $\kappa^{2}<0$ para a casca.

A solução do campo magnético segue a mesma estrutura, diferenciando-se apenas pelo índice da função de Bessel [13].

A solução da equação 2.4, como citado anteriormente, é definida a partir da escolha da base, gerando assim as seguintes possíveis soluções:

$$
\phi_{v}(\phi)=\left\{\begin{array}{l}
e^{j v \phi} \\
\cos (v \phi) \\
\sin (v \phi)
\end{array} .\right.
$$

Como $Y_{V}(\kappa r)$ tende a $-\infty$ à medida que $r \rightarrow 0$ para todas as ordens de $Y_{V}(\kappa r)$ :

$$
\lim _{|\kappa| r \rightarrow+\infty} Y_{v}(|\kappa| r)=-\infty,|v| \geq 0
$$

e que $K_{V}(\kappa r)$ na equação 2.7 tende a zero assimptoticamente e $I_{V}(|\kappa| r)$ na equação 2.8 diverge:

$$
\begin{gathered}
\lim _{|\kappa| r \rightarrow+\infty} K_{v}(|\kappa| r)=0,|v| \geq 0 \\
\lim _{|\kappa| r \rightarrow+\infty} I_{\nu}(|\kappa| r)=+\infty,|v| \geq 0
\end{gathered}
$$



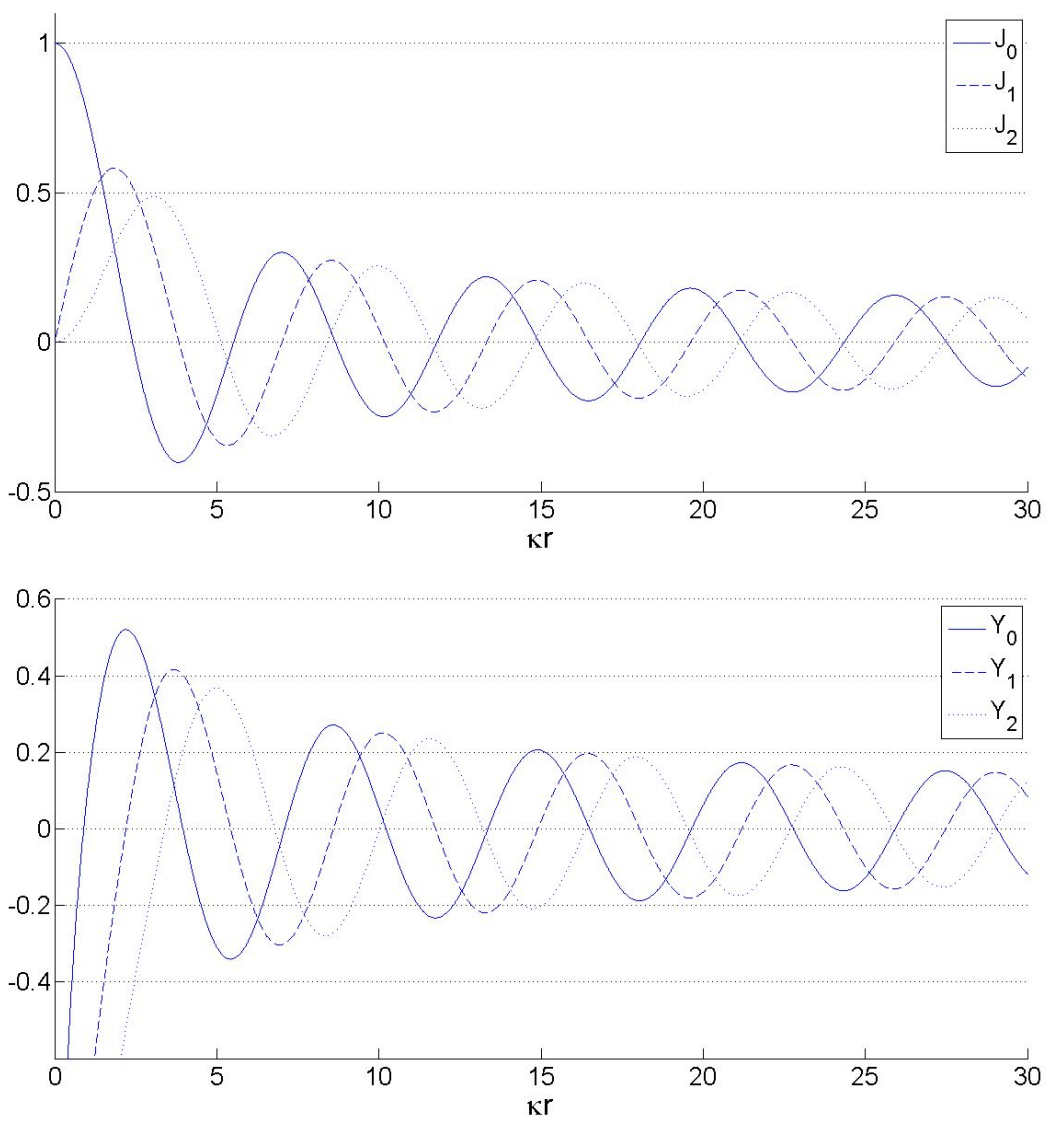

Figura 2.1 Representação das funções de Bessel de primeiro e segundo tipo.

define-se a equação para o núcleo

$$
\Psi(r, \phi)=A J_{v}(\kappa r)\left\{\begin{array}{l}
\sin (v \theta) \\
\cos (v \theta)
\end{array} \quad \Rightarrow 0 \leq r \leq a,\right.
$$

e para a casca

$$
\Psi(r, \phi)=C K_{v}(\kappa r)\left\{\begin{array}{l}
\sin (v \theta) \\
\cos (\nu \theta)
\end{array} \quad \Rightarrow a \leq r<\infty .\right.
$$

As funções de Bessel estão representadas nas Figuras 2.1 e 2.2.

Usando-se a aproximação paraxial [14], e levando em consideração a solução para cada modo, referente ao índice azimutal $v$, tem-se a seguinte equação:

$$
\frac{J_{v}^{\prime}(u)}{u J_{v}(u)}+\frac{K_{v}^{\prime}(w)}{w K_{v}(w)}= \pm v\left(\frac{1}{w^{2}}+\frac{1}{u^{2}}\right),
$$

em que 

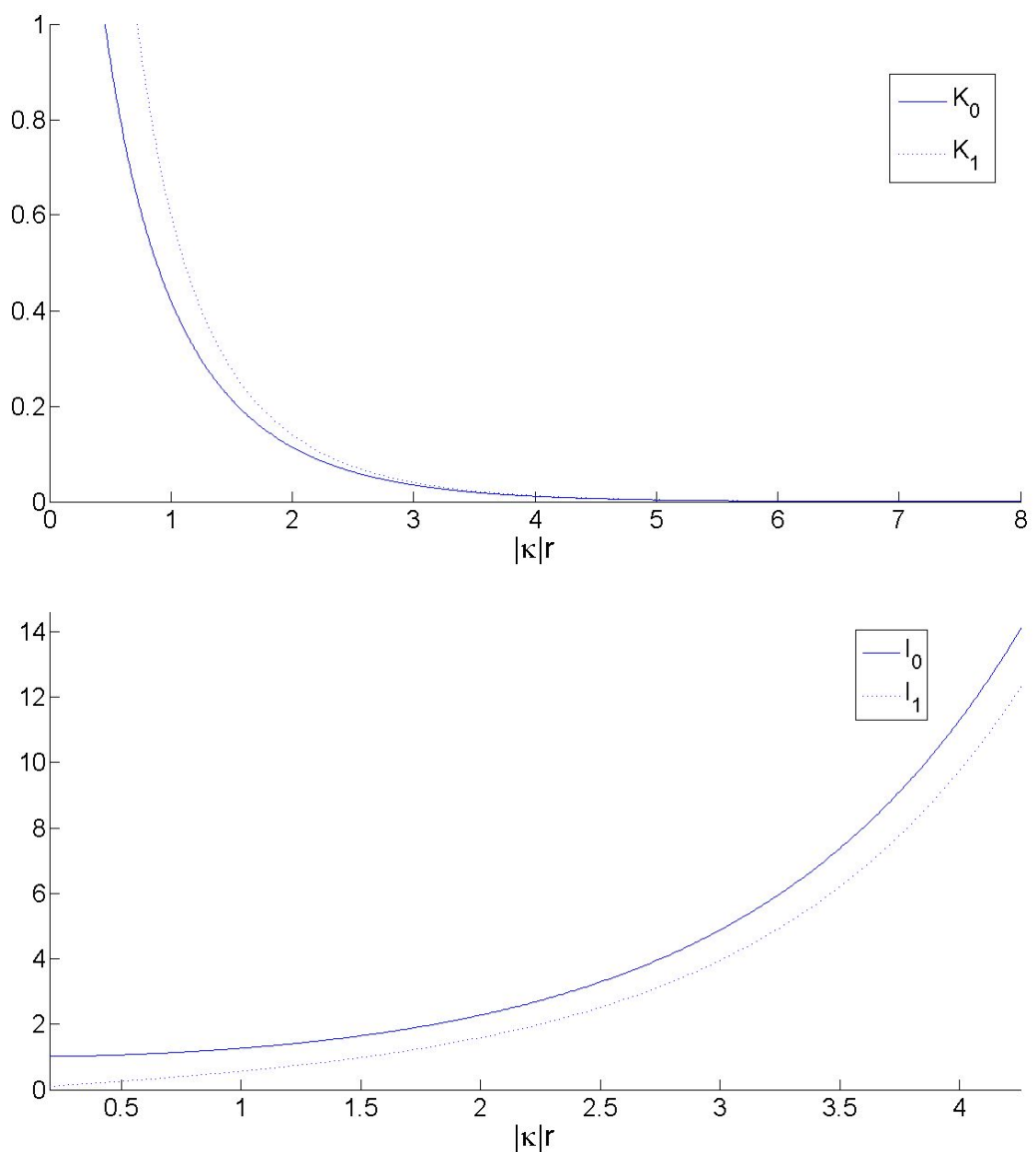

Figura 2.2 Representação das funções de Bessel modificadas de primeiro e segundo tipo. 


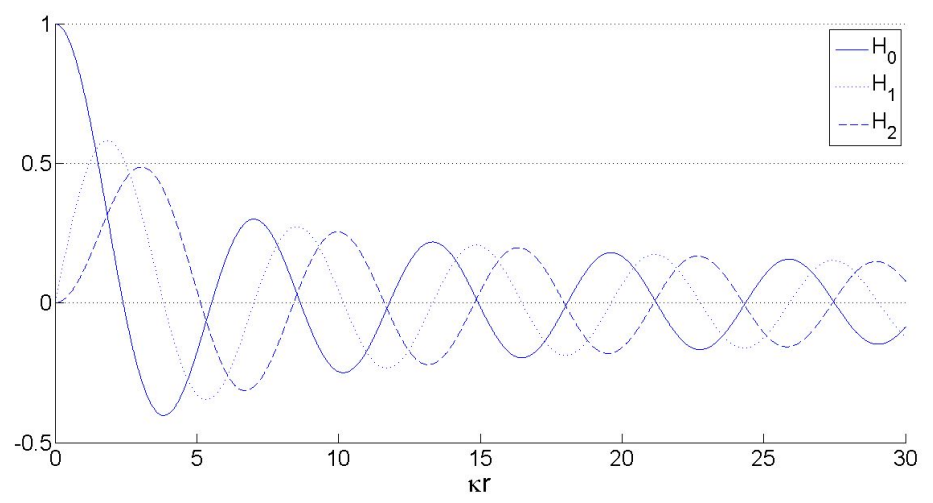

Figura 2.3 Função de Hankell do primeiro tipo.

$$
u \equiv a \kappa=a \sqrt{n_{1}^{2} k^{2}-\beta^{2}} \Rightarrow u \in N
$$

$\mathrm{e}$

$$
w \equiv a \gamma=a \sqrt{\beta^{2}-n_{2}^{2} k^{2}} \Rightarrow w \in N
$$

em que:

$$
\gamma^{2} \equiv\left|\kappa^{2}\right| \equiv \beta^{2}-k^{2} n^{2}
$$

Em coordenadas cartesianas, a solução para os campos transversais para o núcleo na equação 2.14 , ou seja, $r<a$, são as seguintes [13]:

$$
\begin{aligned}
& E_{y}=A J_{v}(\kappa r) \operatorname{sen}(\nu \phi), \\
& E_{x}=A J_{v}(\kappa r) \cos (\nu \phi),
\end{aligned}
$$

e para a casca na equação 2.15, em que $r>a$ :

$$
\begin{aligned}
& E_{y}=A \frac{J_{v}(\kappa a)}{H_{v}^{1}(i \gamma a)} H_{v}^{1}(i \gamma r) \operatorname{sen}(\nu \phi), \\
& E_{x}=A \frac{J_{v}(\kappa a)}{H_{v}^{1}(i \gamma a)} H_{v}^{1}(i \gamma r) \cos (\nu \phi),
\end{aligned}
$$

em que $H_{v}^{1}$ é a função de Hankell do primeiro tipo, representada na Figura 2.3.

A definição da constante $A$ das expressões [13], depende da potência total acoplada $P$, que depende diretamente da condição de lançamento na fibra. Dessa forma:

$$
A=\left(\frac{e\left(\mu_{0} / \varepsilon_{0}\right)^{1 / 2} \gamma^{2} P}{e_{v} \pi a^{2} n\left(n_{1}^{2}-n_{2}^{2}\right) k^{2}\left|J_{v-1}(\kappa a) J_{v+1}(\kappa a)\right|}\right)^{1 / 2}
$$


em que a potência $P$ é definida de acordo com o transmissor.

A constante $e_{v}$ tem 2 soluções:

$$
e_{v}=2
$$

para $v=0$

$$
e_{v}=1
$$

e para $v \neq 0$.

\subsection{Modos de propagação da fibra}

Os modos na fibra óptica podem ser de 4 tipos: TE (Transversal Electric), TM (Transversal Magnetic), HE (Hybrid Mode - Com campo magnético predominante) e EH (Hybrid Mode - Com campo elétrico predominante). Os modos híbridos possuem tanto campo magnético como campo elétrico na seção transversal da fibra com o vetor de Poynting alinhado ao eixo de propagação, mudando apenas a predominância de cada campo. Cada modo possui uma constante de propagação que pode ser igual ou diferente à de outros modos. Pode-se agrupar os modos com constantes de propagação similares nos chamados grupos modais linearmente polarizados, os LP's (linearly polarized). A definição de LP segue da sobreposição dos modos. Assim:

$$
\left\{\begin{array}{l}
L P_{0 \mu}=H E_{1 \mu} \\
L P_{1 \mu}=T E_{0 \mu}, T M_{0 \mu}, H E_{2 \mu} \\
L P_{l \mu}=E H_{v \mu}, H E_{v+2, \mu}, v>1 \text { e } l=v+1 \geq 2 .
\end{array}\right.
$$

Retomando as equações 2.17 e 2.18 , pode-se reescrevê-las levando em consideração os modos existentes na fibra da seguinte forma:

$$
\begin{gathered}
u_{v \mu} \equiv a \kappa_{v \mu}=a \sqrt{n_{1}^{2} k^{2}-\beta_{v \mu}^{2}} \Rightarrow u \in N, \\
w_{v \mu} \equiv a \gamma_{v \mu}=a \sqrt{\beta_{v \mu}^{2}-n_{2}^{2} k^{2}} \Rightarrow w \in N,
\end{gathered}
$$

em que $\mu$ (principal mode group), sendo um valor inteiro, representa as possíveis soluções para o campo da fibra, de acordo com os seus respectivos parâmetros, e para dado índice azimuthal $v$, como pode ser visto na equação 2.34 .

Com os parâmetros definidos da fibra, determina-se a frequência normalizada, dada por:

$$
V \equiv \sqrt{u_{v \mu}^{2}+w_{v \mu}^{2}}=2 \pi \frac{a}{\lambda} \sqrt{n_{1}^{2}-n_{2}^{2}}
$$

Através da equação 2.16 e das equações 2.28 e 2.29, pode-se enfim determinar as constantes de propagação de cada modo $\beta_{v \mu}$. Para $v=0$, tem-se possíveis valores de $\mu$ suportados pela fibra. Usando a equação 2.16, e $v=0$, tem-se: 


$$
\frac{J_{0}^{\prime}(u)}{u J_{0}(u)}+\frac{K_{0}^{\prime}(w)}{w K_{0}(w)}=0
$$

Com as identidades de Bessel

$$
J_{v}^{\prime}(z)=-J_{v+1}(z)+\frac{v}{z} J_{v}(z)
$$

e

$$
K_{v}^{\prime}(z)=-K_{v+1}(z)+\frac{v}{z} K_{v}(z),
$$

obtém-se as seguintes equações:

$$
\left\{\begin{array}{l}
\frac{u_{0 \mu} J_{0}\left(u_{0 \mu}\right)}{J_{1}\left(u_{0 \mu}\right)}+\frac{w_{0 \mu} K_{0}\left(w_{0 \mu}\right)}{K_{1}\left(w_{0 \mu}\right)}=0 \\
u_{0 \mu} \equiv a \kappa_{0 \mu}=a \sqrt{n_{1}^{2} k^{2}-\beta_{0 \mu}^{2}} \\
w_{0 \mu} \equiv a \gamma_{0 \mu}=a \sqrt{\beta_{0 \mu}^{2}-n_{2}^{2} k^{2}}
\end{array} \Rightarrow \beta_{0 \mu} \text { para } \mu=1,2, \ldots, M_{0} .\right.
$$

Essa equação deve ser resolvida numericamente. Pode-se observar que os parâmetros físicos da fibra estão contidos nessa equação, e são eles: raio do núcleo $a$, os índices de refração do núcleo e da casca ( $n_{1}$ e $n_{2}$ respectivamente) e o comprimento de onda $\lambda$. Dessa forma, pode-se usar o método da intersecção das curvas, como solução numérica, em função de $\beta_{0 \mu}$ e verificar os pontos de intersecção, para obter os possíveis valores de $\beta$.

Para cada índice azimutal $v$, faz-se o mesmo procedimento, com isso, determina-se todos os modos suportados pela fibra. Por exemplo, para o $H E_{1 \mu}$, que corresponde ao $v=1$, existem 8 possíveis soluções para $\mu$, ou seja, $8 \beta$ 's diferentes. As possíveis soluções são limitadas pelos índices de refração do núcleo e da casca, pois o $\beta$, deve satisfazer a equação 2.9 .

Com os valores de $\beta$ definidos a partir da frequência normalizada e dos parâmetros da fibra, como pode ser visto na Tabela 2.1, pode-se enfim avaliar o comportamento do campo elétrico para cada modo.

Na Tabela 2.1, estão representados os valores das constantes de propagação para todos os modos suportados pela fibra, bem como as amplitudes modais $\left(a_{l m}\right)$.

\subsection{Definição das amplitudes modais}

O fluxo de potência do campo magnético é dado pelo vetor de poynting:

$$
S \equiv \frac{1}{2} \operatorname{Re}\left[E x H^{*}\right]
$$




\begin{tabular}{|c|c|c|}
\hline$L P_{l m}$ & $\beta\left(\mu \mathrm{m}^{-1}\right)$ & $a_{l m}$ \\
\hline Modo fundamental $L P_{01}\left(H E_{11}\right)$ & 7,0980 & 0,0630 \\
\hline Modo de segunda ordem $L P_{02}$ & 7,0954 & 0,0373 \\
\hline Modo de quinta ordem $L P_{03}$ & 7,0908 & 0,0081 \\
\hline$L P_{04}\left(H E_{14}\right)$ & 7,0841 & $-0,0078$ \\
\hline$L P_{05}\left(H E_{15}\right)$ & 7,0754 & $-0,0076$ \\
\hline$L P_{06}\left(H E_{16}\right)$ & 7,0647 & $-3,1973 e-05$ \\
\hline$L P_{07}\left(H E_{17}\right)$ & 7,0521 & 0,0044 \\
\hline$L P_{08}\left(H E_{18}\right)$ & 7,0377 & 0,0028 \\
\hline Modo de primeira ordem $L P_{11}\left(T E_{01}, T M_{01}, H E_{21}\right)$ & 7,0970 & $5,3577 \mathrm{e}-05$ \\
\hline Modo de quarta ordem $L P_{12}\left(T E_{02}, T M_{02}, H E_{22}\right)$ & 7,0934 & $6,3649 \mathrm{e}-05$ \\
\hline Modo de sétima ordem $L P_{13}\left(T E_{03}, T M_{03}, H E_{23}\right)$ & 7,0878 & $4,1810 \mathrm{e}-05$ \\
\hline$L P_{14}\left(T E_{04}, T M_{04}, H E_{24}\right)$ & 7,0801 & $1,2090 \mathrm{e}-05$ \\
\hline$L P_{15}\left(T E_{05}, T M_{05}, H E_{25}\right)$ & 7,0704 & $-4,6833 e-06$ \\
\hline$L P_{16}\left(T E_{06}, T M_{06}, H E_{26}\right)$ & 7,0587 & $-3,4176 \mathrm{e}-06$ \\
\hline$L P_{16}\left(T E_{07}, \mathrm{~T} M_{07}, H E_{27}\right)$ & 7,0452 & $5,1122 \mathrm{e}-06$ \\
\hline$L P_{18}\left(T E_{08}, T M_{08}, H E_{28}\right)$ & 7,0302 & $9,5892 \mathrm{e}-06$ \\
\hline Modo de segunda ordem $L P_{21}\left(E H_{11}, H E_{31}\right)$ & 7,0958 & $-6,0227 e-07$ \\
\hline Modo de quinta ordem $L P_{22}\left(E H_{12}, H E_{32}\right)$ & 7,0912 & $-1,0645 \mathrm{e}-06$ \\
\hline$L P_{23}\left(E H_{13}, H E_{33}\right)$ & 7,0845 & $-1,0874 \mathrm{e}-06$ \\
\hline$L P_{24}\left(E H_{14}, H E_{34}\right)$ & 7,0758 & $-6,6648 e-07$ \\
\hline$L P_{25}\left(E H_{15}, H E_{35}\right)$ & 7,0651 & $-1,8427 \mathrm{e}-07$ \\
\hline$L P_{26}\left(E H_{16}, H E_{36}\right)$ & 7,0525 & $3,0758 \mathrm{e}-08$ \\
\hline$L P_{27}\left(E H_{17}, H E_{37}\right)$ & 7,0381 & $-3,8271 \mathrm{e}-08$ \\
\hline Modo de terceira ordem $L P_{31}\left(H E_{41}, E H_{21}\right)$ & 7,0943 & $1,1066 \mathrm{e}-05$ \\
\hline Modo de sexta ordem $L P_{32}\left(H E_{42}, E H_{22}\right)$ & 7,0886 & $2,6833 \mathrm{e}-05$ \\
\hline$L P_{33}\left(E H_{23}, H E_{43}\right)$ & 7,0809 & $3,5781 \mathrm{e}-05$ \\
\hline$L P_{34}\left(E H_{24}, H E_{44}\right)$ & 7,0712 & $3,0820 \mathrm{e}-05$ \\
\hline$L P_{35}\left(E H_{25}, H E_{45}\right)$ & 7,0595 & $1,6849 \mathrm{e}-05$ \\
\hline$L P_{36}\left(E H_{26}, H E_{46}\right)$ & 7,0460 & $4,2699 \mathrm{e}-06$ \\
\hline$L P_{37}\left(E H_{27}, H E_{47}\right)$ & 7,0309 & $8,1721 \mathrm{e}-07$ \\
\hline$L P_{41}\left(E H_{31}, H E_{51}\right)$ & 7,0926 & $1,1238 \mathrm{e}-06$ \\
\hline$L P_{42}\left(E H_{32}, H E_{52}\right)$ & 7,0858 & $3,5413 \mathrm{e}-06$ \\
\hline$L P_{43}\left(E H_{33}, H E_{53}\right)$ & 7,0771 & $5,7827 \mathrm{e}-06$ \\
\hline$L P_{44}\left(E H_{34}, H E_{54}\right)$ & 7,0664 & $6,2810 \mathrm{e}-06$ \\
\hline$L P_{45}\left(E H_{35}, H E_{55}\right)$ & 7,0537 & $4,8065 \mathrm{e}-06$ \\
\hline$L P_{46}\left(E H_{36}, H E_{56}\right)$ & 7,0392 & $2,4431 \mathrm{e}-06$ \\
\hline
\end{tabular}

Tabela 2.1 $\beta$ 's e $a_{l m}$ 's.

Introduzindo a definição de potência modal, bem como o conceito de amplitude modal 
como fator de ponderação, tem-se o fluxo de potência por modo:

$$
S_{l m}(r, \theta)=\frac{1}{2}\left|a_{l m}\right|^{2} \operatorname{Re}\left[E_{t, m}(r, \theta) x H_{t, m}^{*}(r, \theta)\right]
$$

em que $a_{l m}$ é a amplitude modal. Dessa forma, a potência eletromagnética associada a cada modo $L P_{l m}$ é dada pela integração da equação 2.36 , em toda sua área:

$$
P_{l m}=\int_{A_{\infty}} S_{l m}(r, \theta) d A
$$

Expandindo a expressão, tem-se:

$$
P_{l m}=\frac{1}{2}\left|a_{l m}\right|^{2} \int_{A_{\infty}} S_{l m}(r, \theta) d A
$$

sendo então a potência total a soma da potência de cada modo:

$$
P_{t}=\sum_{l, m} P_{l m}
$$

Definiu-se a normalização modal $\left(N_{l m}\right)$ como

$$
N_{l m}=\frac{1}{2} \int_{A_{\infty}} S_{l m}(r, \theta) d A,
$$

dessa forma, tem-se a expressão da potência modal por

$$
P_{l m}=\left|a_{l m}\right|^{2} N_{l m}
$$

e a potência total por

$$
P_{b}=\sum_{l, m}\left|a_{l m}\right|^{2} N_{l m}
$$

Sabendo que

$$
E_{t} \perp H_{t},
$$

e utilizando a aproximação paraxial para $E_{t}$ e $H_{t}$, tem-se:

$$
\begin{aligned}
& H_{x} \cong \frac{n}{Z_{0}} E_{y}, \\
& H_{y} \cong \frac{n}{Z_{0}} E_{x} .
\end{aligned}
$$

Substituindo a equação 2.44 e 2.45 na equação 2.40 , tem-se:

$$
\begin{aligned}
N_{l m} \equiv \frac{1}{2 Z_{0}} & \int_{0}^{r_{n} \text { cleo }} \int_{0}^{2 \pi} n_{1}\left|E_{t, l m}(r, \phi)\right|^{2} r d r d \phi+ \\
& +\int_{r_{\text {nucleo }}}^{r_{\text {casca }}} \int_{0}^{2 \pi} n_{2}\left|E_{t, l m}(r, \phi)\right|^{2} r d r d \phi
\end{aligned}
$$




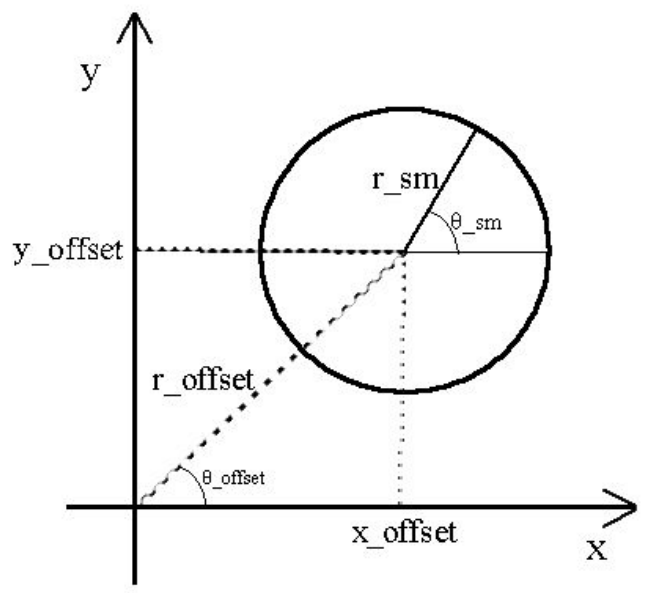

Figura 2.4 Sistema de coordenadas.

em que dividiu-se a integral para o núcleo e para a casca, bem como os seus respectivos índices de refração.

Em seguida deve-se definir as amplitudes modais $a_{l m}$, integrando numericamente o campo elétrico $\left(E_{x}\right)$ na área circular da fibra multimodo em relação ao campo emitido pela fonte:

$$
a_{l m}=\frac{\int_{A_{\infty}} E_{s}(\rho, \phi) E_{x, l m}(\rho, \phi) d A}{\int_{A_{\infty}}\left|E_{t, l m}(\rho, \phi)\right|^{2} d A}
$$

em que $E_{S}$ é o campo emitido pela fonte, $E_{x, l m}$ o campo elétrico modal no eixo X, pois assumese o campo emitido pela fonte polarizado no eixo X e $E_{t, l m}$ o campo transversal total da fibra multimodo.

\subsection{Condições de lançamento}

De acordo com a equação 2.47, percebe-se que a condição de lançamento é um fator relevante para determinar a amplitude modal respectiva para cada modo, que altera a parcela de potência que cada modo carrega. Pode-se verificar ainda na equação 2.47 que, à medida que deslocase o campo incidente na fibra ao longo do plano transversal da fibra multimodo, afastando do centro da fibra multimodo, os modos de ordem mais elevada são privilegiados em detrimento dos modos de menor ordem.

Para analisar o campo incidente em relação aos campos de cada modo da fibra multimodo, deve-se fazer uma mudança no eixo de coordenadas, como na Figura 2.4, para que se obtenha uma forma genérica de observação das diversas condições de lançamento na fibra multimodo. Assumindo a origem do eixo de coordenadas centrado na fibra multimodo e assumindo uma fibra monomodo como fonte para gerar o campo incidente, tem-se os respectivos pontos correspondentes para a fibra monomodo: 


$$
\left\{\begin{array}{l}
x_{m m}=x_{s m}+x_{o f f s e t} \\
y_{m m}=y_{s m}+y_{o f f s e t}
\end{array},\right.
$$

em que $x_{o f f s e t}$ e $y_{\text {offset }}$ representam o deslocamento do ponto central da fibra monomodo em relação à fibra multimodo nos eixos x e y respectivamente. Para o eixo da fibra monomodo, temos:

$$
\left\{\begin{array}{l}
x_{s m}=r_{s m} \cos \left(\theta_{s m}\right) \\
y_{s m}=r_{s m} \sin \left(\theta_{s m}\right)
\end{array}\right.
$$

em que $r_{s m}$ e $\theta_{s m}$ representam o raio e o ângulo da fibra monomodo com o eixo de coordenadas centrado na fibra monomodo. Dessa forma, através das equações 2.48 e 2.49, define-se a expressão para $r_{m m}$ :

$$
r_{m m}=\sqrt{x_{m m}^{2}+y_{m m}^{2}}
$$

Substituindo as equações 2.48 e 2.49 na equação 2.50 , tem-se:

$$
r_{m m}=\sqrt{\left(r_{s m} \cos \left(\theta_{s m}\right)+x_{o f f}\right)^{2}+\left(r_{s m} \sin \left(\theta_{s m}\right)+y_{o f f}\right)^{2}} .
$$

Desenvolvendo a equação 2.51, tem-se então a equação 2.52 , que define o eixo radial da fibra multimodo em função do posicionamento da fibra multimodo:

$$
r_{m m}=\sqrt{r_{s m}^{2}+2 r_{s m}\left[\cos \left(\theta_{s m}\right) x_{o f f}+\sin \left(\theta_{s m}\right) y_{o f f}\right]+x_{o f f}^{2}+y_{o f f}^{2}} .
$$

Para o eixo angular segue um desenvolvimento semelhante na equação 2.53:

$$
\theta_{m m}=\arctan \left(\frac{y_{m m}}{x_{m m}}\right)
$$

Sabendo que o contradomínio da função arctan retorna valores de $-\pi$ a $\pi$, deve-se fazer uma correta interpretação para a análise dos casos em que a fibra monomodo ou parte dela, estiver posicionada no segundo ou terceiro quadrante, no sistema de coordenadas representado em 2.4, ou seja, quando $x_{m m}<0$. Para isso, deve-se somar $\pi$ na resposta da função arctan para esses quadrantes. Assim tem-se a expressão para o eixo angular:

$$
\theta_{m m}=\arctan \left(\frac{r_{s m} \sin \left(\theta_{s m}\right)+y_{o f f}}{r_{s m} \cos \left(\theta_{s m}\right)+x_{o f f}}\right)
$$

O mapeamento feito em Matlab para esses sistemas de coordenadas pode ser interpretado no Apêndice A. 


\subsection{Resposta impulsional da fibra}

Uma vez definida a parcela de potência transportada por cada modo

$$
\alpha_{l m}=\frac{P_{l m}}{P_{b}}
$$

e conhecendo-se a constante de propagação, pode-se determinar o tempo de propagação de cada modo:

$$
t_{l m}=L \tau_{l m}(\lambda)
$$

em que $L$ é o comprimento da fibra e $\tau_{l m}(\lambda)$ (atraso por unidade de comprimento) é dado por:

$$
\tau_{l m}(\lambda)=\frac{\beta_{l m} \lambda}{2 \pi c} .
$$

Conhecendo-se as parcelas de potência que cada modo transmite, tem-se a resposta ao impulso de potência da fibra $h(t)$, que é dada por:

$$
h(t)=\sum_{l, m} \alpha_{l m} \delta\left(t-t_{l m}\right) .
$$

Dessa maneira, para se obter o sinal modulado em intensidade de saída na fibra, basta fazer a convolução do sinal de entrada pela resposta ao impulso da fibra multimodo. 


\section{CAPÍtUlo 3 \\ Transmissão DD-OFDM}

Este capítulo descreve o sistema OFDM de detecção direta (direct detection OFDM - DDOFDM) modelado neste trabalho: o transmissor, o canal e o receptor. Também apresentam-se vantagens e desvantagens do uso desta técnica de modulação.

Modelou-se o sistema representado nessa monografia de acordo com o diagrama em blocos apresentado nas Figuras 3.1, 3.2 e 3.3. Para detalhes de como implementou-se o sistema em Matlab, ver Apêndice B.

\subsection{Transmissor}

Primeiramente, definiram-se os parâmetros de simulação. Fixaram-se a quantidade de subportadoras piloto, o espaçamento entre elas e a informação que elas carregam. Essas informações são conhecidas pelo receptor, para que ele possa então estimar a função de transferência do sistema por meio do estimador de canal. Calculou-se a banda pretendida do sinal em banda base como:

$$
B_{O F D M}=\frac{K}{2} \Delta_{K}
$$

em que $K$ é o número de sub-portadoras, escolhido como uma potência de 2 , e $\Delta_{K}$ é o espaçamento em frequência entre cada sub-portadora.

Geraram-se os bits a partir de amostras de uma distribuição uniforme discreta entre zero e um. Arredondaram-se em seguida estas amostras para resultar em uma sequência de 0's e 1's. Primeiramente, no transmissor OFDM, mapearam-se os bits de informação em $M$ símbolos quadrature phase-shift keying (QPSK):

$$
\bar{a}=\left[\begin{array}{llll}
a_{1} & a_{2} & \ldots & a_{M}
\end{array}\right] .
$$

Em seguida, passaram-se os símbolos por uma conversão de série para paralelo (S/P), quebrando o vetor $\bar{a}$ (fluxo contínuo de símbolos) em vetores menores (fluxos em paralelo), definindose cada um da seguinte forma:

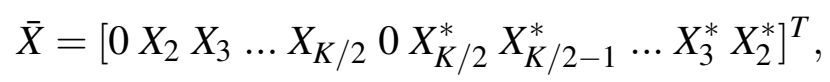

em que $\bar{X}$ denota um fluxo em paralelo de símbolos e $K$ é o número de sub-portadoras, sendo * o complexo conjugado. De modo a simplificar tanto o transmissor quanto o receptor, é desejável que o sinal na saída da IFFT seja real para que toda a informação esteja contida em 


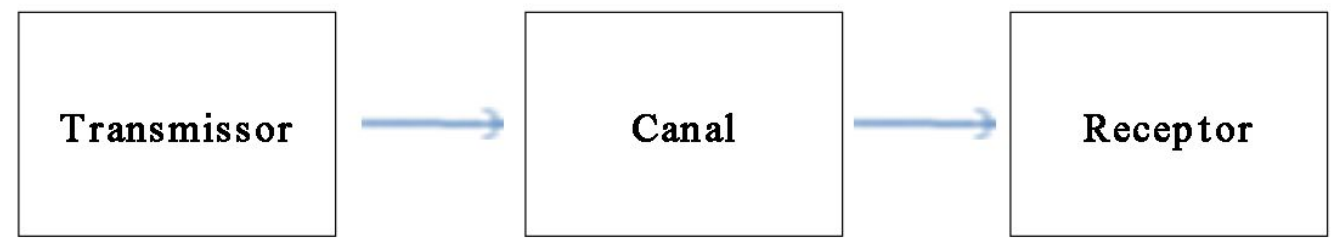

Figura 3.1 Diagrama em blocos do sistema.

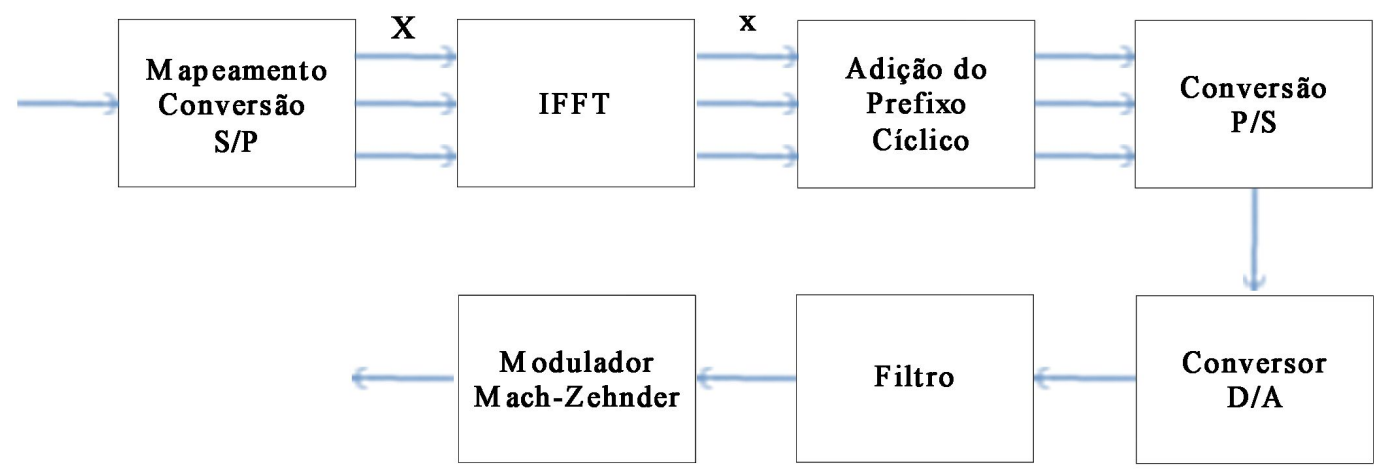

Figura 3.2 Diagrama em blocos do transmissor. 


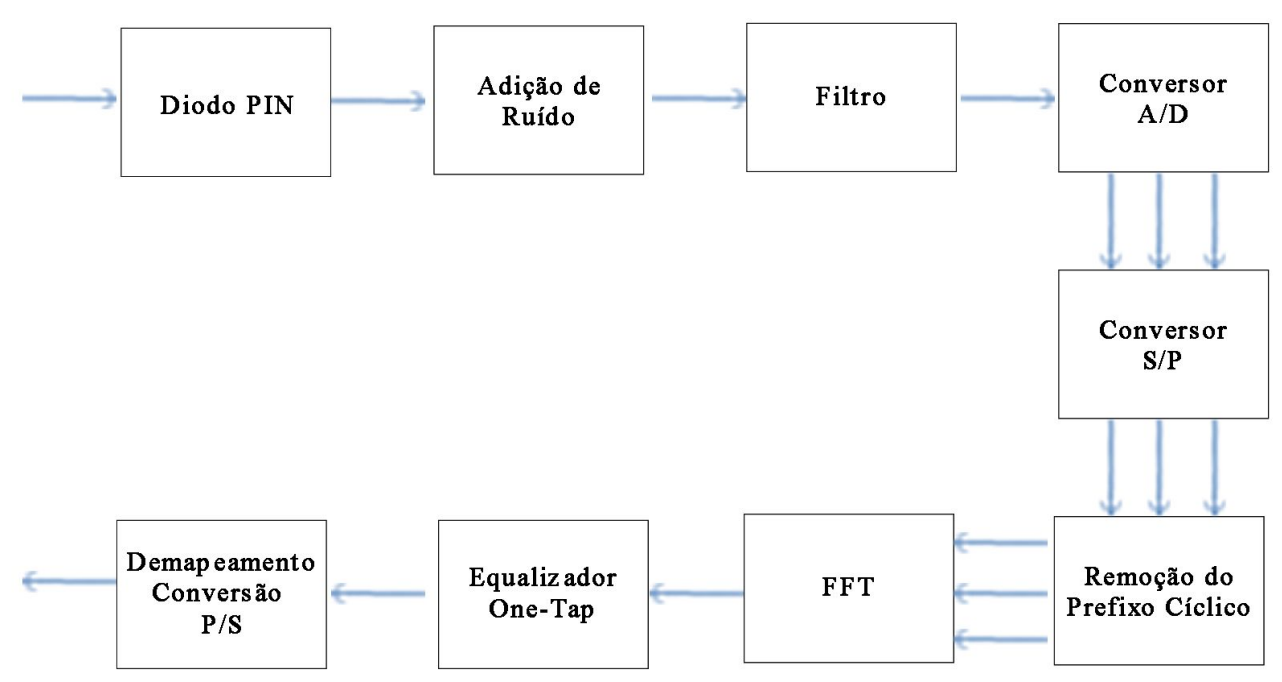

Figura 3.3 Diagrama em blocos do receptor.

sua amplitude, necessitando apenas de um modulador Mach-Zehnder no transmissor e possibilitando a detecção direta do sinal. Realizou-se esta condição fazendo-se simetria Hermitiana no sinal na entrada da IFFT, conforme se pode observar na equação 3.3, o que causa perda de metade da capacidade de transmissão. Dessa forma, o número de sub-portadoras efetivamente utilizadas para transmitir dados foi:

$$
K_{d}=\frac{\left(K-K_{\rho}\right)}{2}-1
$$

em que $K_{\rho}$ é o número de sub-portadoras piloto.

Em seguida, fez-se a IFFT para colocar cada símbolo QPSK em uma sub-portadora, gerando o vetor real $\bar{x}=\left[\begin{array}{llll}x_{1} & x_{2} & \ldots & x_{K}\end{array}\right]^{T}$. Apenas $K$ amostras são necessárias para formar um símbolo OFDM (excluindo o prefixo cíclico). Conforme citado em [15], para $K \geq 64, \bar{x}$ apresenta uma distribuição aproximadamente Gaussiana.

A próxima parte do diagrama em blocos é adicionar o prefixo cíclico. Implementou-se isso copiando-se um número de amostras do final de $\bar{x}$ para o seu início. Dessa forma, ao invés de se transmitir $\bar{x}$, transmitiu-se a sequência

$$
\bar{x}_{C P}=\left[x_{K-C+1} \ldots x_{K-1} x_{K}, x_{1} x_{2} \ldots x_{K}\right]^{T},
$$

em que $\mathrm{C}$ é o número de amostras do prefixo cíclico. Calculou-se o tempo útil do símbolo OFDM $(T u)$, sem o prefixo cíclico, como $1 / \Delta_{K}$. Assim, a expressão para o tempo de duração do prefixo cíclico é:

$$
\Delta t_{c p}=G * T u,
$$

em que $G$ representa a parcela de $T u$ que forma o prefixo cíclico, ou seja, $G=C / K$. Em simulações, por o sistema ser discreto, $G$ deve ser escolhido de modo que $C$ seja um inteiro. 


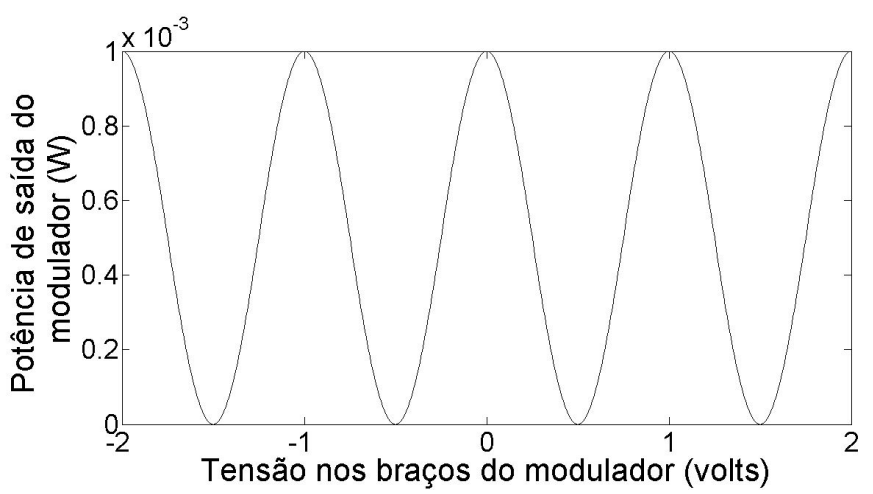

Figura 3.4 Potência de saída do modulador Mach-Zehnder em função da tensão em seus braços para $V_{\pi}=0.5 \mathrm{~V}$ e $P_{I N}=1 \mathrm{~mW}$.

Dessa forma, calculou-se o período do símbolo OFDM por $T s=T u+\Delta t_{c p}$.

Em seguida, como pode ser visto ainda na Figura 3.2, $x_{C P}$ passou por um conversor P/S, formando efetivamente o símbolo OFDM. O sinal transmitido é composto de uma sequência destes símbolos.

O sinal então passou por um conversor D/A, representado no diagrama em blocos pelo Sample-and-Hold, que permite analisar o sinal OFDM em uma faixa de frequência mais extensa, devido ao aumento de resolução no domínio do tempo. $\mathrm{O}$ aumento de resolução utilizado neste trabalho foi de 50 vezes. De modo a reduzir a banda infinita do sinal após passar pelo Sample-and-Hold, utilizou-se um filtro passa-baixa de Butterworth de sexta ordem e frequência de corte (-3 dB do máximo) igual a $B_{O F D M}$ à saída do conversor D/A.

Para o gerar o sinal óptico unipolar, o sinal elétrico filtrado passa pelo modulador MachZehnder, definido pela seguinte equação:

$$
P_{\text {OUT }}=P_{I N} \cos ^{2}\left(\frac{\pi V}{2 V_{\pi}}\right)
$$

em que $P_{I N}$ é a potência do laser de bombeio e $V$ é a tensão nos braços do Mach-Zehnder, dada pelo sinal OFDM na entrada do modulador somado de $V_{b}$, o ponto de quadratura. O ponto de quadratura é um nível DC adicionado ao sinal de entrada para que este varie apenas entre um máximo e um mínimo da senóide (metade do período) que define o modulador. Definiu-se o ponto de quadratura do Mach-Zehnder igual a $-V_{\pi} / 2$, em que $V_{\pi}$ é a tensão necessária para deslocar em $\pi$ a fase do sinal de saída do modulador. Para $P_{I N}=1 \mathrm{~mW}$ e $V_{\pi}=0.5 \mathrm{~V}$, apresentase o gráfico de $P_{O U T}$ em função de $V$ na Figura 3.4. É possível perceber por essa figura que o sinal de entrada varia em torno de $-0.25 \mathrm{~V}$, o ponto de quadratura do modulador.

Definiu-se o índice de modulação por:

$$
m=\left|\frac{S_{R M S}}{V_{b}}\right|,
$$

em que $S_{R M S}$ é o valor quadrático médio (root mean square - RMS) do sinal OFDM à entrada do modulador Mach-Zehnder. Considerando que a Figura 3.4 representa um modulador com 


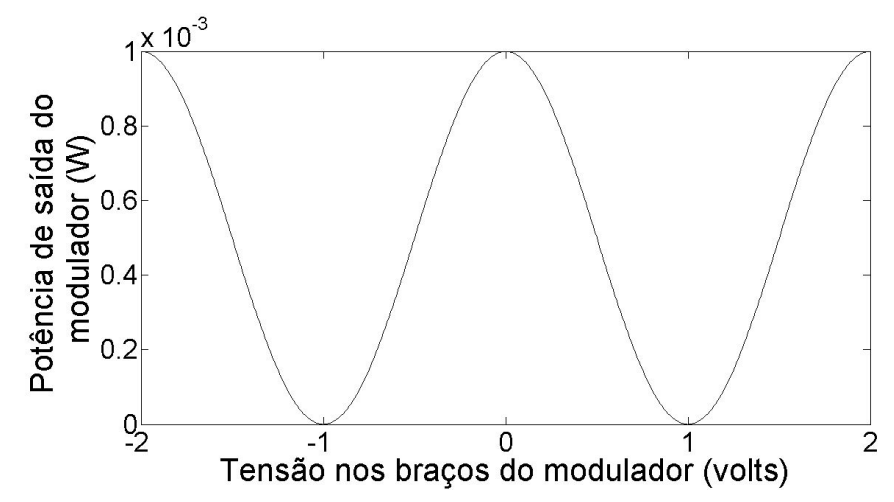

Figura 3.5 Potência de saída do modulador Mach-Zehnder em função da tensão em seus braços para $V_{\pi}=1 \mathrm{~V}$ e $P_{I N}=1 \mathrm{~mW}$.

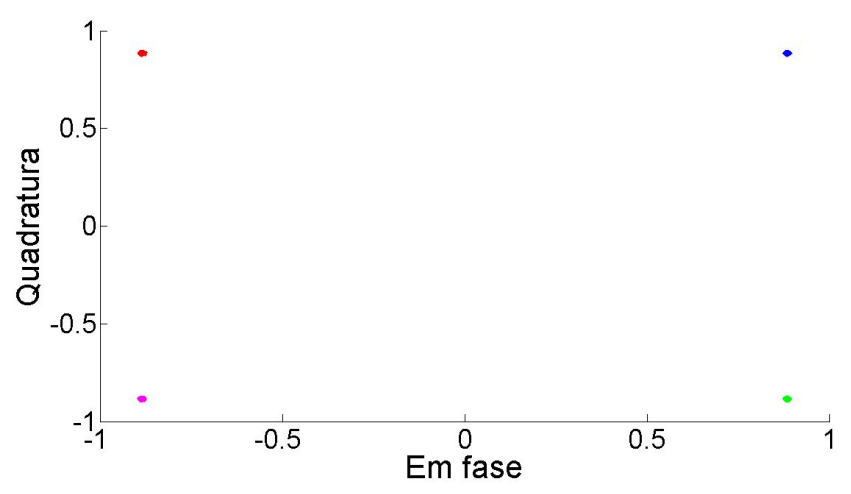

Figura 3.6 Constelação recebida para $m=5 \%$, sem ruído, sem equalização, sem filtragem e sistema back-to-back (sem canal).

índice de modulação qualquer, um modulador com índice menor teria um $V_{\pi}$ maior, por exemplo igual a $1 \mathrm{~V}$, aumentando o período da senóide conforme visto na Figura 3.5. Assim, é possível perceber que o mesmo sinal de entrada teria uma variação absoluta menor na saída. $\mathrm{O}$ índice de modulação define então a máxima variação absoluta do sinal na saída do modulador.

Depois de passar pelo Mach-Zehnder, o sinal sofre uma certa distorção devido à função de transferência do modulador não ser linear e sim ter a forma de um cosseno ao quadrado, como pode-se perceber nas Figuras 3.6 e 3.7. Geraram-se estas figuras para um sistema back-to-back, sem equalização, sem filtragem e sem ruído. É possível notar que quanto menor o valor de $m$, menor será a distorção causada pelo Mach-Zehnder, pois o sinal de entrada estará confinado em uma região mais linear do modulador. Porém, a potência do sinal de saída também diminui quando $m$ é reduzido, deixando o sinal mais suscetível a ruído. Existe portanto uma relação de compromisso na escolha do índice de modulação do sistema.

OFDM possui um número de desvantagens que podem causar degradação de desempenho do sistema. Dessas, podemos destacar a alta relação potência de pico por potência média (peakto-average power ratio - PAPR) e a sensibilidade a ruído de fase. 


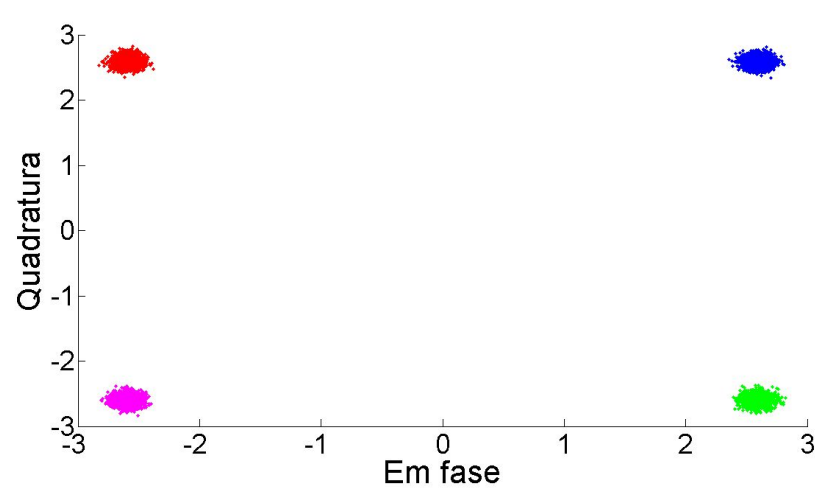

Figura 3.7 Constelação recebida para $m=15 \%$, sem ruído, sem equalização, sem filtragem e sistema back-to-back (sem canal).

Uma alta PAPR pode ocasionar distorções significativas devido às não-linearidades da fibra e do modulador. Intermodulação causada por este fenômeno resulta em dois prejuízos: potência fora da banda do sinal e distorção na banda do sinal. De acordo com a referência [15], apenas uma em mil amostras do sinal estão $8 \mathrm{~dB}$ ou mais acima da média. Apesar da ocorrência dos picos não ser tão frequente, eles podem fazer surgir componentes de potência significativos fora da banda do sinal [15]. Já o efeito principal da distorção dentro da banda do sinal causada pelo PAPR em certos casos é de encolher a constelação, e não causar interferência [15].

\subsection{Canal}

Com o sinal de potência óptica gerado, passou-se este pelo canal, como pode ser visto na Figura 3.1. O canal considerado é a fibra multimodo, sendo que a fonte de distorção causada pela fibra considerada neste trabalho é a dispersão modal.

Calcula-se a resposta ao impulso da fibra (aqui chamada de $h(t)$ ) de acordo com a equação 2.58. Investigaremos agora o efeito do canal sobre o sinal OFDM. O sinal à entrada do receptor é a soma de várias versões do sinal transmitido com diferentes ganhos e atrasos:

$$
y(t)=\sum_{n=1}^{N_{l}} \alpha_{n} s\left(t-\tau_{n}\right)
$$

em que $s(t)$ é o sinal à saída do transmissor OFDM, $\alpha_{n}$ o ganho do modo $n, N_{l}$ é o número de modos excitados na MMF e $\tau_{n}$ é o atraso do modo $n$. Como $s(t)$ é um sinal banda-base, tanto os ganhos quanto os sinais da equação 3.9 são reais.

Quando OFDM é utilizado em conjunto com o prefixo cíclico, pode-se perceber que desde que o início da janela de recepção esteja alinhado com o começo do símbolo OFDM "principal"do primeiro sinal recebido, e se a diferença dos atrasos dos modos $\left(\left|\tau_{n}-\tau_{m}\right|\right.$, para quaisquer $n$ e $m$ ) seja menor que a duração do prefixo cíclico, não há interferência inter-simbólica[15]. O sinal recebido na $i$-ésima janela de tempo depende apenas do $i$-ésimo símbolo transmitido. 
Para maior eficiência computacional na simulação do sistema, passou-se o sinal OFDM pelo canal no domínio da frequência. Garantindo através do tamanho do prefixo cíclico que não haja interferência inter-simbólica, não haverá perda de precisão do sistema modelado. Deste modo, calculou-se o sinal no domínio da frequência à entrada do receptor OFDM por:

$$
Y(f)=S(f) H(f)
$$

em que $S(f)$ e $H(f)$ são as transformadas de Fourier de $s(t)$ e $h(t)$ respectivamente. Obteve-se então o sinal $y(t)$ fazendo-se uma transformada rápida de Fourier inversa (IFFT) sobre $Y(f)$.

\subsection{Receptor}

Na recepção, o sinal OFDM passou primeiro pelo fotodiodo PIN, transformando potência óptica em corrente elétrica. Como toda informação está na amplitude do sinal, detectar apenas o módulo não causa perda de informação.

Adicionou-se então ruído térmico imposto pelo circuito elétrico ao sinal. Supôs-se que o ruído é branco e suas amostras são geradas a partir de uma distribuição Gaussiana. Dessa forma, para uma dada relação energia de bit por densidade espectral do ruído $\left(\frac{E_{b}}{N_{0}}\right)$, tem-se a potência média do sinal $\left(\bar{P}_{S}\right)$ na saída do fotodiodo PIN dada por:

$$
\bar{P}_{s}=\frac{1}{T_{w}} \int_{0}^{T_{w}} s_{a}^{2}(t) d t
$$

em que $T_{w}$ é a duração do sinal OFDM em segundos e $s_{a}(t)$ corresponde ao sinal analógico detectado pelo diodo PIN sem nível dc. Dessa forma, sabendo que utilizou-se QPSK como formato de modulação de cada sub-portadora, para um dado $\frac{E_{b}}{N_{0}}$, calcula-se a relação sinal-ruído por:

$$
S N R=\frac{E_{b}}{N_{0}} \log _{2} M
$$

Com $S N R$ definido e sabendo que a variância do ruído é igual à sua potência, tem-se:

$$
\sigma_{n}^{2}=\frac{P_{S}}{S N R}
$$

$\mathrm{e}$

$$
\sigma_{n}=\sqrt{\sigma_{n}^{2}}
$$

em que $\sigma_{n}^{2}$ é a variância do ruído e $\sigma_{n}$ o seu desvio padrão. Define-se a expressão para determinar a SNR média do sistema por:

$$
S N R_{d B}=10 \log _{10}\left(\frac{\bar{P}_{s}}{N}\right)[\mathrm{dB}]
$$

em que $N$ corresponde à potência média do ruído, definida a partir de sua variância $\left(N=\sigma_{n}^{2}\right)$. Enfim, define-se o sinal na saída do diodo PIN, com adição do ruído $\left(s_{o}(t)\right)$, dado por: 


$$
s_{o}(t)=s_{i}(t)+n(t),
$$

em que $n(t)$ é o ruído no domínio do tempo, gerado por simulação numérica a partir de uma distribuição Gaussiana com desvio padrão $\sigma_{n}$ e média nula, e $s_{i}(t)$ é o sinal na saída do diodo PIN.

Após a adição do ruído e visando amenizar os efeitos dele e do canal fora da banda do sinal OFDM, utilizou-se um filtro passa-baixa de Butterworth com frequência de corte igual à banda do sinal $\left(B_{O F D M}\right)$, uma vez que este está em banda base.

Converteu-se então o sinal de analógico para digital por meio do conversor $\mathrm{A} / \mathrm{D}$, que retira uma amostra do sinal a cada $T_{K}$ segundos, dado por:

$$
T_{K}=\frac{1}{B_{O F D M}} .
$$

Em seguida, converteu-se cada símbolo OFDM recebido de série para paralelo (S/P) e removeu-se o prefixo cíclico, resultando na sequência $\bar{x}^{\prime}=\left[\begin{array}{llll}x_{1}^{\prime} & x_{2}^{\prime} & \ldots & x_{K}^{\prime}\end{array}\right]^{T}$, em que $\bar{x}^{\prime}$ é a estimativa de $\bar{x}$.

Aplicou-se então FFT em cada símbolo, gerando a sequência $\bar{X}^{\prime}=\left[X_{1}^{\prime} X_{2}^{\prime} \ldots X_{K}^{\prime}\right]^{T}$, a estimativa de $\bar{X}$. Recuperaram-se apenas os elementos $\left[X_{2}^{\prime} X_{3}^{\prime} \ldots X_{K / 2}^{\prime}\right]$, por se tratarem dos únicos que carregam informação útil. Com o objetivo de compensar ao máximo todos os efeitos de distorção ao longo de todo o sistema, utilizou-se um equalizador "one-tap", cujo funcionamento é explicado no Capítulo 5. Na saída do equalizador, retiraram-se as informações piloto do sinal, permanecendo apenas sinal de dados. Converteu-se este então para série e concatenou-se com os outros símbolos OFDM detectados, formando a sequência $\bar{a}^{\prime}=\left[a_{1}^{\prime} a_{2}^{\prime} \ldots a_{M}^{\prime}\right]$, os símbolos QPSK recebidos. Passaram-se estes símbolos então por um dispositivo de decisão, que os decodificou em bits de informação de acordo com o quadrante em que se detectou cada símbolo.

Com os bits de informação, realizou-se então uma análise de desempenho do sistema, de acordo com os procedimentos descritos no Capítulo 5. 


\section{CAPÍtUlo 4 \\ Resultados de Simulação para uma Fibra Multimodo com Perfil Degrau}

Para a simulação, definiram-se primeiramente os parâmetros da fibra. O núcleo tem raio igual a $25 \mu \mathrm{m}$. O comprimento de onda de operação é $1310 \mathrm{~nm}$, com índices de refração do núcleo e da casca iguais a 1,48 e 1,465 , respectivamente.

Realizamos simulações usando o software Matlab para avaliar o comportamento da fibra multimodo. O processo foi realizado para uma fibra de índice degrau, o que permite obter as soluções por função de Bessel de primeira ordem para o núcleo e de segunda ordem para a casca, como visto no Capitulo 2.

\subsection{Resultados de simulação dos campos da fibra multimodo}

Supomos que o campo incidente na fibra multimodo provém de uma fibra monomodo, servindo como um "pig-tail". O acoplamento dessas fibras pode ser perfeito e isso implica em um alinhamento perfeito em relação ao eixo de propagação da fibra multimodo. Outra possibilidade, é a fibra monomodo estar deslocada em relação ao eixo de propagação da fibra multimodo, gerando assim diversas possibilidades de condições de lançamento e consequentemente, funções de transferências da fibra diferentes, devido aos vários modos excitados. Para a fibra multimodo, obtivemos os seguintes comportamentos do campo para alguns LP's, isto é, para algumas constantes de propagação representados nas Figuras 4.1 , 4.2 , 4.3 , 4.4 , 4.5 , 4.6 , 4.7 , 4.8 , 4.9 e 4.10, vide Capítulo 2. Percebe-se que à medida que aumenta-se o índice azimutal, a quantidade de lóbulos aumenta, e à medida que aumenta-se a ordem para cada índice azimutal, percebem-se ondulações no campo, cada vez mais distante do centro da fibra.

Na Tabela 2.1, estão representados os valores das constantes de propagação para todos os modos suportados pela fibra, bem como as amplitudes modais $\left(a_{l m}\right)$. Na tabela 4.1 constam os valores do $N_{l m}$ e do $\alpha_{l m}$ para cada modo.

Supondo o campo da fonte $\left(P_{S}\right)$, obtém-se a distribuição do campo da fonte nos eixos $\mathrm{X}$ e $\mathrm{Y}$, representado na Figura 4.11, para uma condição de lançamento centralizada, ou seja, os eixos da fibra multimodo e monomodo coincidem. Percebe-se que a forma do campo de lançamento é equivalente ao campo modal $L P_{01}$ da fibra multimodo, representado na Figura 4.1. O campo de lançamento limita-se pelo raio da fibra monomodo de $4 \mu \mathrm{m}$, assim como o modo fundamental da fibra multimodo limita-se pelo seu raio do núcleo. 


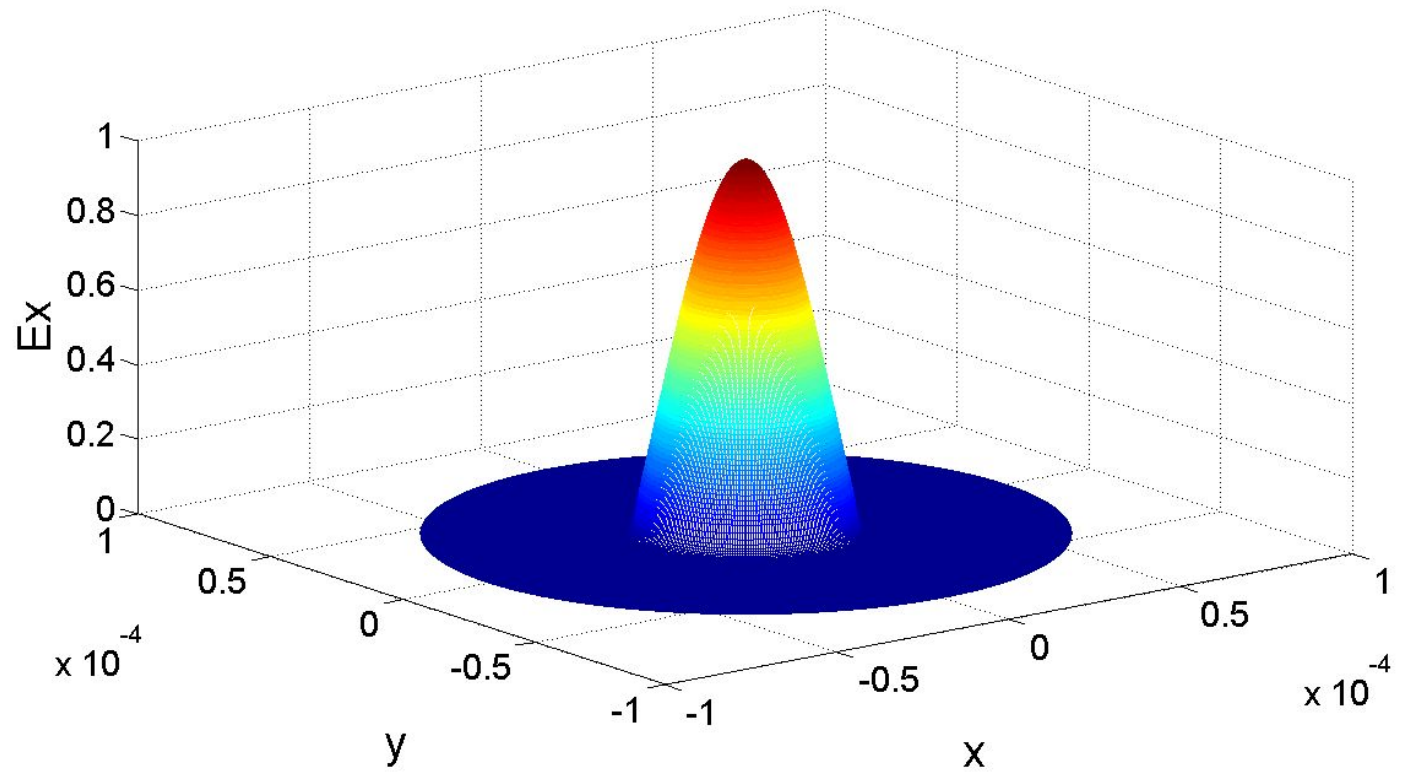

Figura 4.1 Modo fundamental LP01.

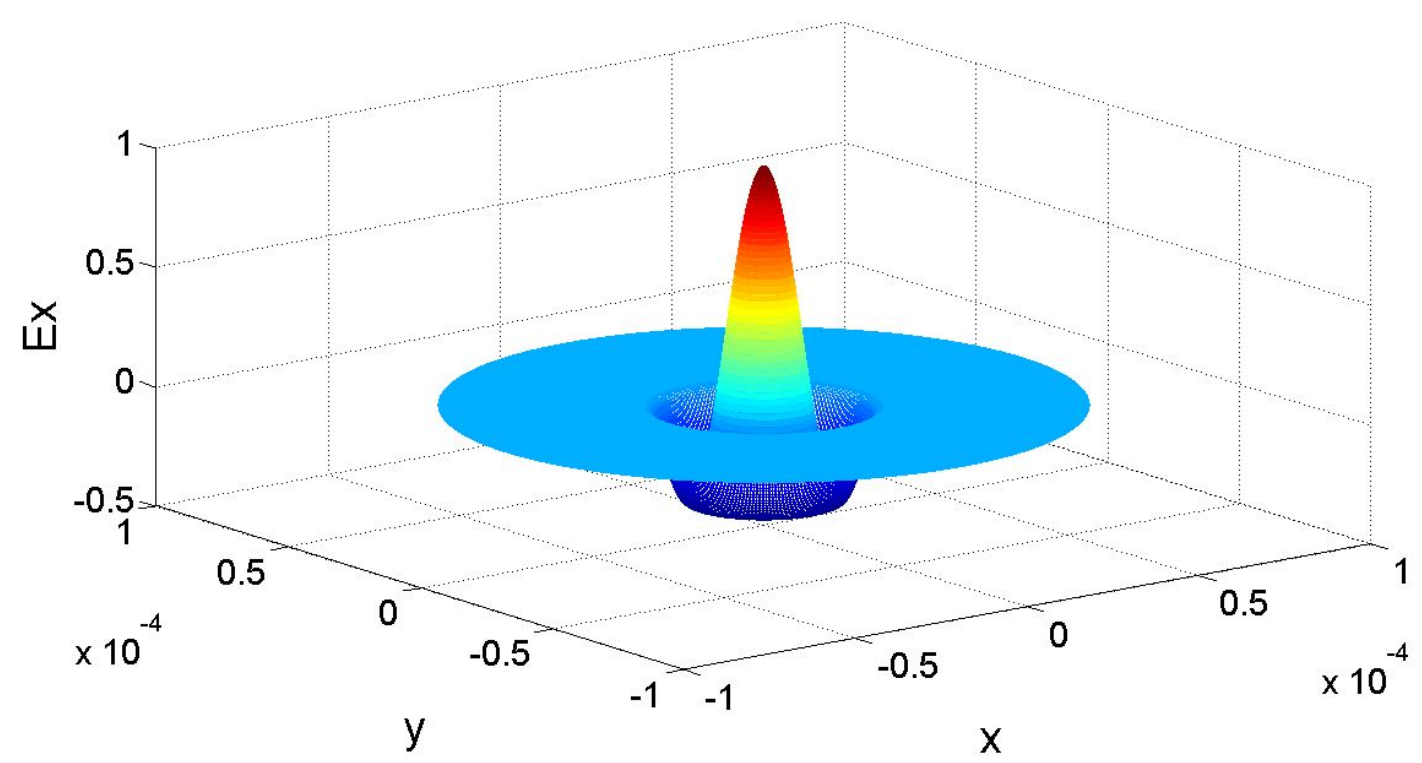

Figura 4.2 Modo de segunda ordem LP02 (HE12). 


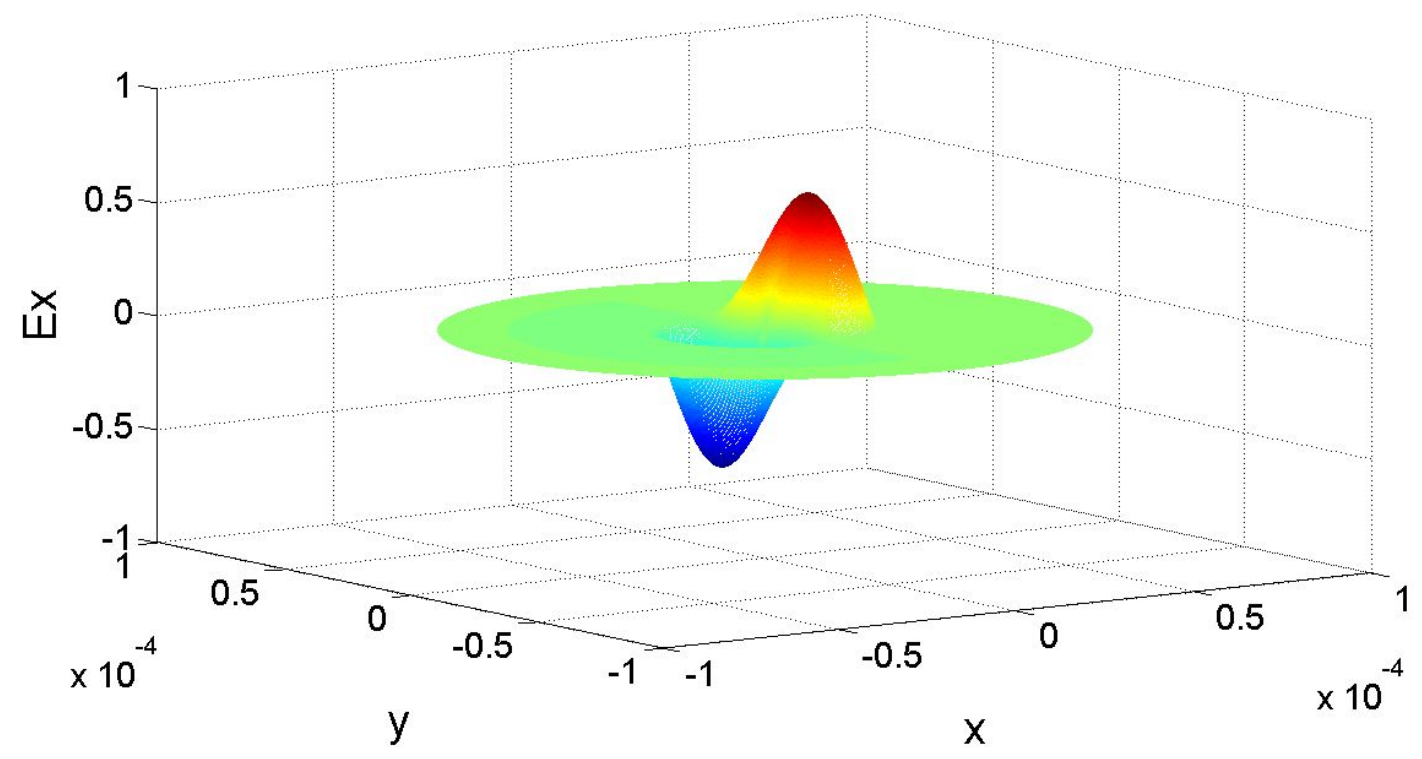

Figura 4.3 Modo de primeira ordem LP11 (TE01, TM01, HE21).

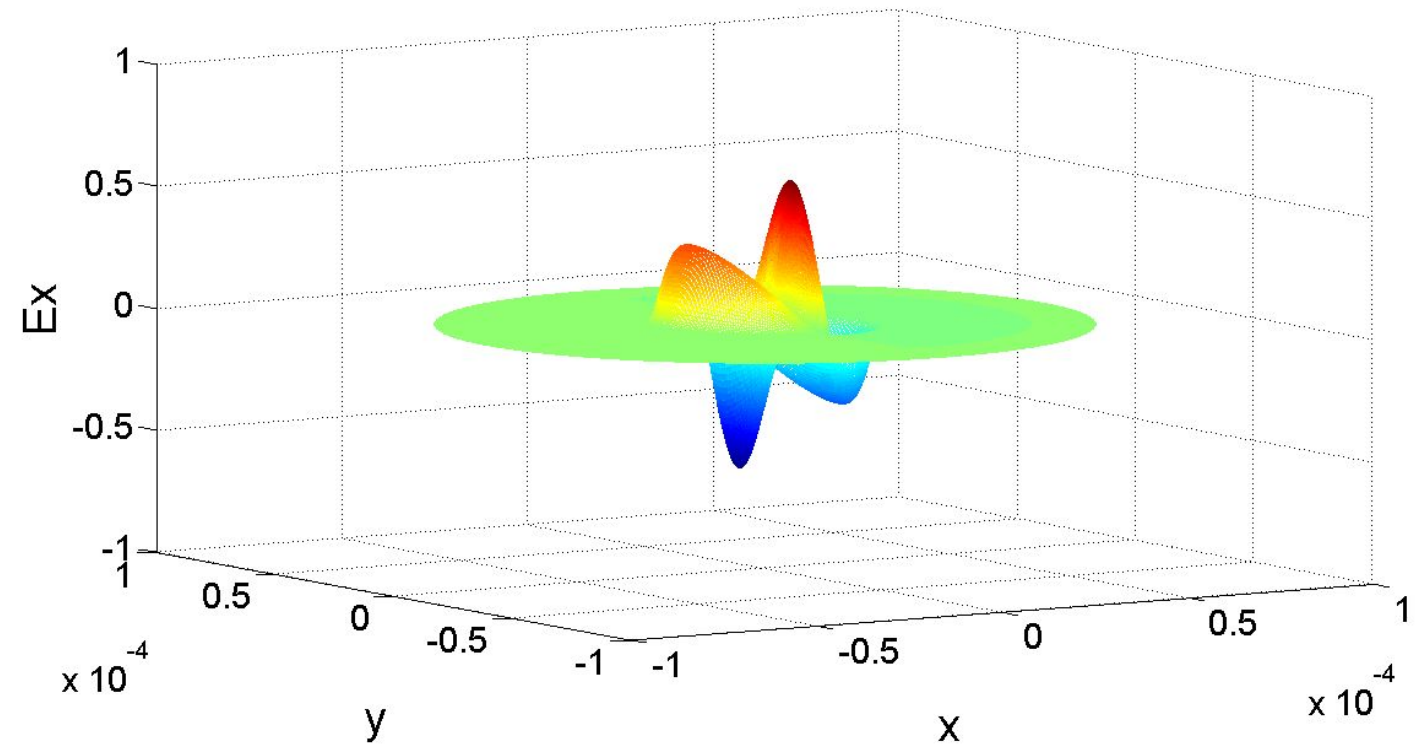

Figura 4.4 Modo de quarta ordem LP12 (TE02, TM02, HE22). 


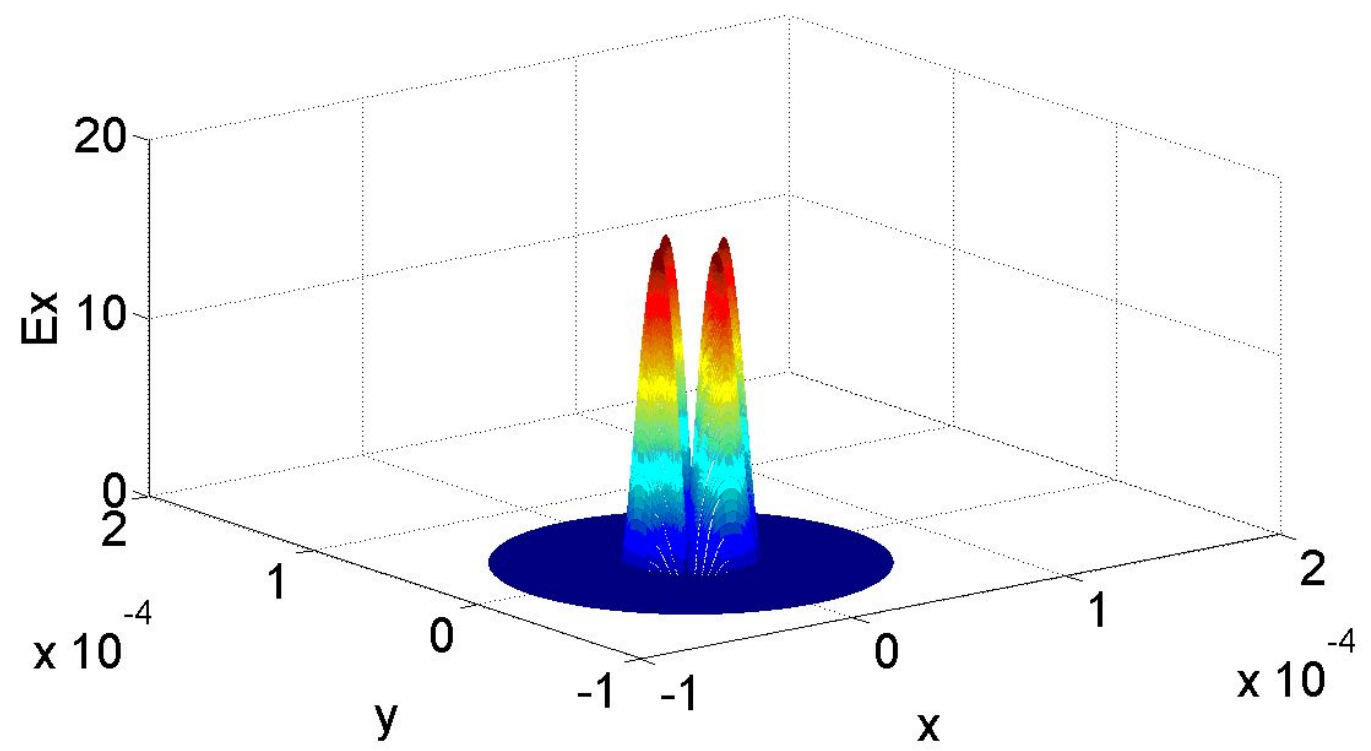

Figura 4.5 Modo de segunda ordem LP21 (EH11, HE31).

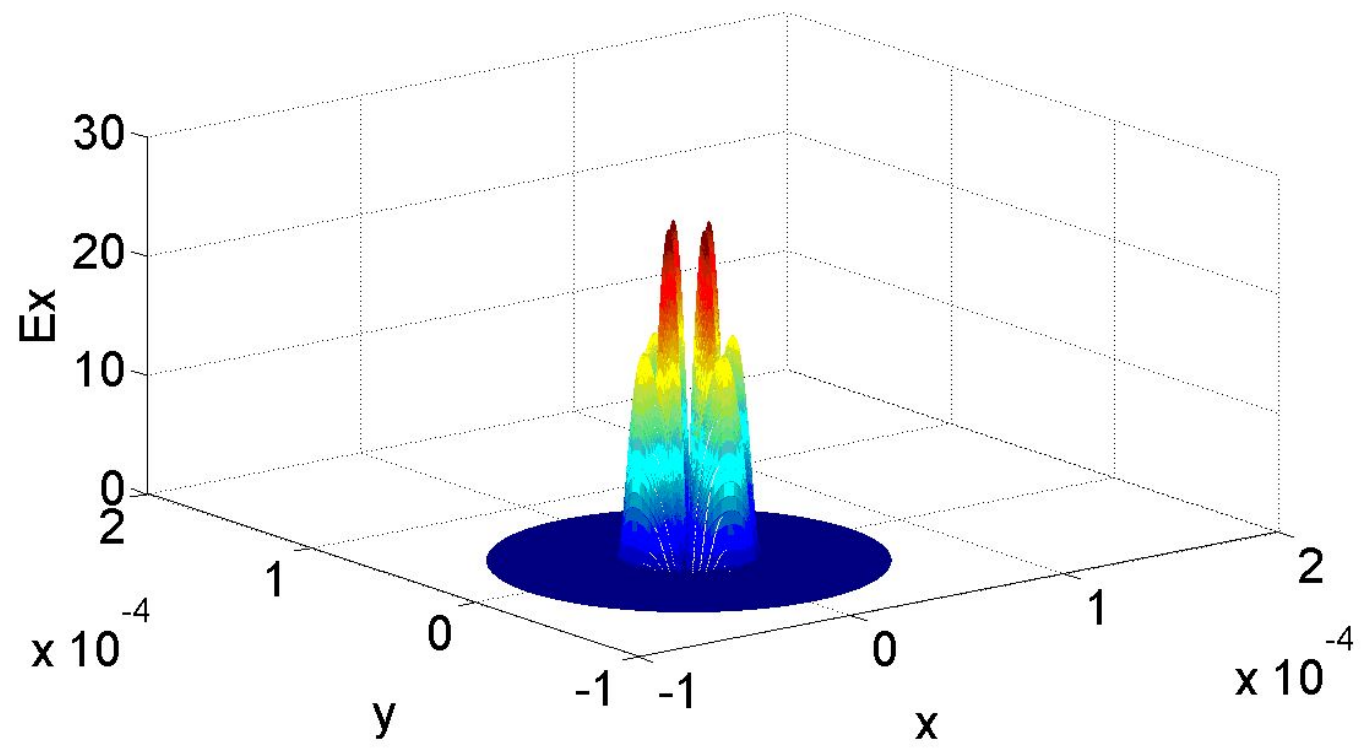

Figura 4.6 Modo de quinta ordem LP22 (EH12, HE32). 


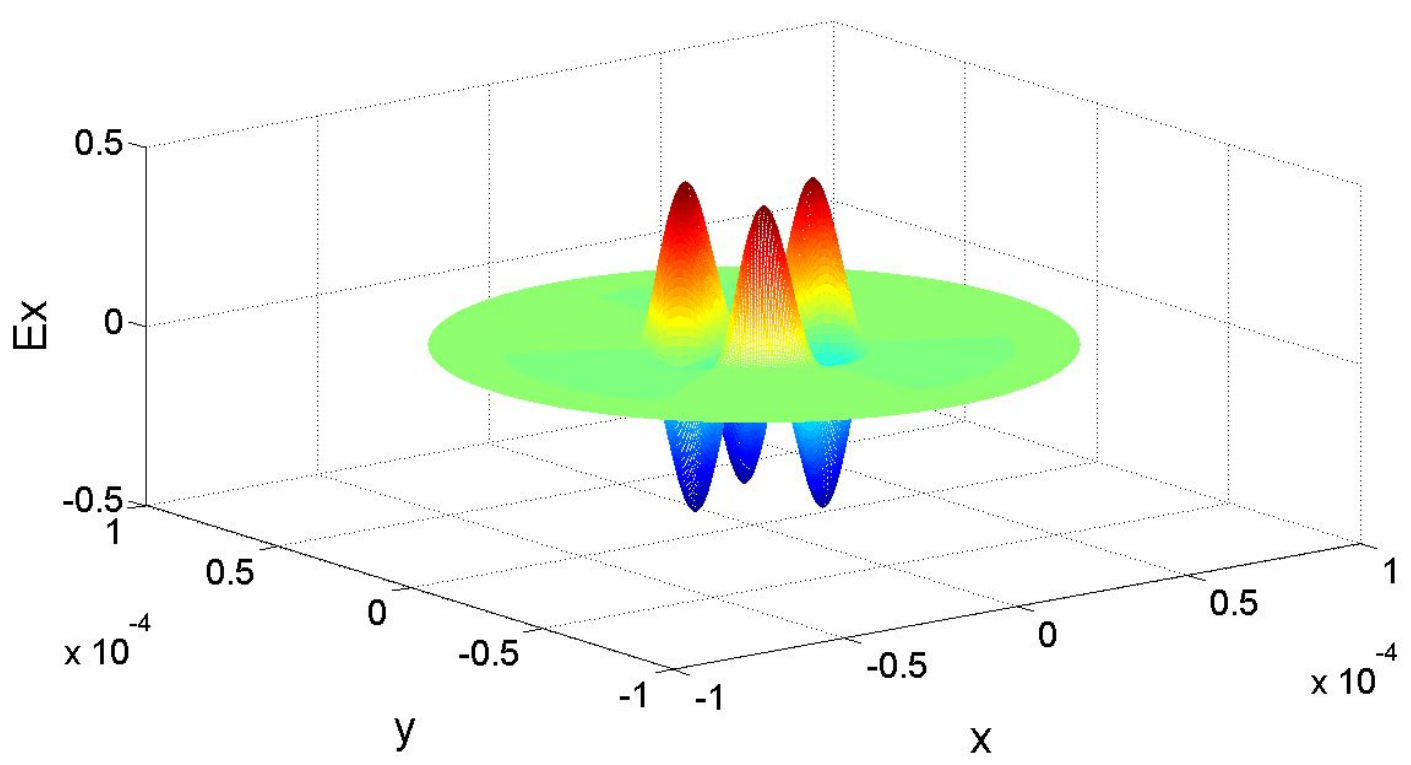

Figura 4.7 Modo de terceira ordem LP31 (HE41, EH21).

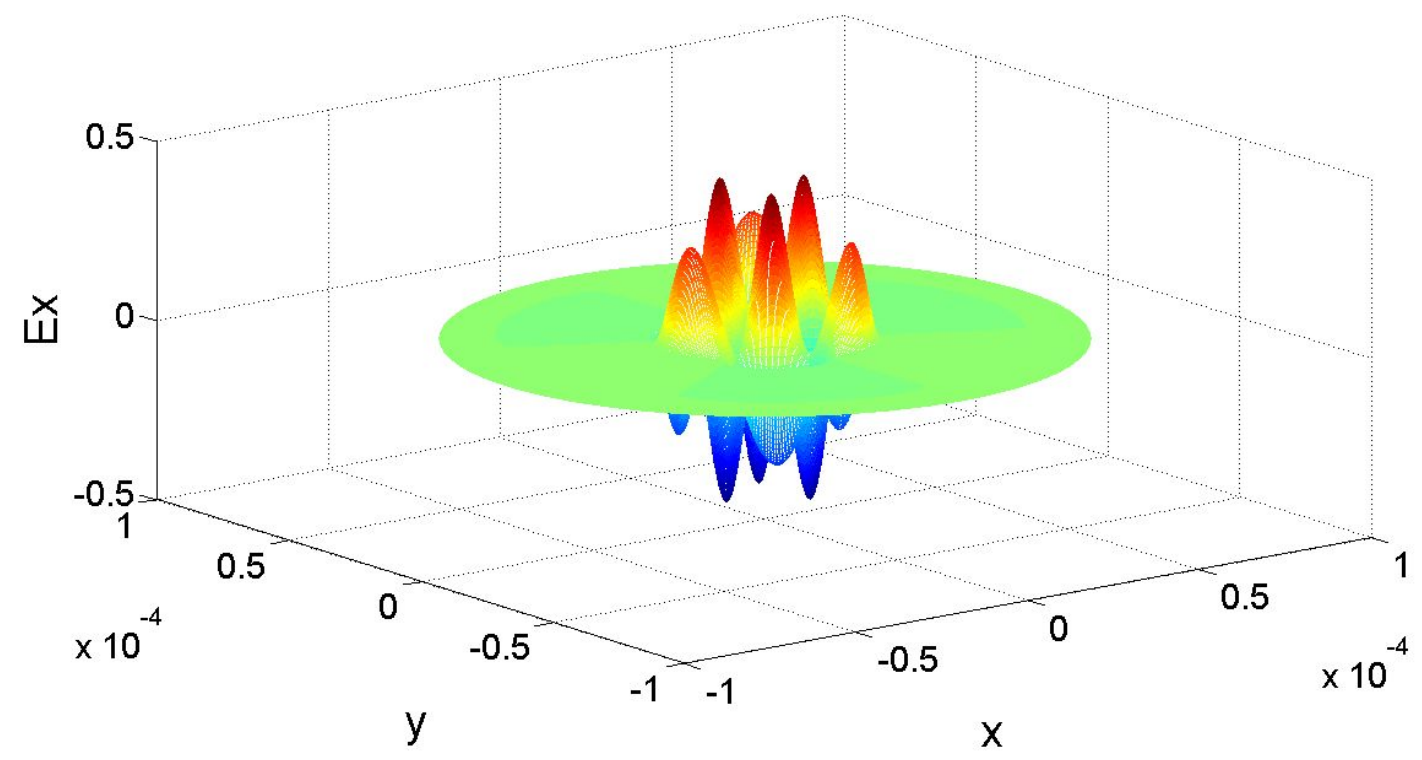

Figura 4.8 Modo de sexta ordem LP32 (HE42, EH22). 
B̊PPÍTULO 4 RESULTADOS DE SIMULAÇÃO PARA UMA FIBRA MULTIMODO COM PERFIL DEGRAU

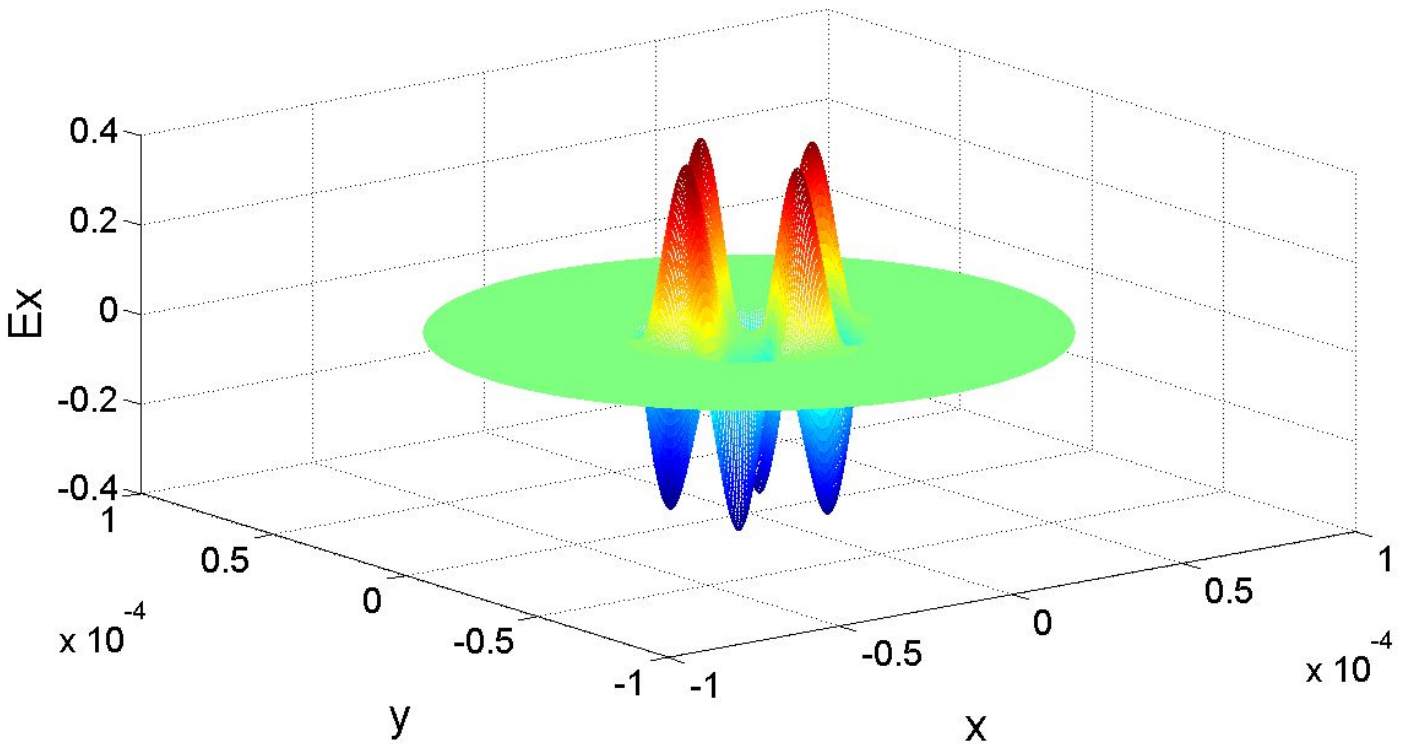

Figura 4.9 LP41 (EH31, HE51).

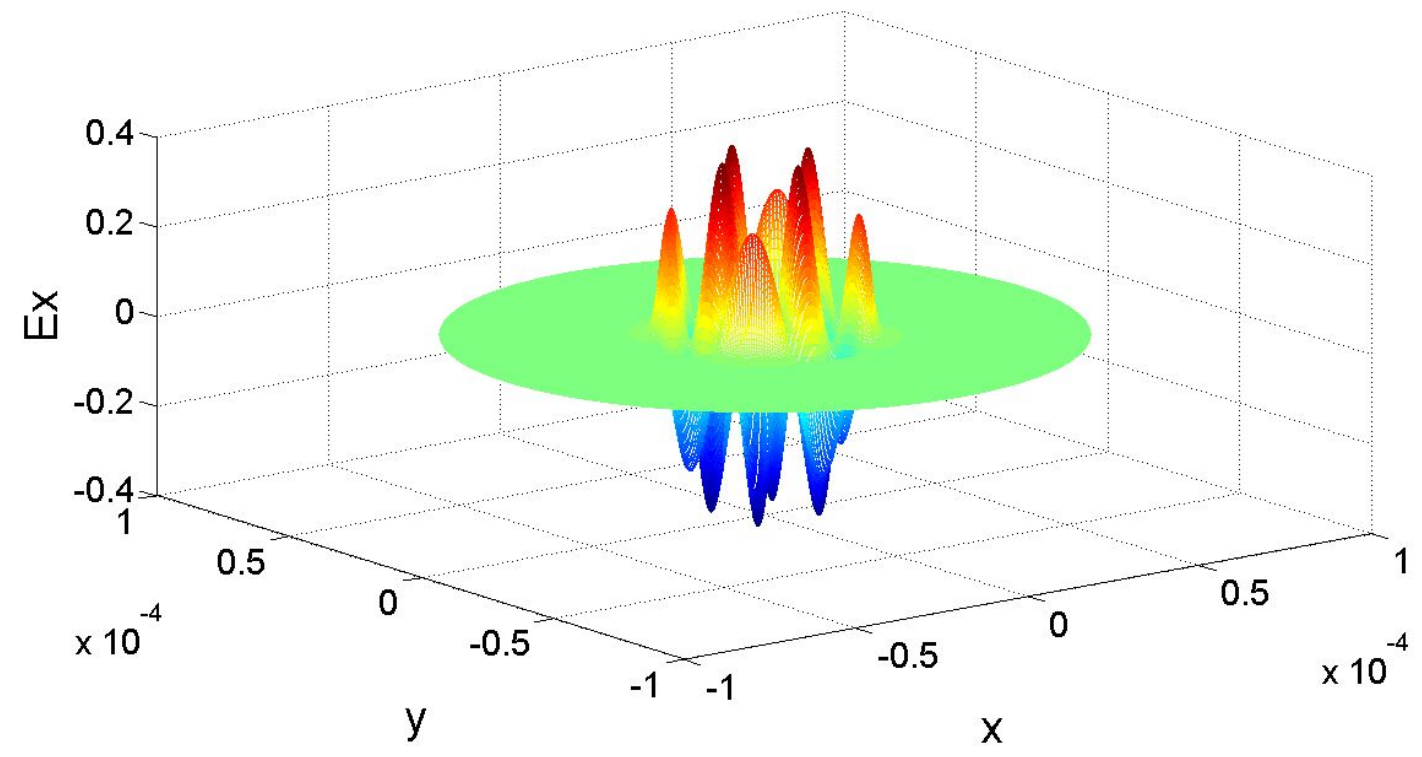

Figura 4.10 LP42 (EH32, HE52). 


\begin{tabular}{|lrr|}
\hline LP $l m$ & \multicolumn{1}{l}{$N_{l m}$} & $\alpha_{l m}$ \\
& & \\
Modo fundamental LP01 (HE11) & $5,82 \mathrm{e}-14$ & 0,3123 \\
Modo de segunda ordem LP02 & $1,40 \mathrm{e}-13$ & 0,4195 \\
Modo de quinta ordem LP03 & $2,24 \mathrm{e}-13$ & 0,1764 \\
LP04 (HE14) & $3,00 \mathrm{e}-13$ & 0,0071 \\
LP05 (HE15) & $3,79 \mathrm{e}-13$ & 0,0258 \\
LP06 (HE16) & $4,55 \mathrm{e}-13$ & 0,0456 \\
LP07 (HE17) & $5,45 \mathrm{e}-13$ & 0,0113 \\
LP08 (HE18) & $5,63 \mathrm{e}-13$ & 0,0019 \\
Modo de primeira ordem LP11 (TE01, TM01, HE21) & $3,98 \mathrm{e}-13$ & 0,00 \\
Modo de quarta ordem LP12 (TE02, TM02, HE22) & $7,05 \mathrm{e}-13$ & 0,00 \\
Modo de sétima ordem LP13 (TE03, TM03, HE23) & $1,05 \mathrm{e}-12$ & 0,00 \\
LP14 (TE04, TM04, HE24) & $1,35 \mathrm{e}-12$ & 0,00 \\
LP15 (TE05, TM05, HE25) & $1,67 \mathrm{e}-12$ & 0,00 \\
LP16 (TE06, TM06, HE26) & $1,92 \mathrm{e}-12$ & 0,00 \\
LP16 (TE07, TM07, HE27) & $2,23 \mathrm{e}-12$ & 0,00 \\
LP18 (TE08, TM08, HE28) & $1,97 \mathrm{e}-12$ & 0,00 \\
Modo de segunda ordem LP21 (EH11, HE31) & $5,58 \mathrm{e}-13$ & 0,00 \\
Modo de quinta ordem LP22 (EH12, HE32) & $8,88 \mathrm{e}-13$ & 0,00 \\
LP23 (EH13, HE33) & $1,19 \mathrm{e}-12$ & 0,00 \\
LP24 (EH14, HE34) & $1,50 \mathrm{e}-12$ & 0,00 \\
LP25 (EH15, HE35) & $1,81 \mathrm{e}-12$ & 0,00 \\
LP26 (EH16, HE36) & $2,18 \mathrm{e}-12$ & 0,00 \\
LP27 (EH17, HE37) & $2,36 \mathrm{e}-12$ & 0,00 \\
Modo de terceira ordem LP31 (HE41, EH21) & $7,20 \mathrm{e}-13$ & 0,00 \\
Modo de sexta ordem LP32 (HE42, EH22) & $8,88 \mathrm{e}-13$ & 0,00 \\
LP33 (EH23, HE43) & $1,19 \mathrm{e}-12$ & 0,00 \\
LP34 (EH24, HE44) & $1,50 \mathrm{e}-12$ & 0,00 \\
LP35 (EH25, HE45) & $1,81 \mathrm{e}-12$ & 0,00 \\
LP36 (EH26, HE46) & $2,18 \mathrm{e}-12$ & 0,00 \\
LP37 (EH27, HE47) & $2,36 \mathrm{e}-12$ & 0,00 \\
LP41 (EH31, HE51) & $9,20 \mathrm{e}-13$ & 0,00 \\
LP42 (EH32, HE52) & $1,19 \mathrm{e}-12$ & 0,00 \\
LP43 (EH33, HE53) & $1,54 \mathrm{e}-12$ & 0,00 \\
LP44 (EH34, HE54) & $2,140 \mathrm{e}-12$ & 0,00 \\
LP45 (EH35, HE55) & 0,00 \\
LP46 (EH36, HE56) & & \\
& & 0,00 \\
\hline
\end{tabular}

Tabela 4.1 $N_{l m}$ 's e $h_{l m}$ 's. 


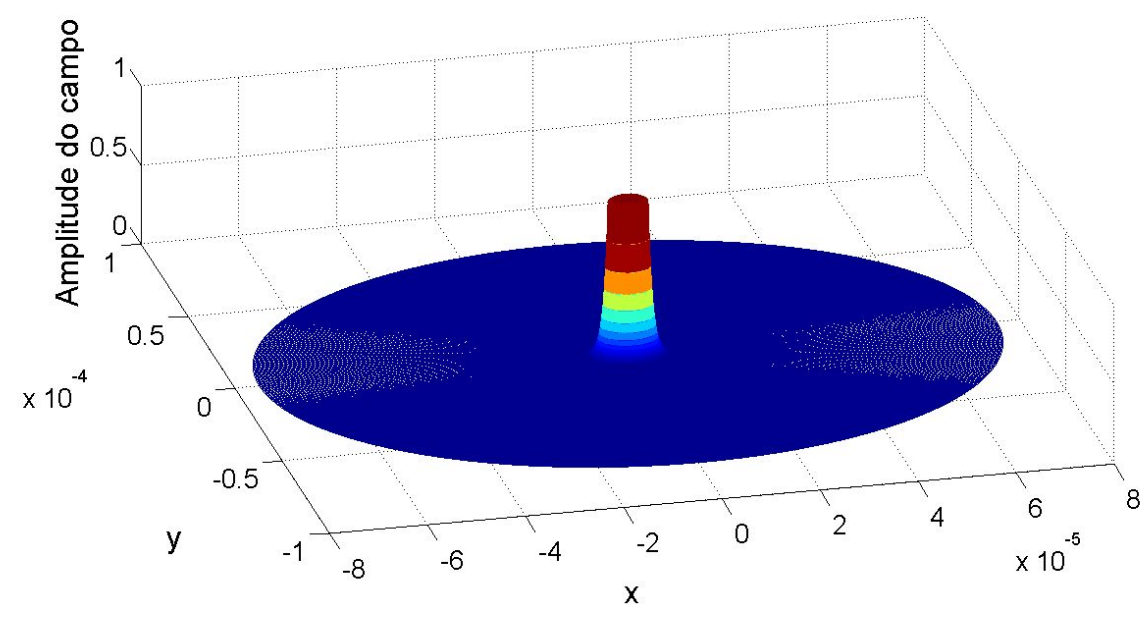

Figura 4.11 Campo da fibra monomodo. $R_{\text {offset }}=0$ e $\theta_{\text {offset }}=0$ radiano.

\subsection{Função de transferência para diversas condições de lançamento}

Esta seção avalia o comportamento da função de transferência da fibra multimodo para diversas condições de lançamento. Simulou-se o campo incidente em várias posições da fibra multimodo, deslocando-o ao longo do raio e do ângulo. Todas as condições foram analisadas para uma fibra de 500m de comprimento. Primeiramente, o comportamento da fibra multimodo para um lançamento centralizado, sem deslocamento, pode-se observar nas Figuras 4.11, 4.12 , 4.13 e 4.14.

Pode-se observar na Figura 4.11 que o campo da fibra monomodo está centralizado, e de acordo com a distribuição dos campos modais representados no início do capítulo, é de se esperar que os modos de mais baixa ordem sejam excitados predominantemente, como podese notar na Figura 4.13. O espaçamento dos impulsos na Figura 4.12 deve-se aos modos de constantes de propagação diferentes, como pode-se notar na distribuição de potência na Figura 4.13. Essa diferença na constante de propagação, implica em tempos de propagação diferentes para os modos citados, gerando então essa diferença na resposta impulsional da fibra.

A partir da resposta impulsional, obtém-se a resposta na frequência em amplitude da fibra na Figura 4.14. A informação que obtivemos através da variação da fase (atraso de grupo) da função de transferência da fibra distorce o sinal. Um atraso de grupo constante no tempo não será problema para o sinal, mas como se pode observar na Figura 4.15, não é o que acontece. Picos e vales são difíceis de serem compensados pelo equalizador de uma maneira eficiente, aumentando-se assim a probabilidade de erro do sistema. Tais variações estão diretamente relacionadas com os vales que ocorrem na resposta em amplitude da fibra multimodo.

Em seguida são apresentados uma série de resultados, para as seguintes condições de lançamento: $R_{\text {offset }}=5 \mu \mathrm{m} \mathrm{e} \theta_{\text {offset }}=0$ radiano, $R_{\text {offset }}=5 \mu \mathrm{m} \mathrm{e} \theta_{o f f s e t}=\pi / 4$ radianos, $R_{\text {offset }}=$ $5 \mu \mathrm{m} \mathrm{e} \theta_{\text {offset }}=\pi / 2$ radianos, $R_{\text {offset }}=12.5 \mu \mathrm{m}$ e $\theta_{\text {offset }}=0$ radiano, $R_{o f f s e t}=12.5 \mu \mathrm{m} \mathrm{e}$ $\theta_{\text {offset }}=\pi / 2$ radianos, $R_{\text {offset }}=20 \mu \mathrm{m} \mathrm{e} \theta_{\text {offset }}=0$ radiano, $R_{\text {offset }}=30 \mu \mathrm{m} \mathrm{e} \theta_{\text {offset }}=0$ 


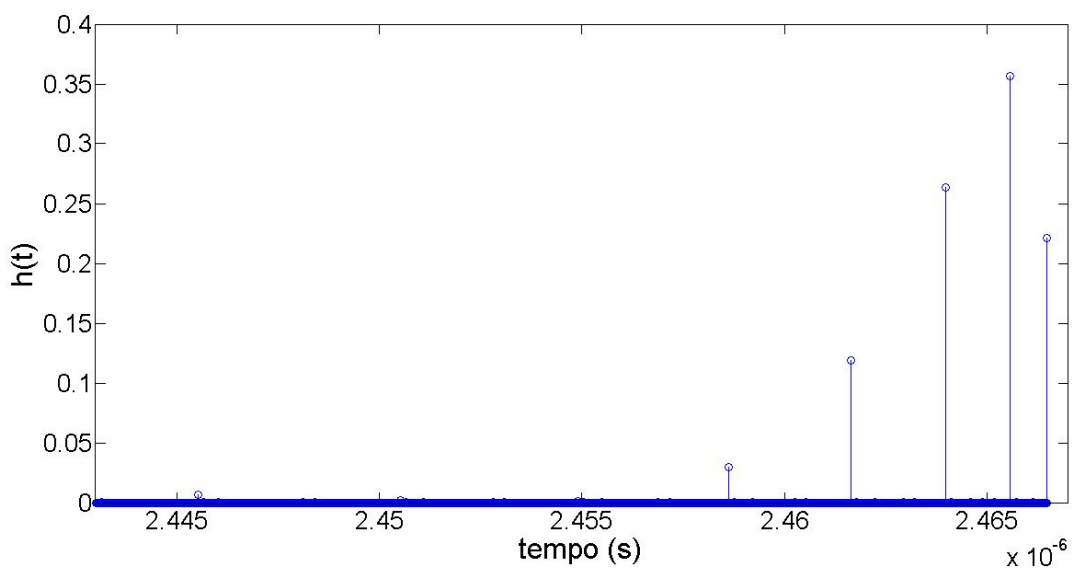

Figura 4.12 Resposta impulsional da fibra multimodo. $R_{\text {offset }}=0$ e $\theta_{\text {offset }}=0$ radiano.

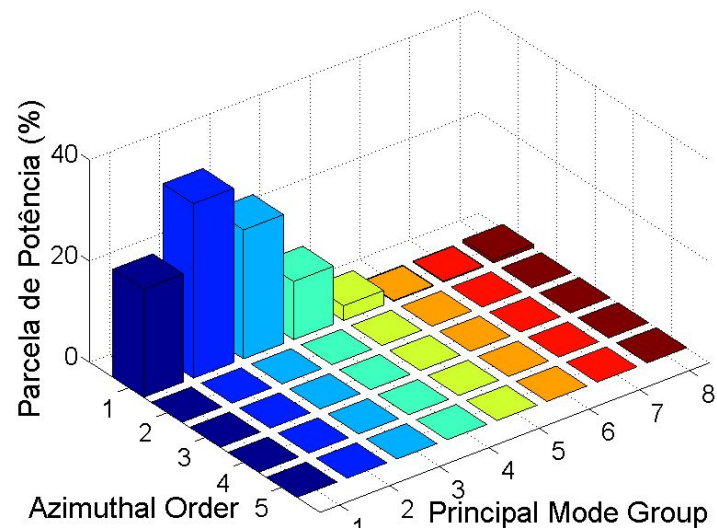

Azimuthal Order $5<_{2}$ Principal Mode Group

Figura 4.13 Distribuição da parcela de potência por modo. $R_{o f f s e t}=0$ e $\theta_{o f f s e t}=0$ radiano.

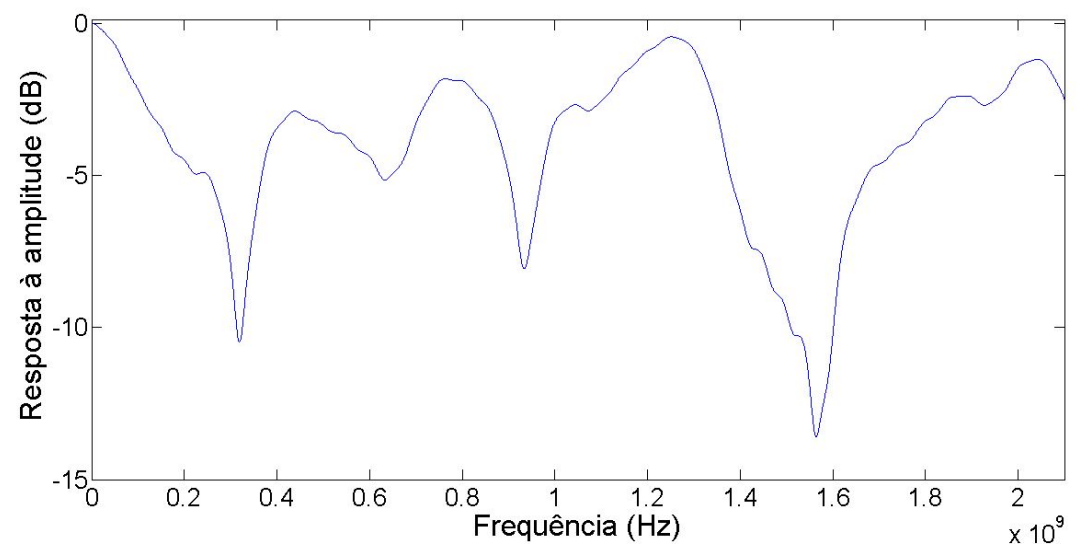

Figura 4.14 Resposta em amplitude da fibra multimodo. $R_{\text {offset }}=0$ e $\theta_{\text {offset }}=0$ radiano. 


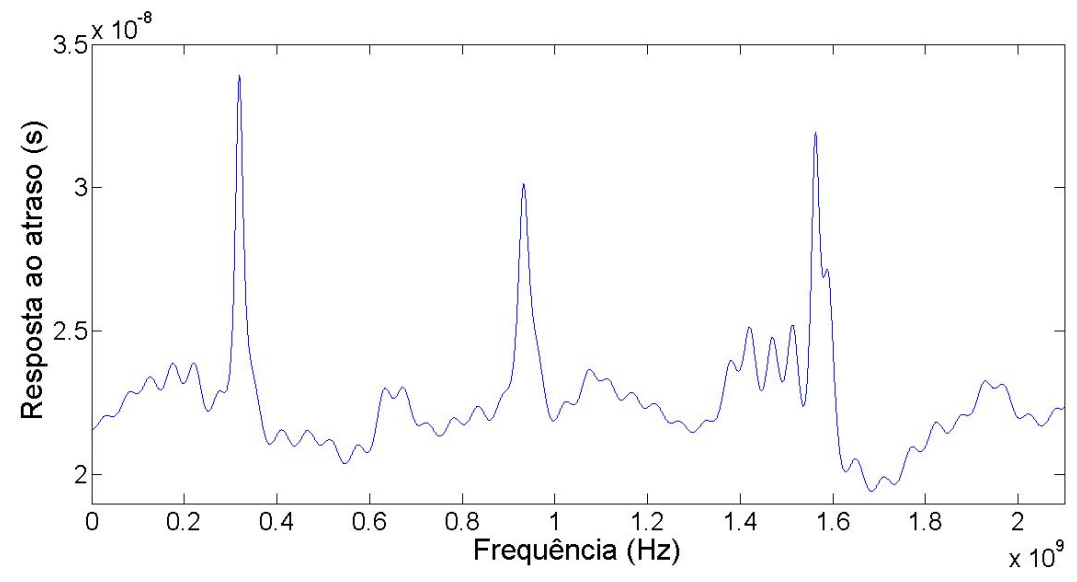

Figura 4.15 Atraso de grupo da fibra multimodo. $R_{o f f s e t}=0$ e $\theta_{o f f s e t}=0$ radiano.

radiano. Pode-se perceber nos resultados, que os modos de ordem superior vão sendo excitados à medida que afasta-se o eixo de lançamento do feixe de luz do eixo de propagação da fibra multimodo, como esperado de acordo com 2.47.

Nota-se também, que o deslocamento da condição de lançamento ao longo do eixo angular também gera uma variação dos modos excitados. Pode-se notar que nas condições de lançamento em que a fibra possui um deslocamento de $\pi / 2$ radianos, os modos de índice azimutal ímpares não são excitados. Isso está de acordo com os resultados obtidos nas figuras que representam os campos da fibra multimodo, pois as distribuições do campo para os índices ímpares estão ao longo do eixo $X$, ou seja, em coordenadas polares, estão distribuídas em torno do ângulo 0 radiano, e do ângulo $\pi$ radianos. No fim do capítulo é apresentada uma comparação entre as respostas à amplitude e a variação do atraso para cada condição de lançamento.

\section{Deslocamento de $: R_{\text {offset }}=5 \mu \mathrm{m}$ e $\theta_{\text {offset }}=0$ radiano}

Nessa situação, com um deslocamento de $5 \mu \mathrm{m}$, como pode ser visto na Figura 4.16, notase que a potência se distribui em uma quantidade de modos maior quando comparado ao lançamento centralizado na fibra. Tal comportamento pode ser visto nas Figuras 4.17 e 4.18. Para um pequeno deslocamento, a potência ainda se concentra nos modos de mais baixa ordem, o que era de se esperar de acordo com a distribuição dos campos da fibra multimodo. A resposta em amplitude pode ser vista na Figura 4.19, bem como o atraso de grupo na Figura 4.20.

2. Deslocamento de $: R_{\text {offset }}=5 \mu \mathrm{m}$ e $\theta_{\text {offset }}=\pi / 4$ radianos

Mantendo-se o deslocamento radial de $5 \mu \mathrm{m}$, supomos agora um deslocamento angular de $\pi / 4$ radianos, como pode ser visto na Figura 4.21. Percebe-se que o lançamento em $\pi / 4$ radianos diminui a quantidade de modos que carregam potência, quando comparado à condição de lançamento anterior. Em relação à resposta em amplitude, representada na Figura 4.24, notam-se 2 pontos de atenuação de aproximadamente 10dB, que dificultam 


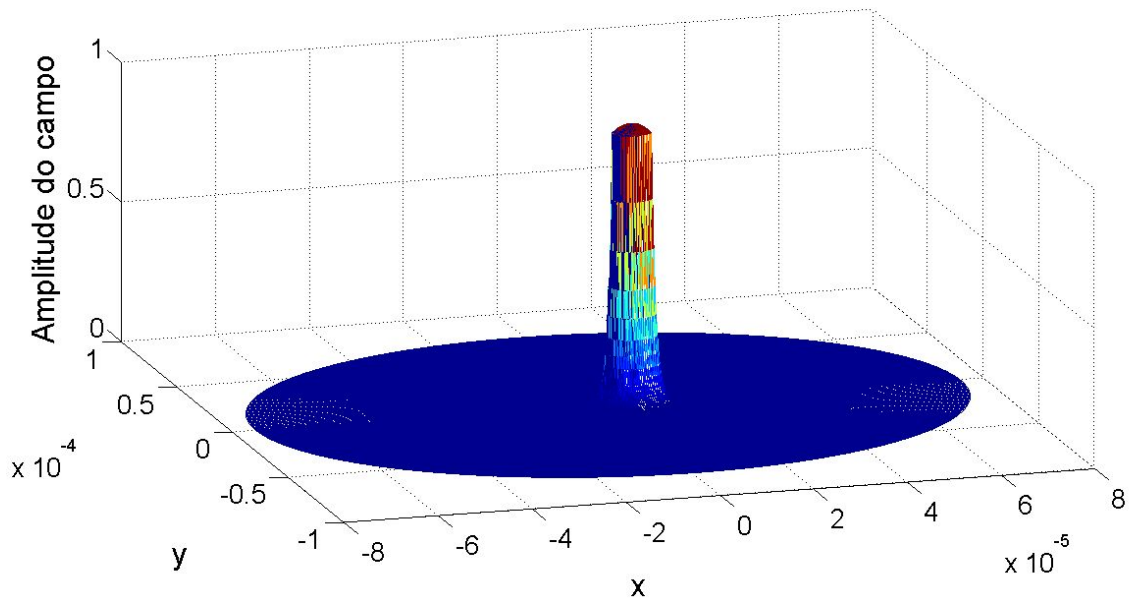

Figura 4.16 Campo da fibra monomodo. $R_{\text {offset }}=5 \mu \mathrm{m}$ e $\theta_{\text {offset }}=0$ radiano.

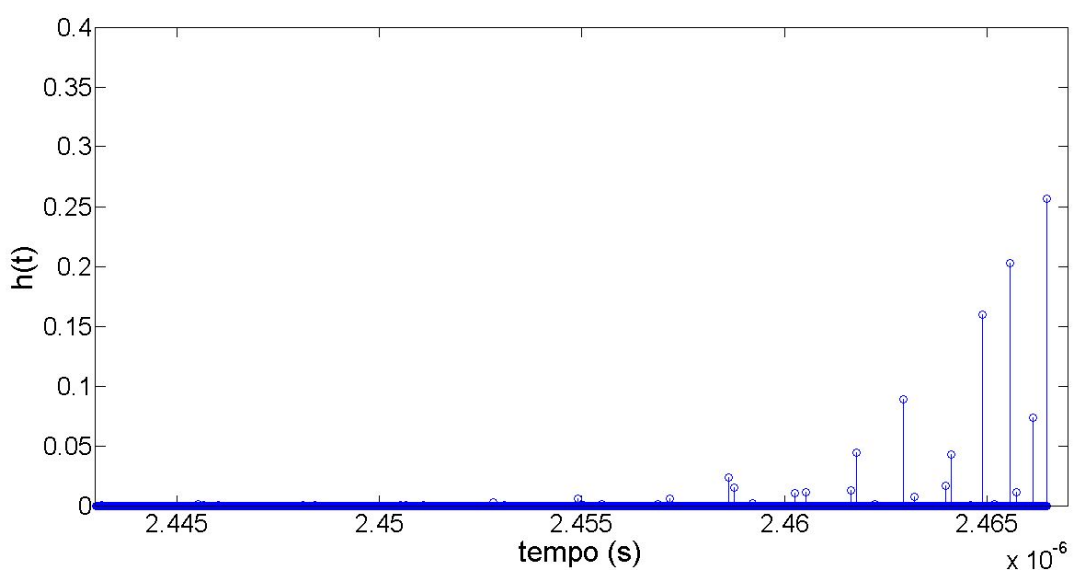

Figura 4.17 Resposta impulsional da fibra multimodo. $R_{\text {offset }}=5 \mu \mathrm{m}$ e $\theta_{\text {offset }}=0$ radiano. 


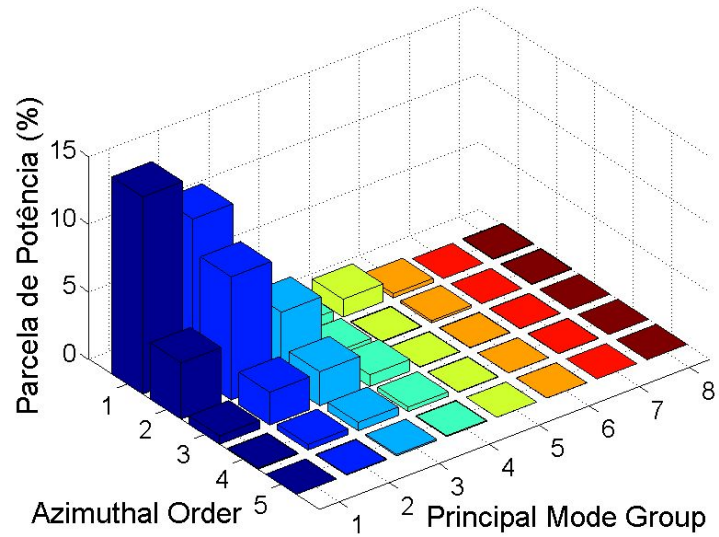

Figura 4.18 Distribuição da parcela de potência por modo. $R_{\text {offset }}=5 \mu \mathrm{m}$ e $\theta_{\text {offset }}=0$ radiano.

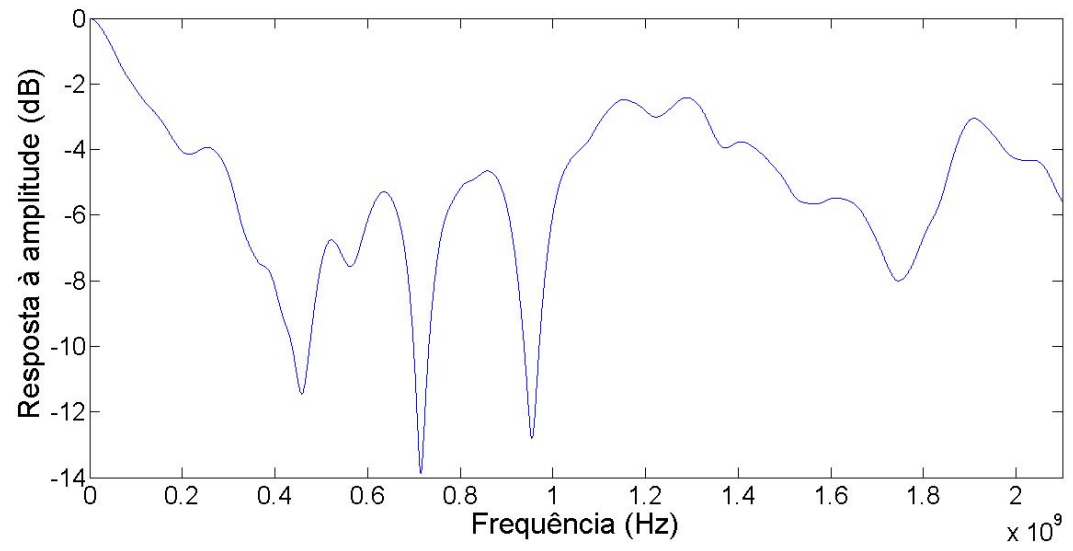

Figura 4.19 Resposta em amplitude da fibra multimodo. $R_{o f f s e t}=5 \mu \mathrm{m}$ e $\theta_{o f f s e t}=0$ radiano.

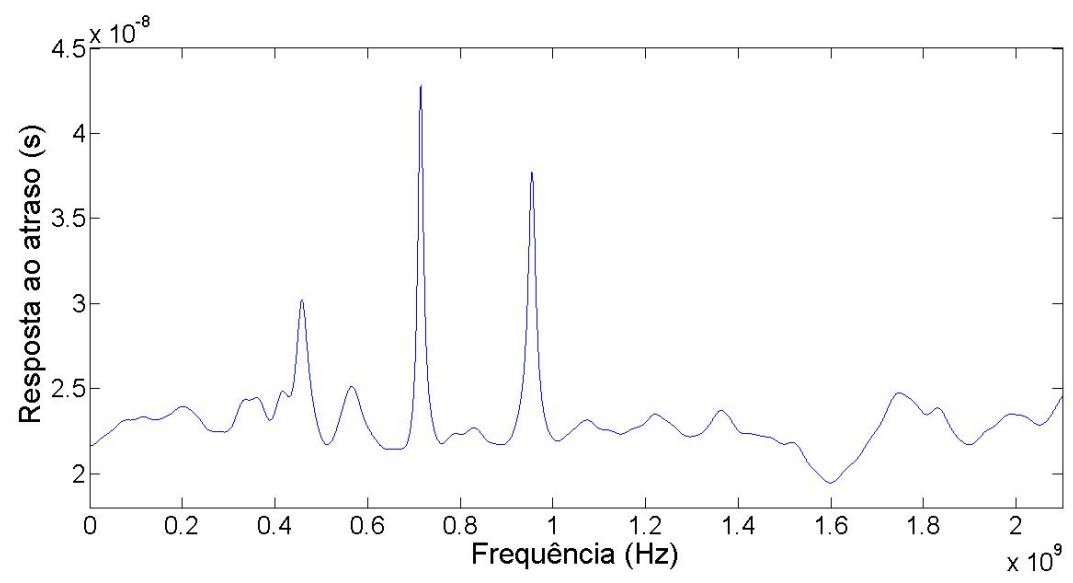

Figura 4.20 Atraso de grupo da fibra multimodo. $R_{\text {offset }}=5 \mu \mathrm{m}$ e $\theta_{\text {offset }}=0$ radiano. 


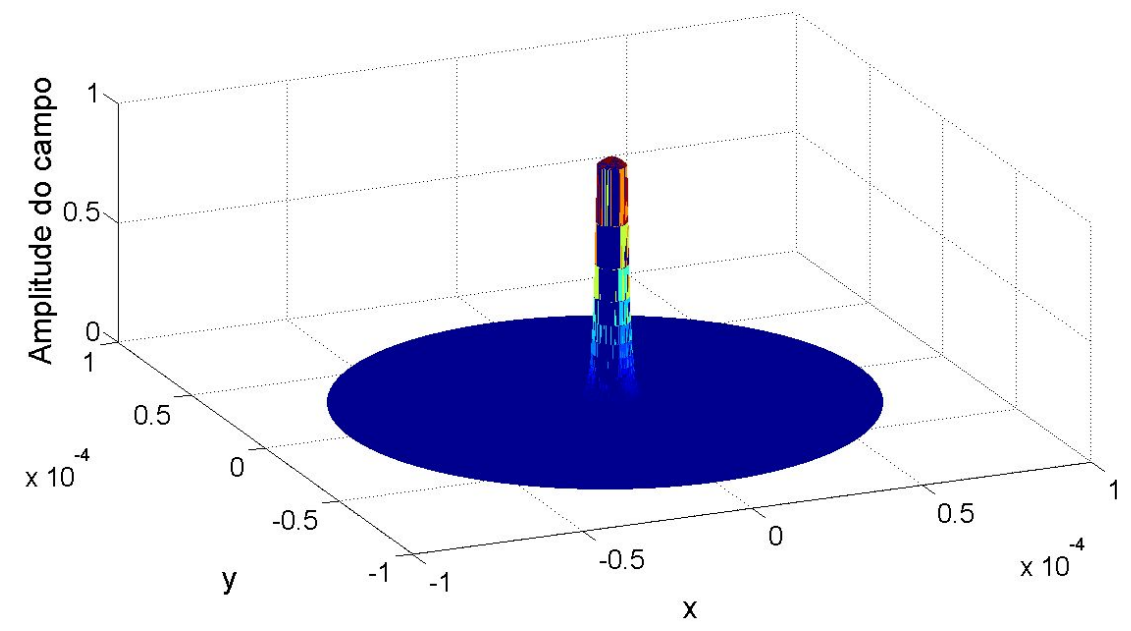

Figura 4.21 Campo da fibra monomodo. $R_{\text {offset }}=5 \mu \mathrm{m}$ e $\theta_{\text {offset }}=\pi / 4$ radianos.

a equalização do sinal transmitido pela fibra. Na Figura 4.25, temos o atraso de grupo para esse caso.

3. Deslocamento de $: R_{\text {offset }}=5 \mu \mathrm{m}$ e $\theta_{\text {offset }}=\pi / 2$ radianos

Ainda fixado o raio em $R_{o f f s e t}=5 \mu \mathrm{m}$, simulamos agora com a fibra monomodo deslocada em $\pi / 2$ radianos, como pode ser visto na Figura 4.26. Nesse ponto, percebemos que os modos ímpares não carregam potência, como pode ser visto na Figura 4.28. A resposta em amplitude da fibra possui uma atenuação de aproximadamente $16 \mathrm{~dB}$ na faixa de 1.6 $\mathrm{GHz}$, como pode ser visto na Figura 4.29. Esse é um fator em que o equalizador não será suficiente para corrigir os erros inseridos no sinal transmitido nessa faixa de frequência. O atraso de grupo para esse caso pode ser observado na Figura 4.30.

\section{Deslocamento de $: R_{\text {offset }}=12.5 \mu \mathrm{m}$ e $\theta_{\text {offset }}=0$ radiano}

Com um deslocamento de $12.5 \mu \mathrm{m}$ e sem deslocamento angular, posicionamos a fibra monomodo na metade do raio da fibra multimodo como pode ser visto na Figura 4.31, garantindo ainda uma condição de lançamento em que a fibra monomodo concentre todo o campo de lançamento dentro do núcleo da fibra multimodo. Percebe-se que ainda mais modos são excitados para essa condição de lançamento, como pode ser visto nas Figuras 4.33 e 4.32. Tal comportamento era de se esperar de acordo com a distribuição dos campos da fibra multimodo, como pode ser visto no início desse capítulo. A resposta em amplitude para esse caso está representada na Figura 4.34, e a variação do atraso na Figura 4.35. Percebe-se que uma atenuação de $16 \mathrm{~dB}$ na faixa de $1.4 \mathrm{GHz}$, bem como uma variação do atraso de grupo também nessa faixa de frequência, gera uma distorção no sinal, dificultando a ação do equalizador.

5. Deslocamento de $: R_{\text {offset }}=12.5 \mu \mathrm{m}$ e $\theta_{\text {offset }}=\pi / 2$ radianos 


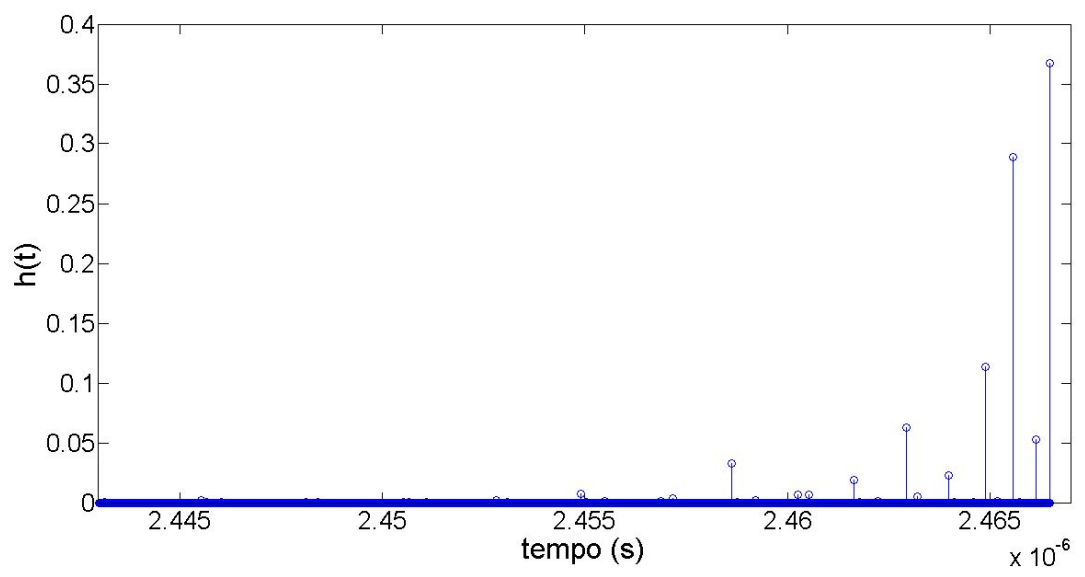

Figura 4.22 Resposta impulsional da fibra multimodo. $R_{\text {offset }}=5 \mu \mathrm{m}$ e $\theta_{\text {offset }}=\pi / 4$ radianos.

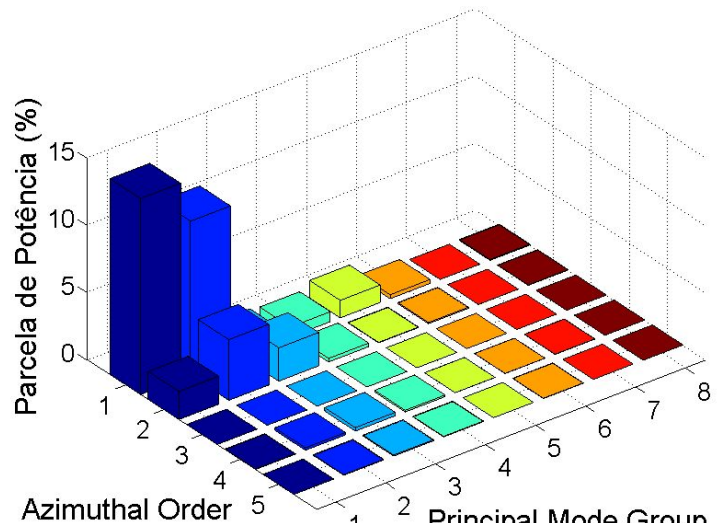

Azimuthal Order $5<_{1}$ Principal Mode Group

Figura 4.23 Distribuição da parcela de potência por modo. $R_{\text {offset }}=5 \mu \mathrm{m}$ e $\theta_{\text {offset }}=\pi / 4$ radianos.

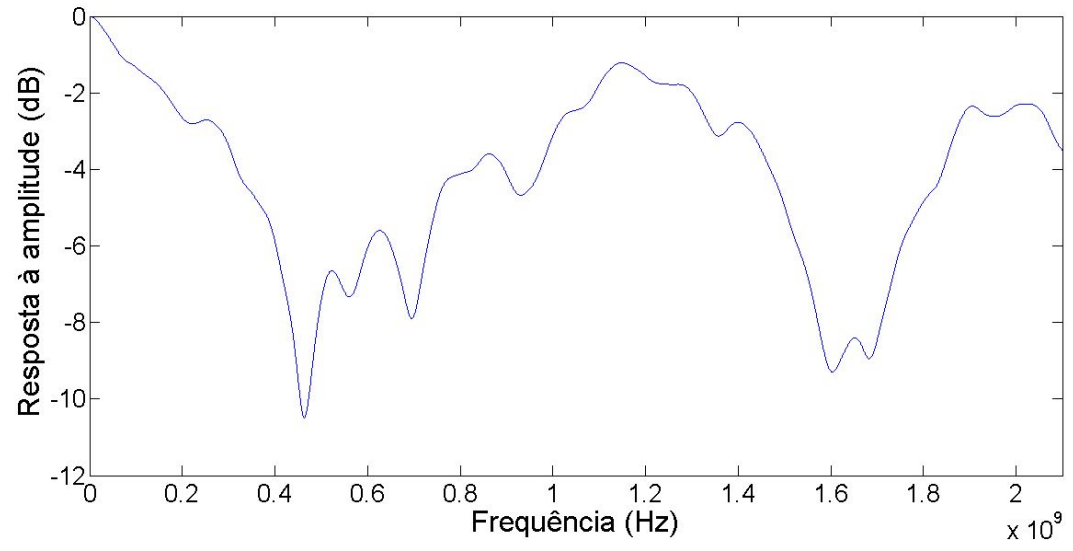

Figura 4.24 Resposta em amplitude da fibra multimodo. $R_{\text {offset }}=5 \mu \mathrm{m}$ e $\theta_{\text {offset }}=\pi / 4$ radianos. 


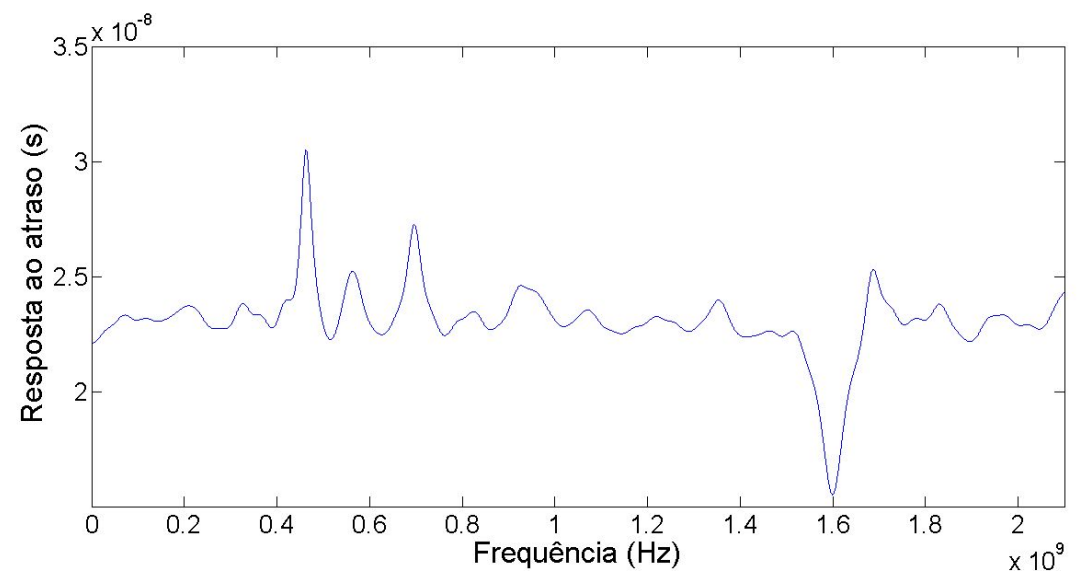

Figura 4.25 Atraso de grupo da fibra multimodo. $R_{\text {offset }}=5 \mu \mathrm{m}$ e $\theta_{\text {offset }}=\pi / 4$ radianos.

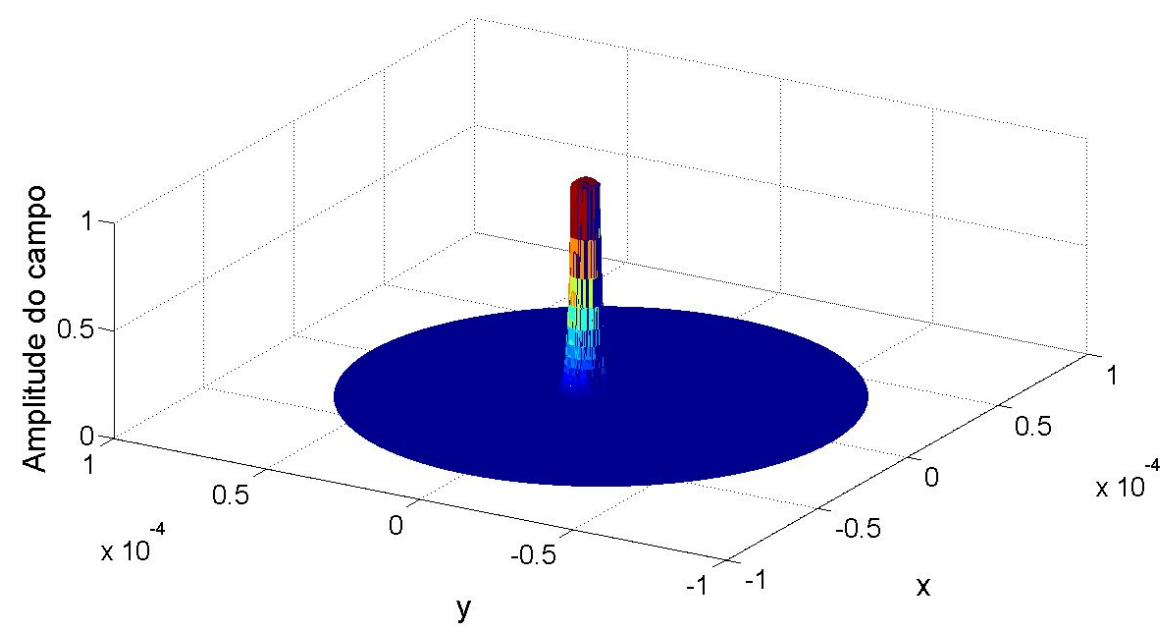

Figura 4.26 Campo da fibra monomodo. $R_{\text {offset }}=5 \mu \mathrm{m}$ e $\theta_{\text {offset }}=\pi / 2$ radianos. 


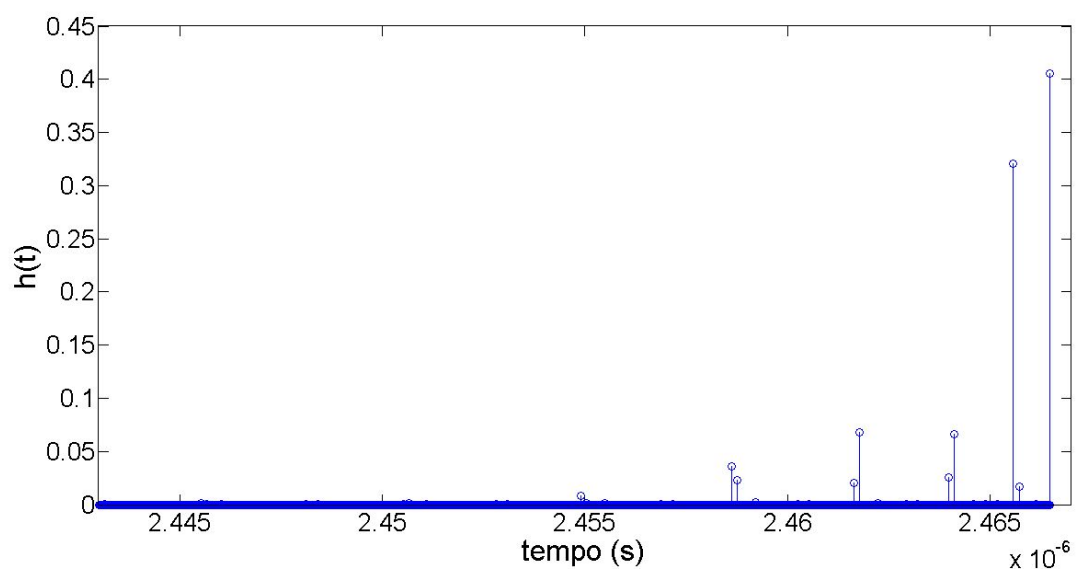

Figura 4.27 Resposta impulsional da fibra multimodo. $R_{o f f s e t}=5 \mu \mathrm{m}$ e $\theta_{o f f s e t}=\pi / 2$ radianos.

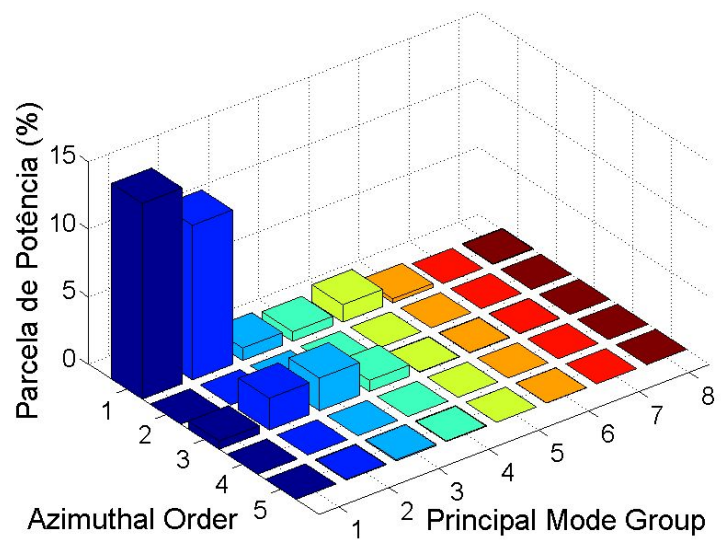

Figura 4.28 Distribuição da parcela de potência por modo. $R_{\text {offset }}=5 \mu \mathrm{m}$ e $\theta_{\text {offset }}=\pi / 2$ radianos. 


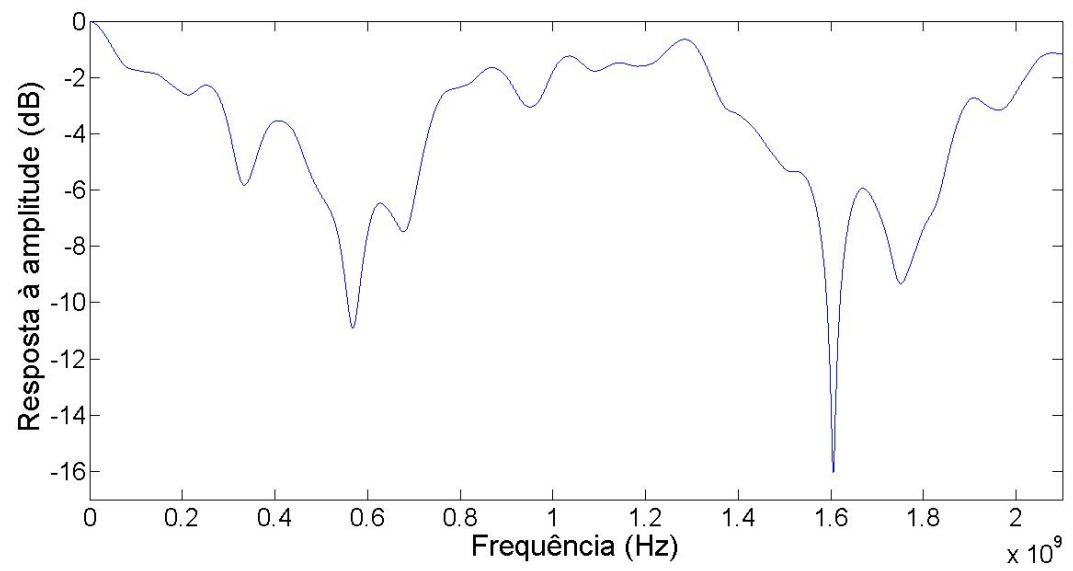

Figura 4.29 Resposta em amplitude da fibra multimodo. $R_{\text {offset }}=5 \mu \mathrm{m}$ e $\theta_{\text {offset }}=\pi / 2$ radianos.

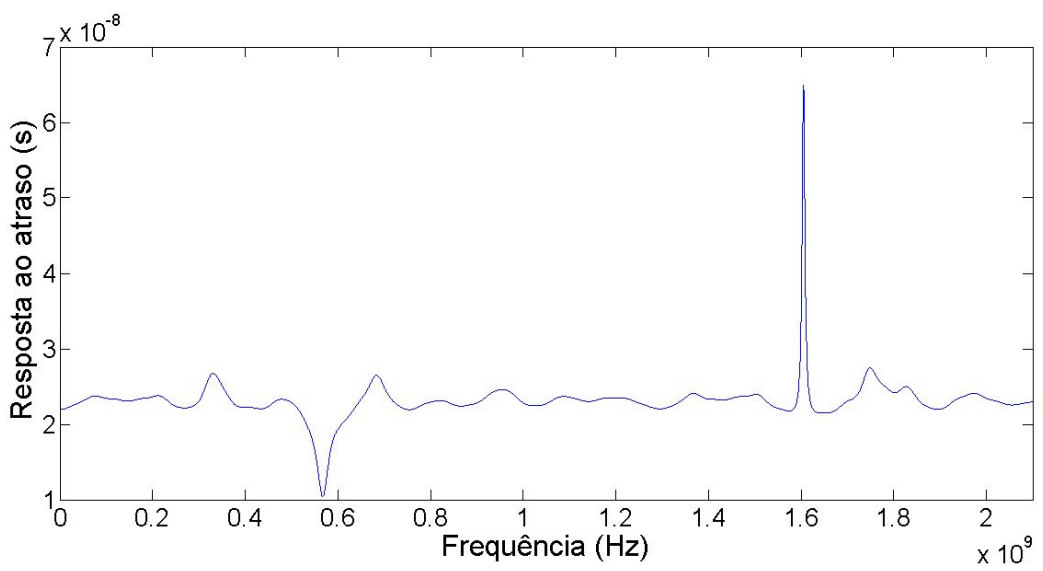

Figura 4.30 Atraso de grupo da fibra multimodo. $R_{\text {offset }}=5 \mu \mathrm{m}$ e $\theta_{\text {offset }}=\pi / 2$ radianos. 


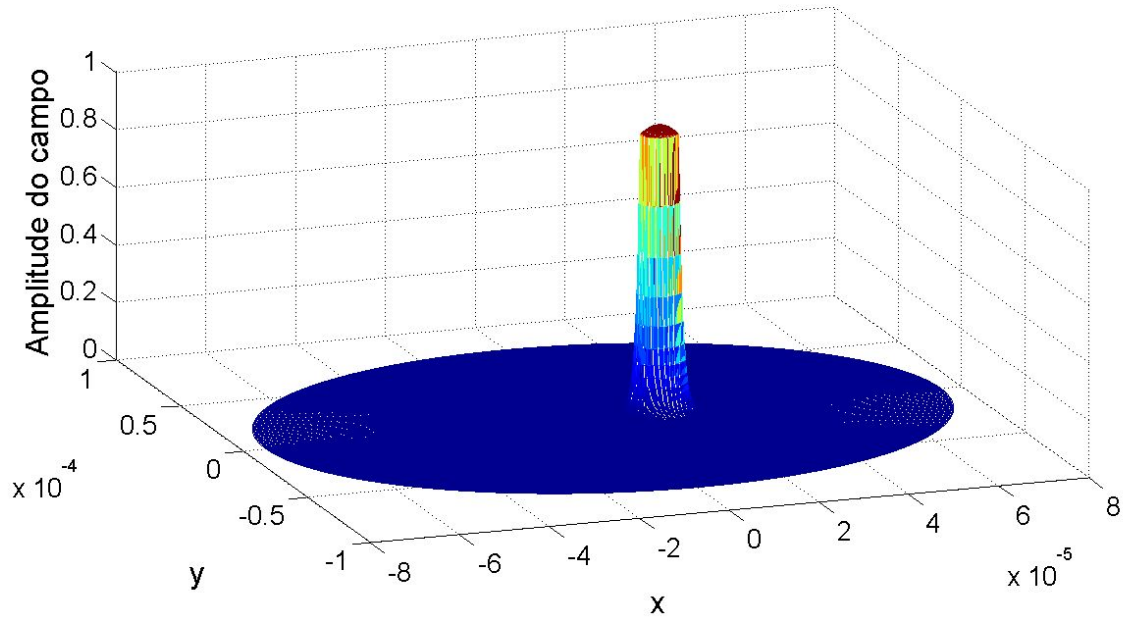

Figura 4.31 Campo da fibra monomodo. $R_{\text {offset }}=12.5 \mu \mathrm{m}$ e $\theta_{\text {offset }}=0$ radiano.

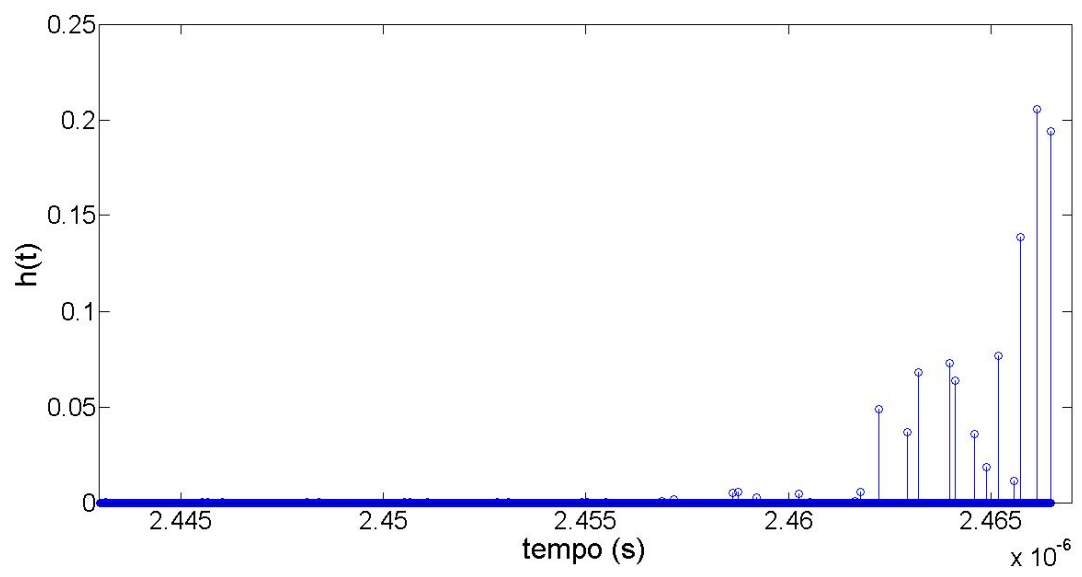

Figura 4.32 Resposta impulsional da fibra multimodo. $R_{\text {offset }}=12.5 \mu \mathrm{m}$ e $\theta_{\text {offset }}=0$ radiano. 


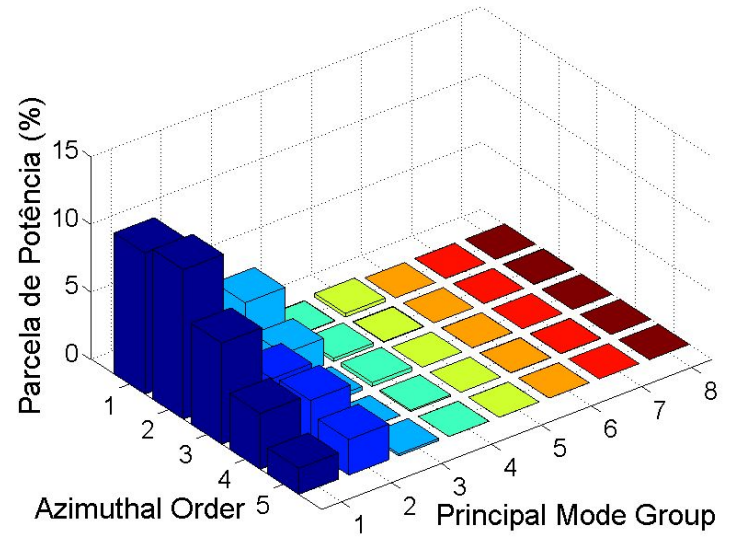

Figura 4.33 Distribuição da parcela de potência por modo. $R_{\text {offset }}=12.5 \mu \mathrm{m}$ e $\theta_{\text {offset }}=0$ radiano.

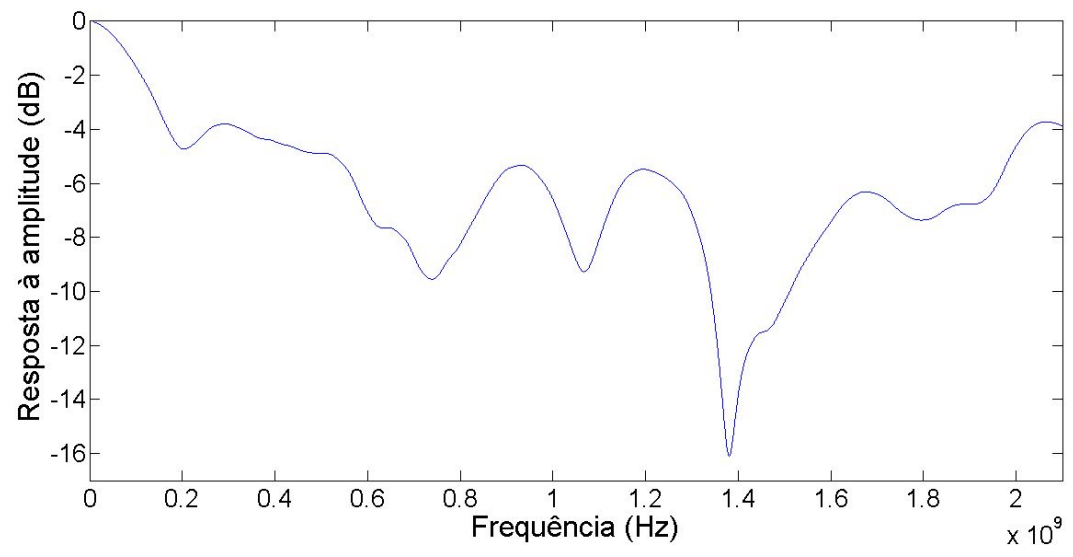

Figura 4.34 Resposta em amplitude da fibra multimodo. $R_{\text {offset }}=12.5 \mu \mathrm{m}$ e $\theta_{\text {offset }}=0$ radiano.

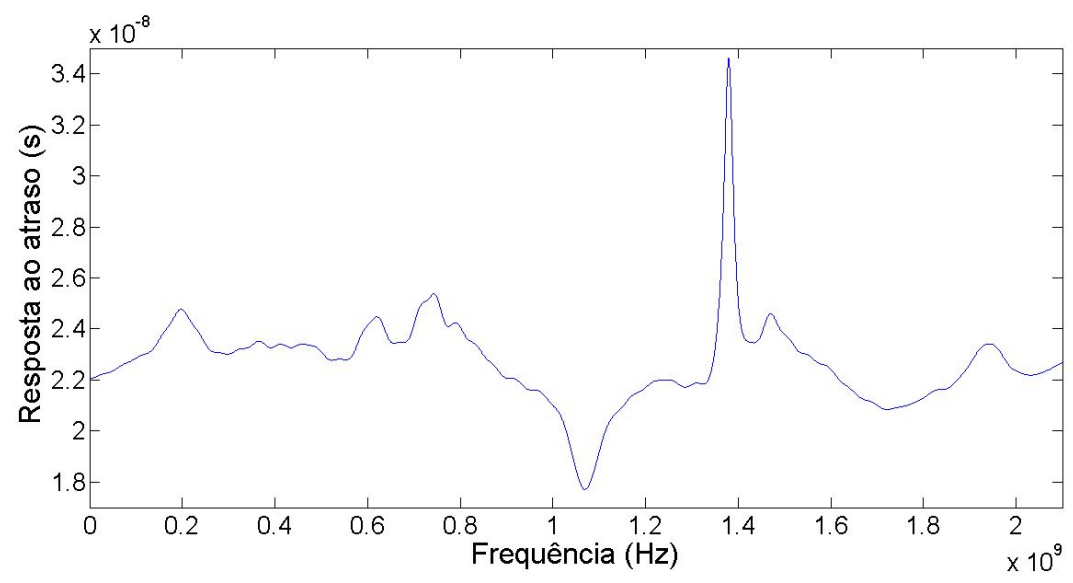

Figura 4.35 Atraso de grupo da fibra multimodo. $R_{o f f s e t}=12.5 \mu \mathrm{m}$ e $\theta_{o f f s e t}=0$ radiano. 


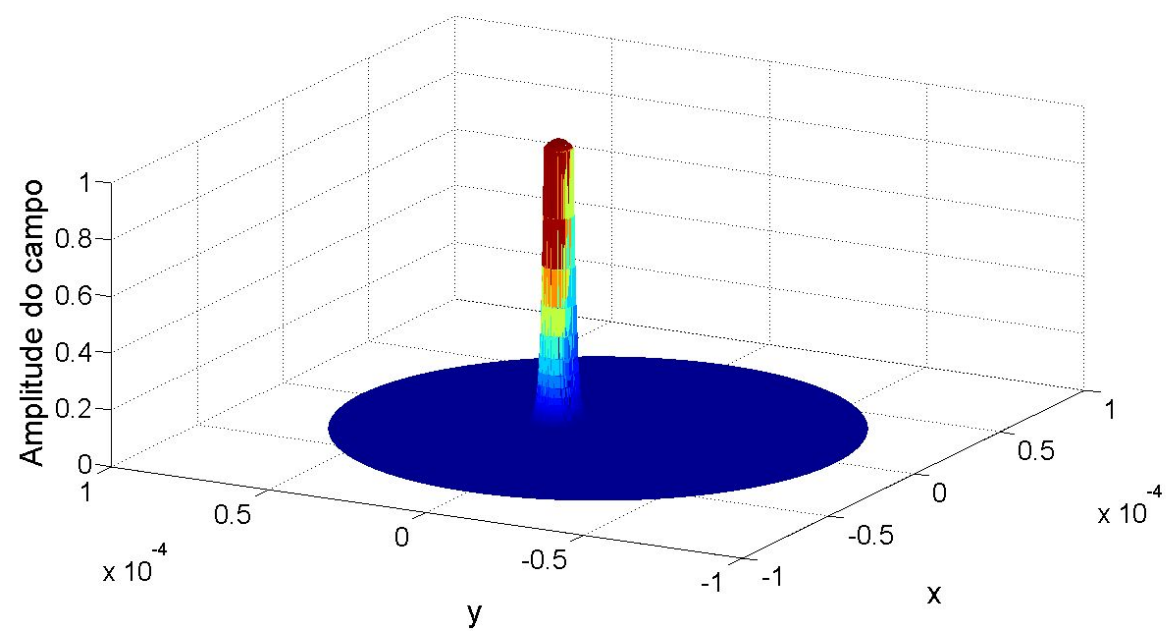

Figura 4.36 Campo da fibra monomodo. $R_{o f f s e t}=12.5 \mu \mathrm{m}$ e $\theta_{o f f s e t}=\pi / 2$ radianos.

Fixando a fibra monomodo em $12.5 \mu \mathrm{m}$, a posicionamos agora em $\pi / 2$ radianos de deslocamento, como pode ser visto em 4.36. Novamente pode-se perceber que os modos ímpares não foram excitados na Figura 4.38. A resposta impulsional da fibra segue na Figura 4.37, bem como a resposta em amplitude na Figura 4.39. Nessa situação, tem-se uma variação na resposta em amplitude que resulta numa degradação do sinal, implicando um comportamento muito diferente entre sub-portadoras próximas. A variação do atraso de grupo pode ser vista na Figura 4.40.

6. Deslocamento de $: R_{\text {offset }}=20 \mu \mathrm{m}$ e $\theta_{\text {offset }}=0$ radiano

Para essa condição de lançamento, o núcleo da fibra monomodo ainda está completamente inserido no núcleo da fibra multimodo. Nota-se o posicionamento da fibra monomodo na Figura 4.41. Nesse caso, os modos que concentram a maior parte da potência lançada na fibra são os modos que possuem o seu campo mais afastado do eixo de propagação, como pode-se observar na Figura 4.43. Isso leva à resposta em amplitude da fibra representada na Figura 4.44, com atenuações de até $25 \mathrm{~dB}$, gerando uma degradação considerável no sinal transmitido. Por esse motivo, o equalizador não consegue compensar essa atenuação, aumentando assim a BER. Observa-se o atraso de grupo na Figura 4.45.

7. Deslocamento de $: R_{\text {offset }}=30 \mu \mathrm{m}$ e $\theta_{\text {offset }}=0$ radiano

Nesse caso, a fibra monomodo foi posicionada fora do núcleo da fibra multimodo, como pode ser visto na Figura 4.46. Pelo fato de os campos da fibra multimodo estarem contidos em seu núcleo na sua grande maioria, apenas os modos de mais alta ordem, que possuem parcelas de seus campos na casca foram mais excitados. Pode-se observar tal comportamento na Figura 4.48. O grande espaçamento entre os impulsos, representado na Figura 4.47, acarreta uma oscilação na resposta em amplitude da fibra, como pode ser 


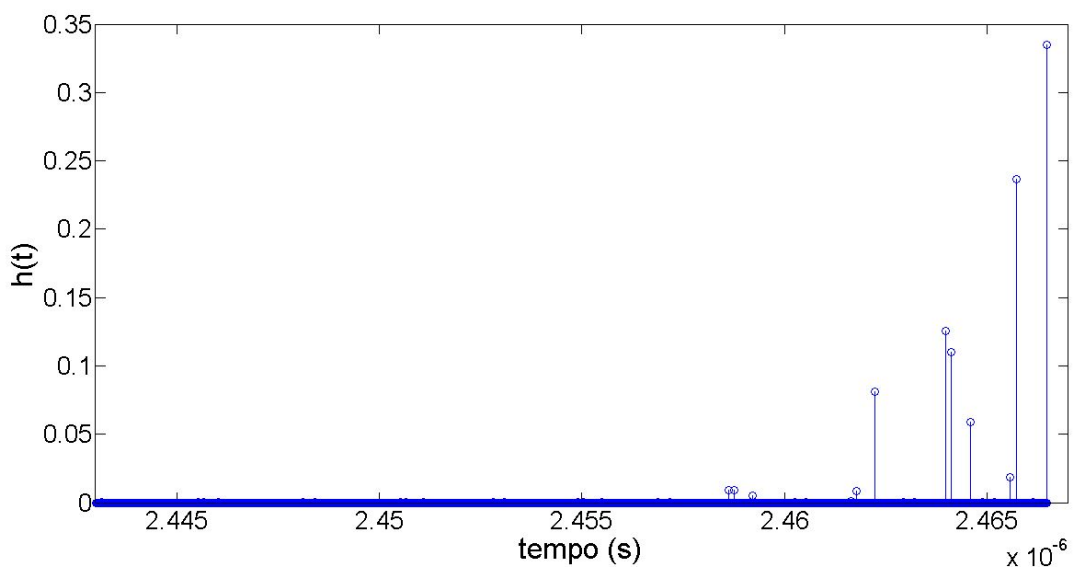

Figura 4.37 Resposta impulsional da fibra multimodo. $R_{\text {offset }}=12.5 \mu \mathrm{m}$ e $\theta_{\text {offset }}=\pi / 2$ radianos.

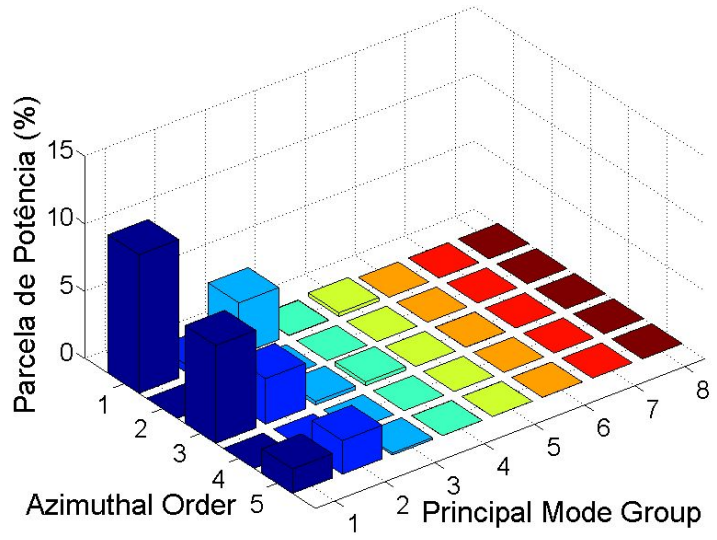

Figura 4.38 Distribuição da parcela de potência por modo. $R_{o f f s e t}=12.5 \mu \mathrm{m}$ e $\theta_{o f f s e t}=\pi / 2$ radianos.

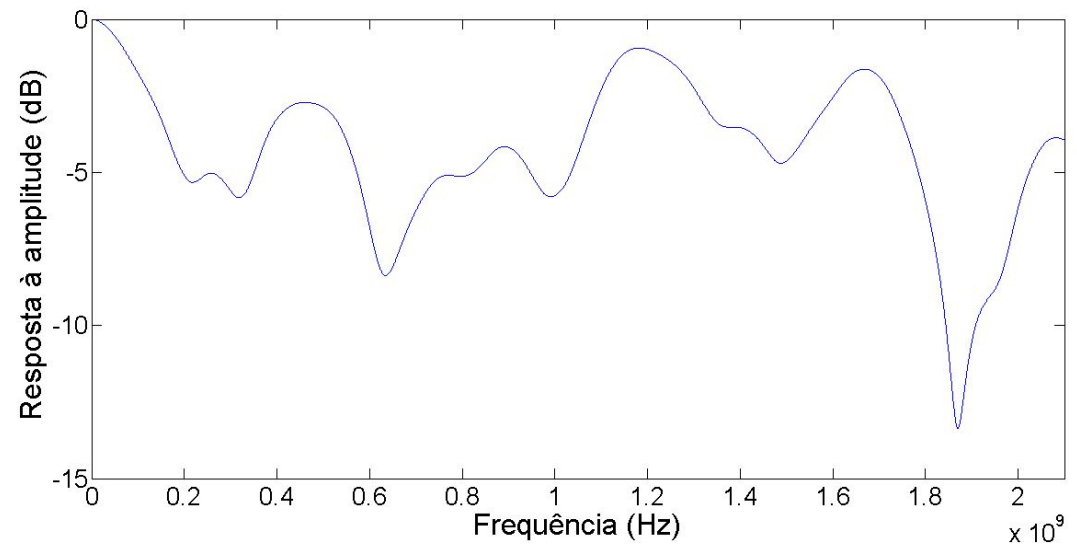

Figura 4.39 Resposta em amplitude da fibra multimodo. $R_{\text {offset }}=12.5 \mu \mathrm{m}$ e $\theta_{\text {offset }}=\pi / 2$ radianos. 


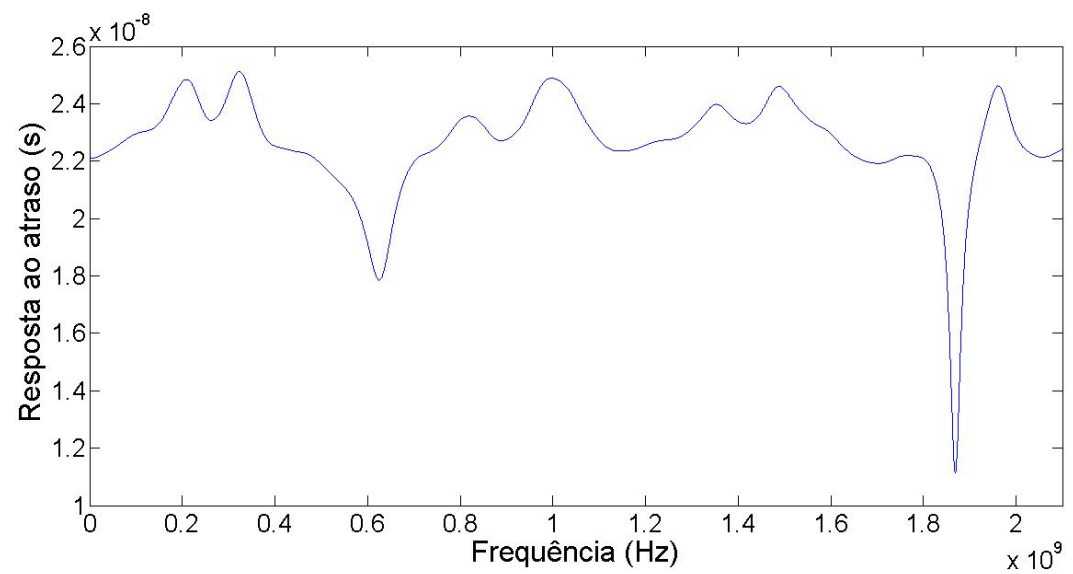

Figura 4.40 Atraso de grupo da fibra multimodo. $R_{o f f s e t}=12.5 \mu \mathrm{m}$ e $\theta_{o f f s e t}=\pi / 2$ radianos.

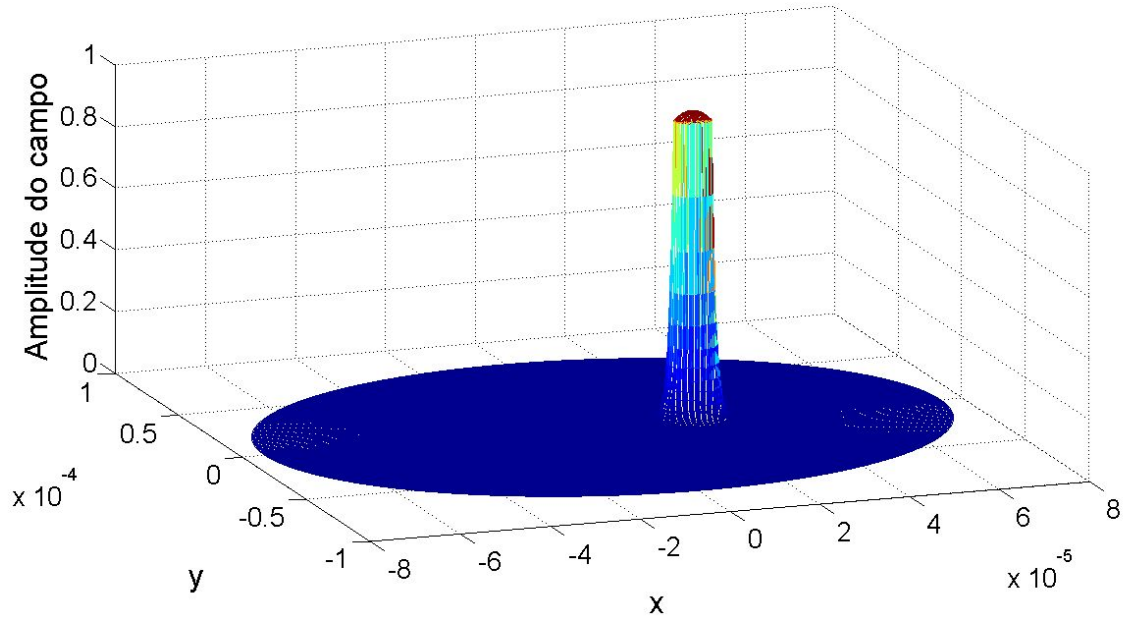

Figura 4.41 Campo da fibra monomodo. $R_{\text {offset }}=20 \mu \mathrm{m}$ e $\theta_{\text {offset }}=0$ radiano. 


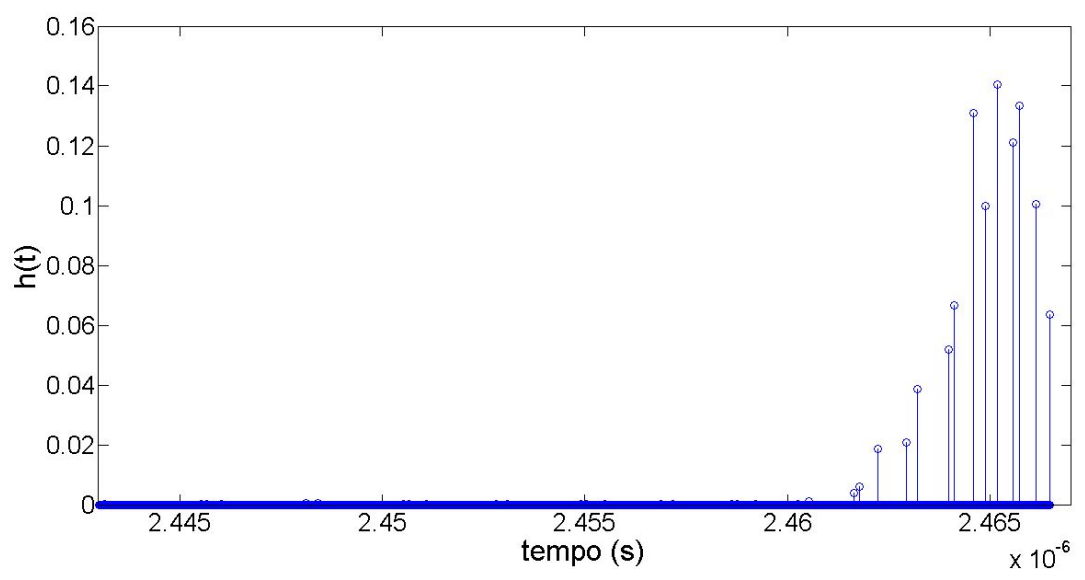

Figura 4.42 Resposta impulsional da fibra multimodo. $R_{\text {offset }}=20 \mu \mathrm{m}$ e $\theta_{o f f s e t}=0$ radiano.

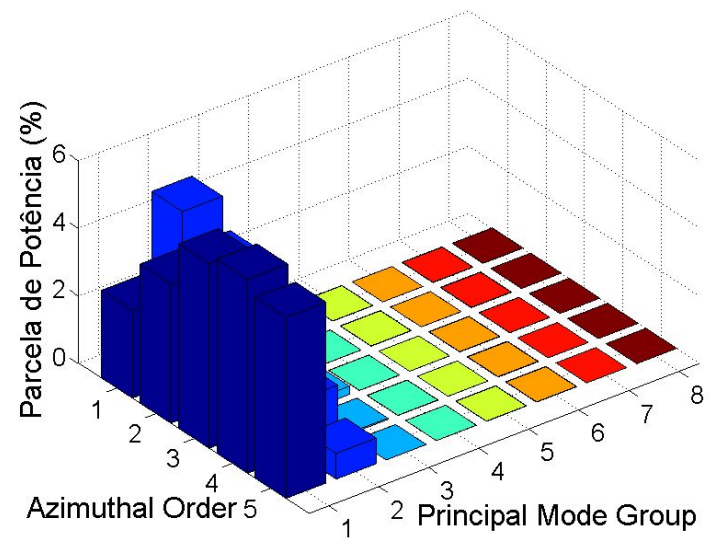

Figura 4.43 Distribuição da parcela de potência por modo. $R_{o f f s e t}=20 \mu \mathrm{m}$ e $\theta_{\text {offset }}=0$ radiano.

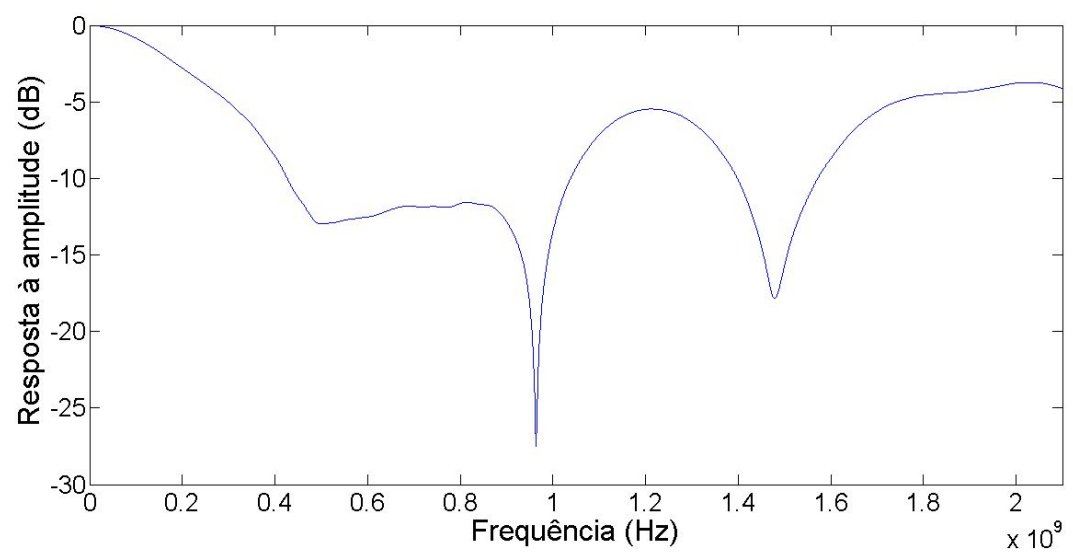

Figura 4.44 Resposta em amplitude da fibra multimodo. $R_{\text {offset }}=20 \mu \mathrm{m}$ e $\theta_{\text {offset }}=0$ radiano. 


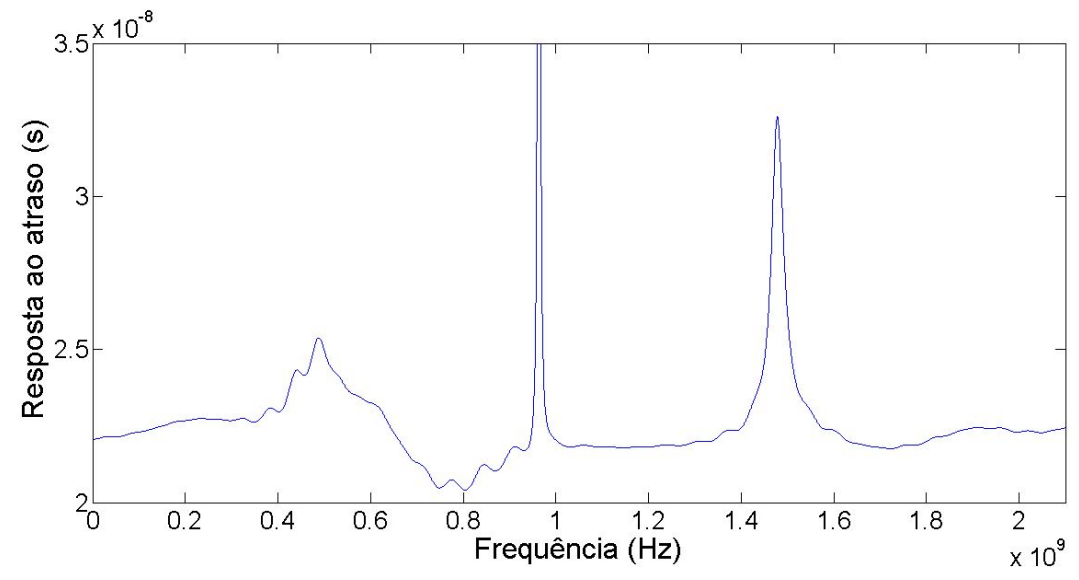

Figura 4.45 Atraso de grupo da fibra multimodo. $R_{\text {offset }}=20 \mu \mathrm{m}$ e $\theta_{\text {offset }}=0$ radiano.

visto na Figura 4.49. A variação do atraso de grupo também é maior quando comparado às condições de lançamento anteriores. Nota-se tal comportamento na Figura 4.50, e na Tabela 4.2 no fim do capítulo.

Visando a uma sumarização de resultados, avaliamos a variação da resposta em amplitude

$$
\Delta H=\frac{\max \left(d\left|H_{M M F}(f)\right|\right)}{d f}\left[H z^{-1}\right]
$$

e ao atraso da fibra,

$$
\Delta \theta=\max \left(\frac{1}{2 \pi} \frac{d \arg \left(H_{M M F}(f)\right)}{d f}\right)[s] .
$$

em que $\max (x)$ representa o máximo valor de x. Os valores estão representados na Tabela 4.2.

\begin{tabular}{|c|c|c|}
\hline Condição de lançamento & $\Delta H\left[\mathrm{GHz}^{-1}\right]$ & $\Delta \theta[\mu \mathrm{s}]$ \\
\hline$R_{\text {offset }}=0 \mu \mathrm{m}$ e $\theta_{\text {offset }}=0$ radiano & 9.02 & 0.91 \\
\hline$R_{\text {offset }}=5 \mu \mathrm{m} \mathrm{e} \theta_{\text {offset }}=0$ radiano & 6.79 & 0.58 \\
\hline$R_{\text {offset }}=5 \mu \mathrm{m} \mathrm{e} \theta_{\text {offset }}=\pi / 4$ radianos & 6.44 & 0.62 \\
\hline$R_{\text {offset }}=5 \mu \mathrm{m} \mathrm{e} \theta_{\text {offset }}=\pi / 2$ radianos & 8.12 & 1.11 \\
$R_{\text {offset }}=12.5 \mu \mathrm{m} \mathrm{e} \theta_{\text {offset }}=0$ radiano & 5.131 & 0.65 \\
\hline$R_{\text {offset }}=12.5 \mu \mathrm{m} \mathrm{e} \theta_{\text {offset }}=\pi / 2$ radianos & 6.11 & 1.08 \\
\hline$R_{\text {offset }}=20 \mu \mathrm{m} \mathrm{e} \theta_{\text {offset }}=0$ radiano & 3.38 & 0.62 \\
\hline$R_{\text {offset }}=30 \mu \mathrm{m} \mathrm{e} \theta_{\text {offset }}=0$ radiano & 23 & 1.17 \\
\hline
\end{tabular}

Tabela 4.2 Variações para a resposta em amplitude e ao atraso para diversas condições de lançamento. 


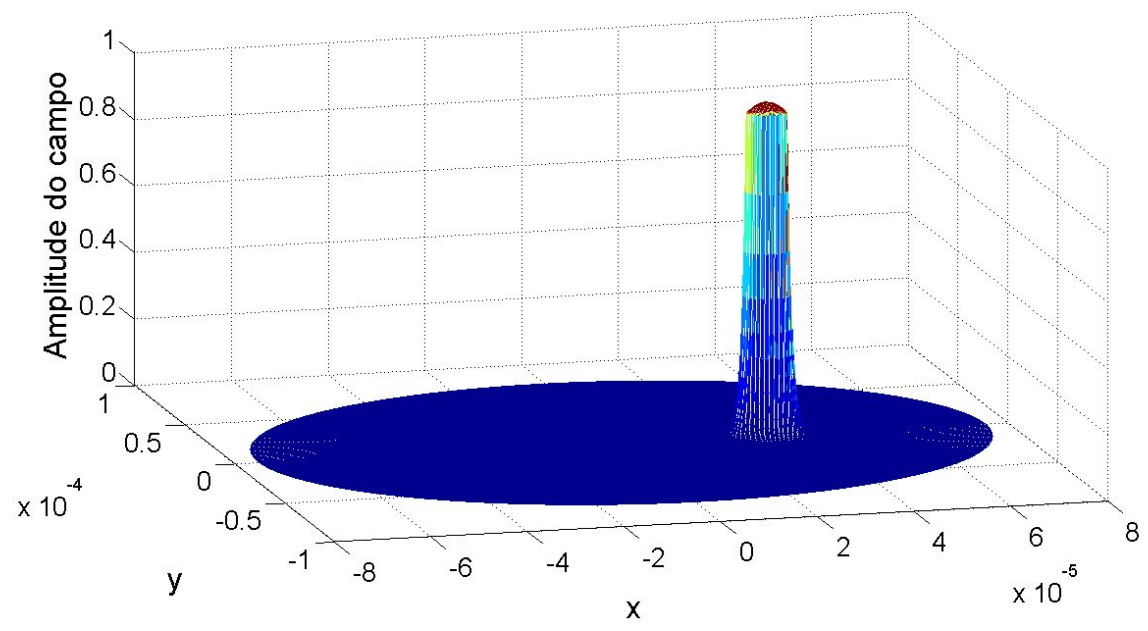

Figura 4.46 Campo da fibra monomodo. $R_{\text {offset }}=30 \mu \mathrm{m}$ e $\theta_{\text {offset }}=0$ radiano.

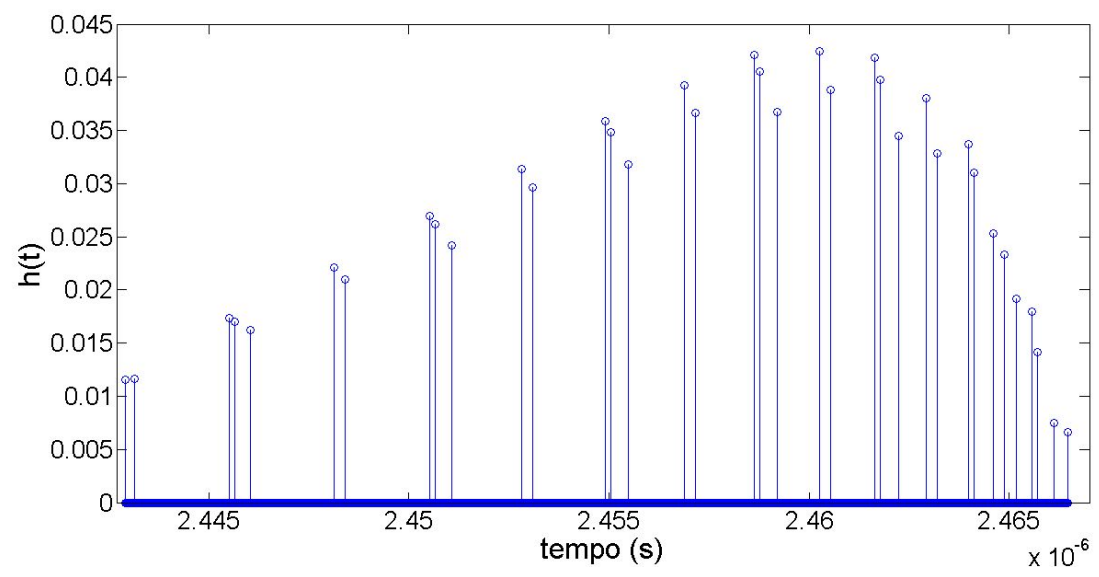

Figura 4.47 Resposta impulsional da fibra multimodo. $R_{\text {offset }}=30 \mu \mathrm{m}$ e $\theta_{\text {offset }}=0$ radiano. 


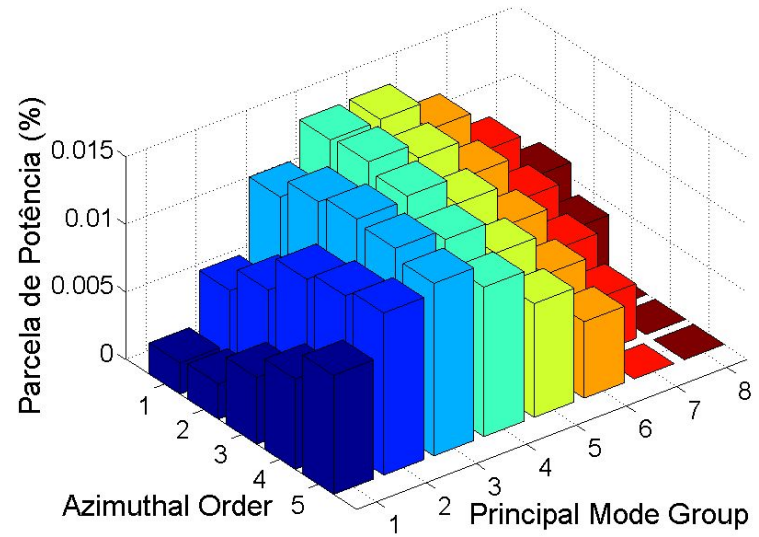

Figura 4.48 Distribuição da parcela de potência por modo. $R_{\text {offset }}=30 \mu \mathrm{m}$ e $\theta_{\text {offset }}=0$ radiano.

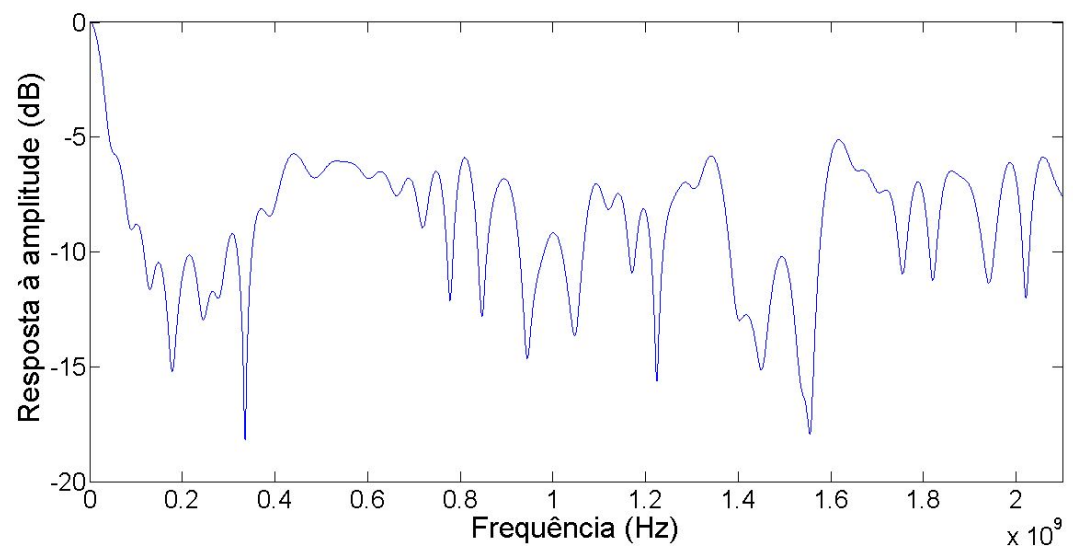

Figura 4.49 Resposta em amplitude da fibra multimodo. $R_{\text {offset }}=30 \mu \mathrm{m}$ e $\theta_{\text {offset }}=0$ radiano.

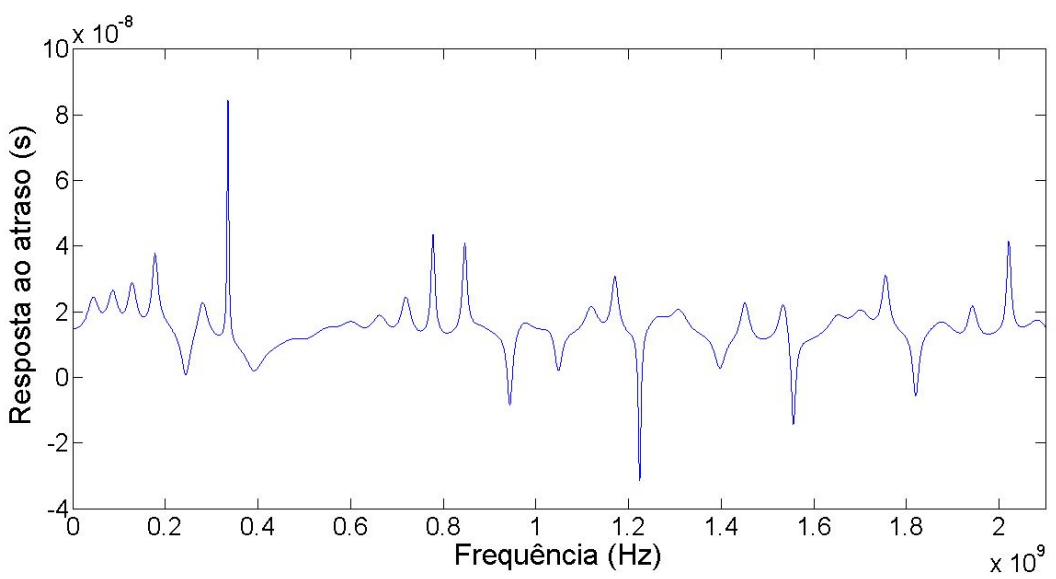

Figura 4.50 Atraso de grupo da fibra multimodo. $R_{\text {offset }}=30 \mu \mathrm{m}$ e $\theta_{\text {offset }}=0$ radiano. 


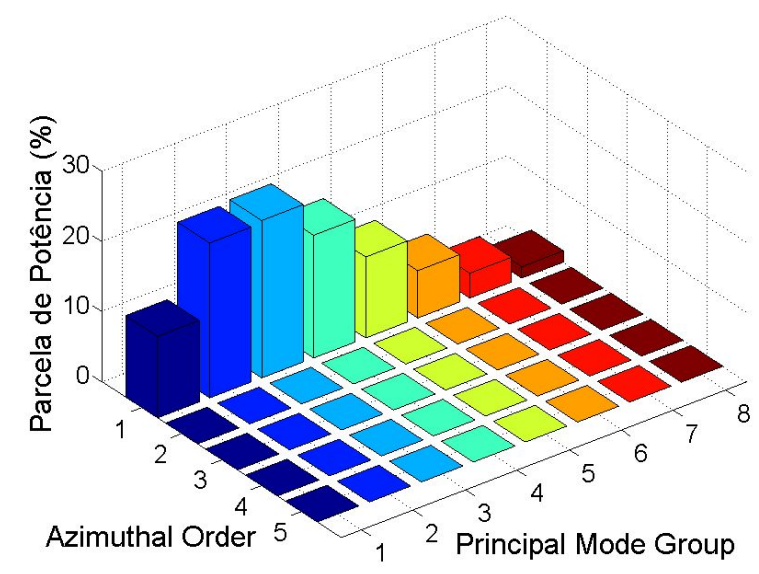

Figura 4.51 Distribuição de potência por modos para uma fibra monomodo de $2 \mu \mathrm{m}$ de raio do núcleo, para um lançamento centrado.

\subsection{Resultados para diferentes raios da SMF}

Uma análise do comportamento da distribuição de potência por modos também foi feita para diferentes raios do núcleo da fibra monomodo. Primeiramente, define-se o maior raio possível, para os parâmetros da fibra como fonte de luz, que garanta que a mesma seja monomodo, isto é, a frequência normalizada $(v<2.405)$. De acordo com a equação 2.30 , tem-se um raio máximo igual a $4,125 \mu \mathrm{m}$.

Analisamos o comportamento da distribuição modal para 3 raios do núcleo da fibra monomodo ( $2 \mu \mathrm{m}, 3 \mu \mathrm{m}$ e $4 \mu \mathrm{m}$ ), como pode ser observados nas Figuras 4.51, 4.52 e 4.53 .

Percebe-se nessas figuras, que quanto menor o raio do núcleo da fibra monomodo, a potência se distribui por uma quantidade maior de modos. Tal comportamento se deve ao perfil dos campos de propagação da fibra multimodo para os modos de primeira ordem. Tais modos, com o índice de "principal mode group"maior, possuem a sua energia cada vez mais concentrada próximo ao ponto central da fibra multimodo, e com um espalhamento espacial menor, quando comparado com o modo fundamental. Pode-se observar os modos nas Figuras 4.1 e 4.2. 


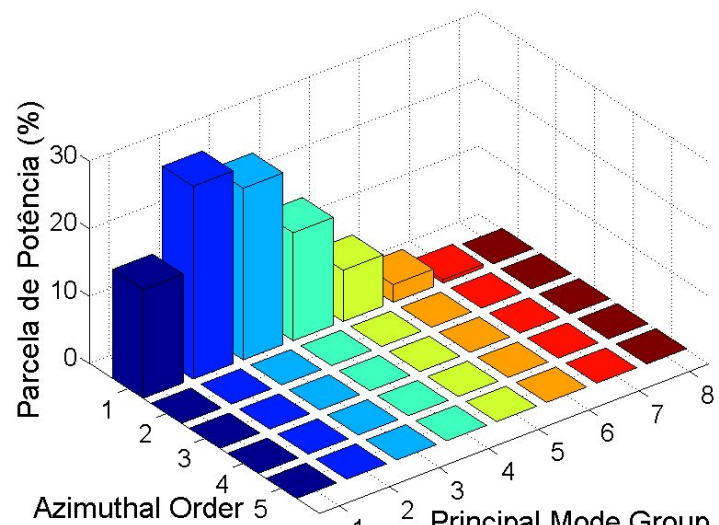

Figura 4.52 Distribuição de potência por modos para uma fibra monomodo de $3 \mu \mathrm{m}$ de raio do núcleo, para um lançamento centrado.

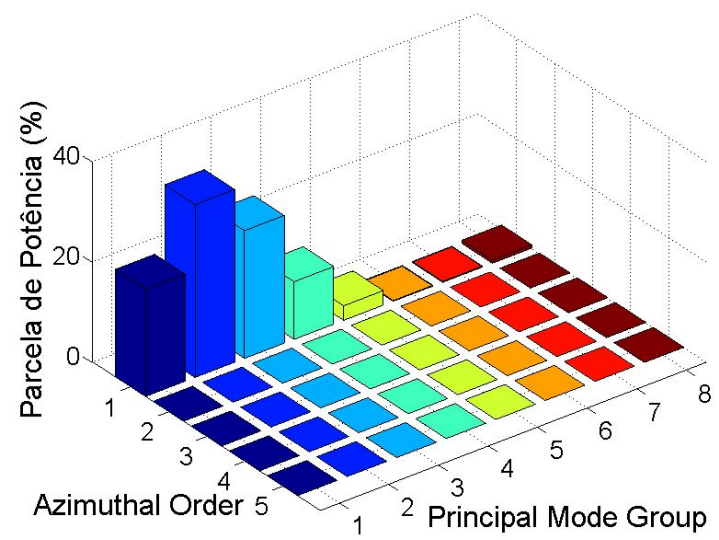

Figura 4.53 Distribuição de potência por modos para uma fibra monomodo de $4 \mu \mathrm{m}$ de raio do núcleo, para um lançamento centrado. 


\section{CAPÍtUlo 5 \\ Resultados de Simulação para o Sistema OFDM}

Quando OFDM é utilizado em conjunto com o prefixo cíclico, a distorção causada por um canal dispersivo linear pode ser minimizada com um equalizador "one-tap". Este capítulo introduz o funcionamento deste equalizador, descrevendo como faz-se a estimativa do canal e, a partir disso, o procedimento para se minimizar a distorção causada por este sobre o sinal OFDM.

A seção seguinte trata dos métodos de análise de desempenho utilizados neste trabalho, bem como uma comparação entre eles. A última seção apresenta alguns resultados das simulações envolvendo os tópicos introduzidos nas demais seções deste capítulo, bem como uma análise crítica desses resultados.

\subsection{Estimador de canal e equalizador}

O estimador de canal utilizado neste trabalho utiliza apenas uma sequência de sub-portadoras piloto na estimativa, sendo que o resultado na saída do equalizador é uma estimativa do sinal transmitido, compensado pelo inverso da estimativa do canal. Assim sendo, o sinal transmitido em cada sub-portadora pode ser recuperado fazendo-se apenas uma multiplicação:

$$
X_{k}^{\prime}=\frac{Y_{k}}{H_{e, k}}=X_{k}+\frac{W_{k}}{H_{e, k}}
$$

em que $X_{k}$ é o sinal transmitido, $X_{k}^{\prime}$ a sua estimativa, $Y_{k}$ o sinal recebido antes de equalizar, $H_{e, k}$ o valor estimado da função de transferência do canal e $W_{k}$ o valor do ruído, todos para a $k$-ésima sub-portadora. Uma desvantagem de estimar o sinal transmitido desta forma é que se $H_{e, k}$ for muito pequeno, o ruído é amplificado.

No simulador, utilizou-se um equalizador "one-tap" e sub-portadoras piloto com espaçamento em frequência igual a $\Delta p$. Desse modo, uma a cada $\Delta p$ sub-portadoras do sinal é uma piloto. Os valores a serem transportados pelas sub-portadoras piloto são os pontos ideais de cada um dos quatro quadrantes $(1+j, 1-j,-1+j \mathrm{e}-1-j)$. Distribuíram-se estes valores igualmente entre as pilotos. Pode-se obter então o valor do canal de acordo com:

$$
\begin{gathered}
H_{m}[p]=\left|\frac{S_{\rho}[p]}{\rho[p]}\right|, \\
H_{a}[p]=\arg \left(\frac{S_{\rho}[p]}{\rho[p]}\right),
\end{gathered}
$$


em que $H_{m}[p]$ é o módulo da função de transferência do canal para a $p$-ésima sub-portadora piloto, $H_{a}[p]$ a sua fase, $\arg (x)$ a função que define o valor da fase de $x, S_{\rho}[p]$ o valor do sinal recebido referente à $p$-ésima sub-portadora piloto e $\rho[p]$ é o valor transmitido na $p$-ésima piloto. Suponha que define-se $\rho[p]$ como uma sub-portadora piloto que transporta um dado valor. Após a transmissão ao longo do sistema, obtém-se o valor de $S_{\rho}[p]$ para essa sub-portadora, possibilitando então estimar o comportamento do sistema para a faixa de frequência em torno da sub-portadora piloto. O número de pilotos utilizados no sistema é um parâmetro importante que afeta a função de transferência do equalizador e consequentemente o desempenho do sistema. Avalia-se a influência desta variável no desempenho do sistema na Seção 5.3.

Para estimar a função de transferência do equalizador, dividiram-se $H_{m}[p]$ e $H_{a}[p]$ em $L$ sub-bandas. Com o valor do canal na frequência das pilotos, fez-se uma interpolação polinomial sobre $H_{m, l}[p]$ e $H_{a, l}[p]$ para estimar $H_{m, l}(f)$ e $H_{a, l}(f)$ respectivamente, o valor do canal nas demais sub-portadoras para a $l$-ésima sub-banda, sendo $l$ um valor entre um e $L$. Realizouse esta divisão em sub-bandas para o polinômio estimar melhor a função de transferência do sistema em cada faixa de frequência, visto que a função de transferência varia mais suavemente em cada sub-banda do que em toda a banda do sinal. Dessa forma, o grau do polinômio interpolador pôde ser menor do que seria se essa divisão não fosse efetuada, reduzindo a complexidade do equalizador. O número de sub-bandas é outro parâmetro importante que afeta o equalizador e o desempenho do sistema.

É importante notar que deve existir em cada sub-banda um número de sub-portadoras piloto que seja pelo menos o grau do polinômio interpolador mais um. Deve-se atender a esta condição para assegurar que os coeficientes do polinômio sejam únicos em cada sub-banda.

Concatenou-se então $H_{m, l}(f)$ para cada $l$ para gerar $H_{m}(f)$, o valor do canal para toda a banda do sinal. Fez-se isso também para $H_{a, l}(f)$ para gerar $H_{a}(f)$. No sistema descrito neste trabalho, estimou-se o valor do canal da sub-portadora 1 à 511, que são as que carregam informação. Em seguida, calculou-se o valor da função de transferência do equalizador de acordo com:

$$
H_{e}(f)=H_{m}(f) e^{j H_{a}(f)},
$$

em que $H_{e}(f)$ representa a função de transferência do equalizador, que é uma estimativa da função de transferência do canal.

Para verificar se obteve-se uma boa estimativa do canal, é possível calcular o erro quadrático médio (EQM):

$$
E Q M=\frac{\sum_{i=1}^{N_{i}}\left(\left|H_{e}(f)\right|-|H(f)|\right)^{2}}{N_{i}}
$$

em que $N_{i}$ representa a quantidade de sub-portadoras, que corresponde à quantidade de pontos obtidos pela discretização no sinal, e $H(f)$ representa a função de transferência real do canal.

Obteve-se então o valor do inverso da função de transferência do equalizador com o intuito de compensar o efeito do canal sobre o sinal, seja para ganho ou atenuação. Obteve-se o sinal na saída do equalizador multiplicando-se o sinal de entrada pelo inverso de $H_{e}(f)$, conforme mostrado na equação 5.1 .

Avaliou-se o atraso de grupo do sistema, expresso como: 


$$
\tau_{g}(f)=-\frac{1}{2 \pi} \frac{d H_{a}(f)}{d f}[s]
$$

pois este ajuda a observar o comportamento de cada sub-portadora ao longo do sistema, permitindo então uma análise da influência da fase do canal sobre o sinal.

\subsection{Métodos de avaliação de desempenho}

No sistema, a figura de mérito utilizada na análise de desempenho foi a BER (Bit Error Rate). Estimou-se esta utilizando o método da simulação de Monte Carlo (MC) com contagem direta de erros e o método EVM (Error Vector Magnitude) e então realizou-se uma comparação entre os dois métodos.

Na simulação de Monte Carlo, gerou-se o sinal OFDM por simulação e transmitiu-se este pelo sistema OFDM, que então foi corrompido pelos diversos componentes do sistema, tais como moduladores externos, fibra multimodo, filtros e ruído. No receptor fez-se uma contagem direta de erros para estimar a taxa de erro de bit (BER). A simulação de MC é um método que gera estimativas bastante precisas para a BER, assumindo que exista um número suficiente de amostras. Mas, para valores muito baixos de BER, é necessário executar o simulador OFDM várias vezes e com diferentes amostras de ruído para se obter o número mínimo de erros necessários para uma boa estimativa da BER. Neste caso, o tempo de simulação requerido é inaceitavelmente alto. Isso torna mais eficaz utilizar outros métodos de avaliação de desempenho que proporcionam estimativas menos precisas mas são mais rápidos computacionalmente, tal como o EVM.

Para a simulação de Monte Carlo, executou-se o simulador várias vezes, sendo que no transmissor tem-se um contador $N_{b, g}[k]$ que armazena o valor referente à quantidade de bits transmitidos em cada sub-portadora $k$. No receptor, também existe um contador $N_{b, e}[k]$ que armazena o valor da quantidade de bits errados detectados em cada sub-portadora $k$. Após a detecção de um certo número de bits errados em uma sub-portadora, o simulador para. Calculou-se este número esperado de bits errados na Seção 5.3. Dessa forma, estimou-se a BER como:

$$
B E R[k]=\frac{N_{b, e}[k]}{N_{b, g}[k]} .
$$

Em seguida, obteve-se a BER de MC através da equação:

$$
B E R=\frac{1}{N_{i}} \sum_{k=1}^{N_{i}} B E R[k],
$$

em que $N_{i}$ corresponde à quantidade de sub-portadoras do sinal OFDM.

Para o método EVM, também estimou-se a BER como a média da BER de cada subportadora $(B E R[k])$, dada pela equação 5.8. Define-se a $B E R[k]$ para o EVM por:

$$
B E R[k]=0.5 \operatorname{erfc}\left[\left(E V M_{R M S}[k] \sqrt{\log _{2} M}\right)^{-1}\right],
$$


em que erfc $(x)$ é a função erro complementar e calcula-se o valor quadrático médio do EVM $\left(E V M_{R M S}[k]\right)$ por:

$$
E V M_{R M S}[k]=\sqrt{\frac{\sum_{l=1}^{N_{s}}\left|s_{o}^{(l)}[k]-s_{i}^{(l)}[k]\right|^{2}}{\sum_{l=1}^{N_{s}}\left|s_{i}^{(l)}[k]\right|^{2}}},
$$

em que $N_{s}$ é quantidade de símbolos OFDM simulados, $s_{o}^{(l)}[k]$ e $s_{i}^{(l)}[k]$ correspondem aos sinais da $k$-ésima sub-portadora do $l$-ésimo símbolo da constelação obtida na saída do equalizador e da média de todos os sinais recebidos originários do mesmo quadrante que $s_{o}^{(l)}[k]$, respectivamente.

Embora para gerar a constelação que é usada no EVM o procedimento seja o mesmo da simulação de MC, normalmente obtém-se as estimativas de BER utilizando as equações 5.8, 5.9 e 5.10 em um tempo consideravelmente menor que no caso da contagem direta de erros. Entretanto, o EVM supõe uma distribuição Gaussiana para a distorção sofrida por cada sub-portadora, portanto, para não gerar uma estimativa precária da BER, esta condição deve ser atendida. Como a interferência inter-simbólica (ISI) e a interferência entre sub-portadoras (inter-carrier interference - ICI) não são bem estimadas com uma distribuição Gaussiana por serem limitadas, estas não devem ser fatores significativos de distorção no sistema, caso contrário a estimativa da BER não será precisa. Tais análises foram realizadas para um comprimento da fibra de $500 \mathrm{~m}$.

\subsection{Resultados e discussões}

Para avaliar os resultados das condições de lançamento de uma forma genérica, e assim avaliar o desempenho de cada uma, deve-se analisar a BER. Dessa forma, na Figura 5.1, tem-se uma variação do raio de $R_{\text {offset }}$, o deslocamento radial da fonte de luz, para uma condição angular fixa em 0 radiano. A BER foi calculada pelo método EVM. Pode-se observar nessa figura que quanto mais se afasta o feixe de lançamento do núcleo da fibra multimodo, a BER aumenta. Isso deve-se a uma quantidade de modos excitados maior. Pelo gráfico também pode-se observar que o melhor desempenho que obtivemos no sistema, foi para um $R_{\text {offset }}=2.5 \mu \mathrm{m}$, em que obtivemos uma BER de $10^{-4}$.

Uma vez definido o $R_{\text {offset }}$ em que obtivemos o melhor desempenho, realizamos o mesmo procedimento, mas agora variando $\theta_{\text {offset }}$, o ângulo de lançamento, e mantendo o $R_{\text {offset }}=$ $2.5 \mu \mathrm{m}$. Na Figura 5.2, o melhor desempenho que obtivemos foi para um $\theta_{\text {offset }}=5 \pi / 4$ radianos. A fonte está centrada do eixo X quando $\theta_{\text {offset }}=n \pi$ radianos, para $n$ inteiro. Da mesma forma, a fonte está centrada no eixo Y quando $\theta_{o f f s e t}=\frac{(2 n-1) \pi}{2}$ radianos, para $n$ inteiro. Podese notar na Figura 5.2 que as condições de lançamento em relação ao $\theta_{\text {offset }}$ possuem melhor desempenho fora dos eixos $\mathrm{X}$ e Y. Isso se deve à superposição de todos os campos de propagação da fibra, como pode ser observado no Capítulo 4 e, assim, para condições de lançamento em que o $\theta_{\text {offset }}$ está fora dos eixos X e Y, uma quantidade menor de modos serão excitados e consequentemente contribui para uma função de transferência da fibra melhor comportada.

Diante disso, também realizamos a simulação para um $R_{\text {offset }}=12.5 \mu \mathrm{m}$ fixo. Na Figura 5.3, pudemos perceber o comportamento um pouco diferente. Os piores resultados foram obti- 


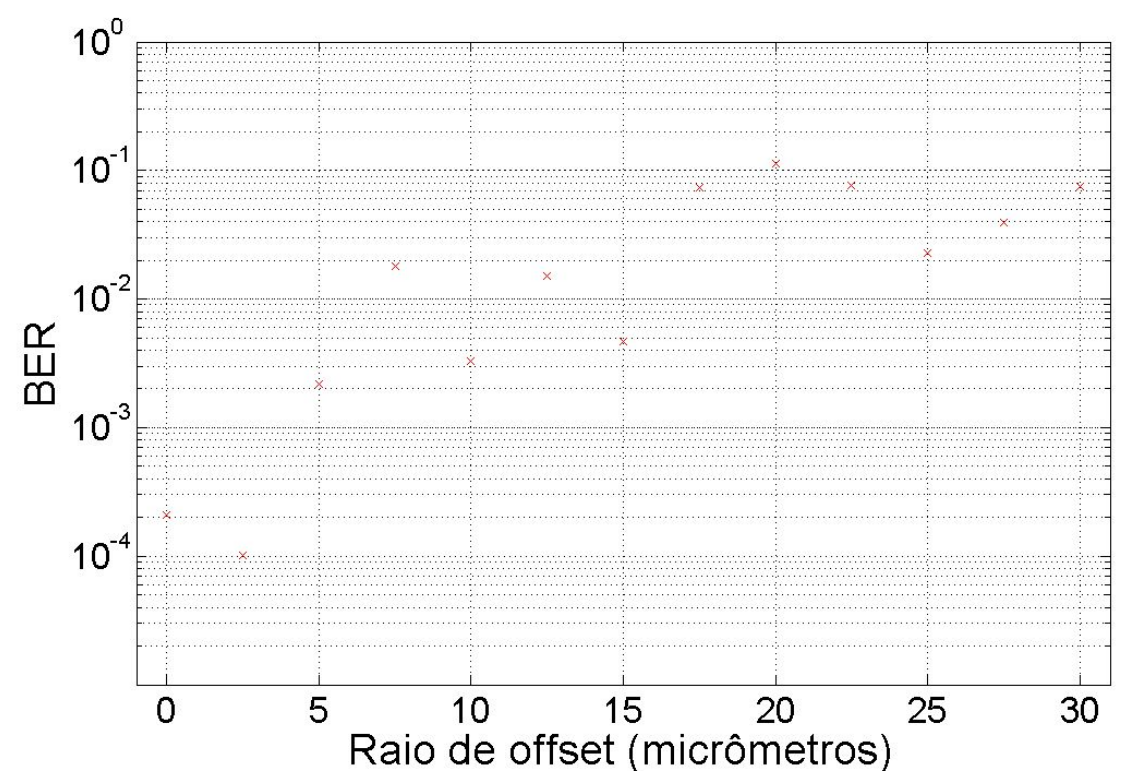

Figura 5.1 BER x $R_{\text {offset }}$ para $\theta_{\text {offset }}=0$ radiano.

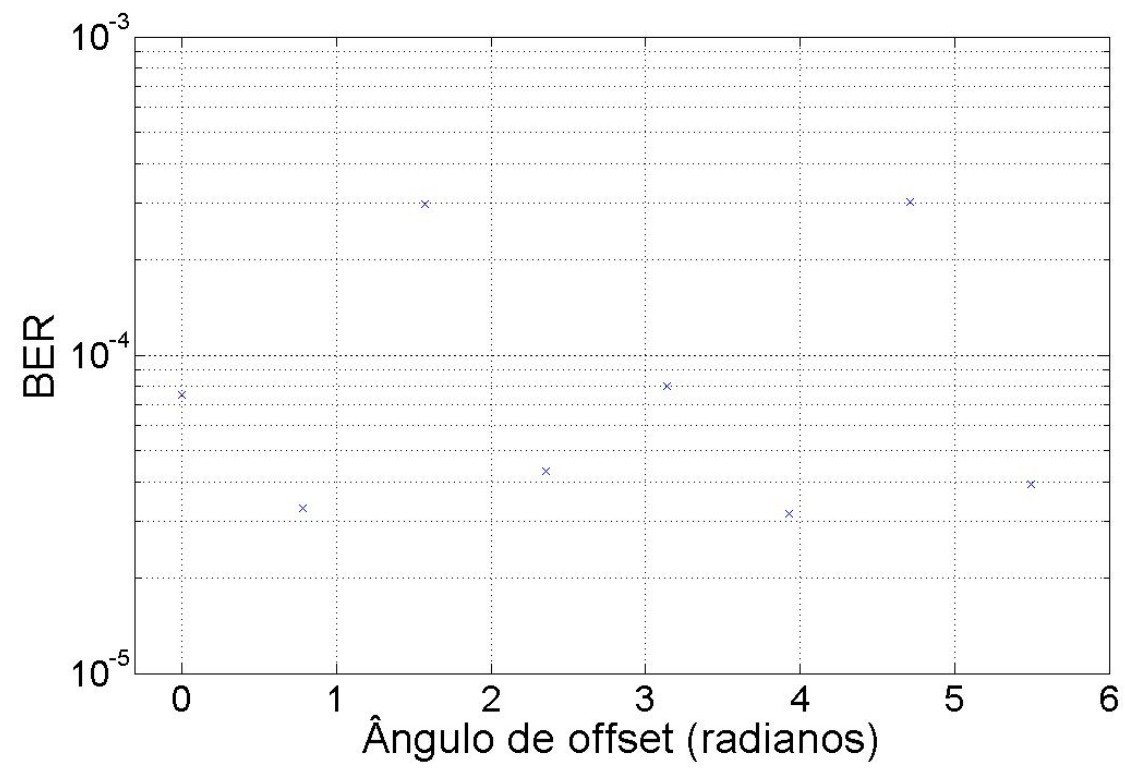

Figura 5.2 BER x $\theta_{\text {offset }}$ para $R_{\text {offset }}=2.5 \mu \mathrm{m}$. 


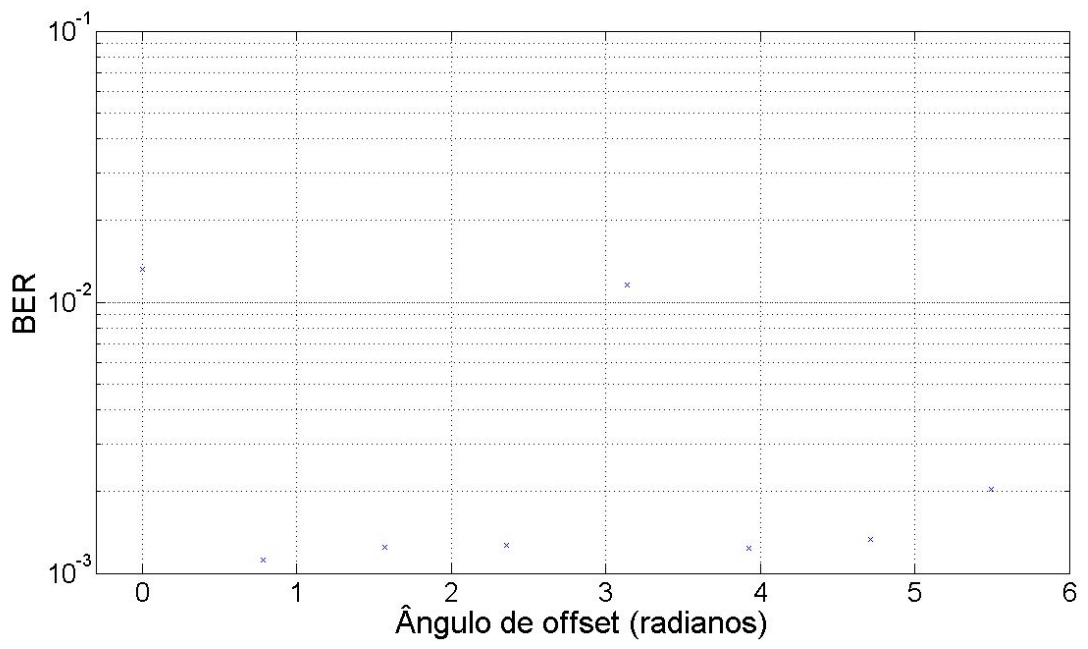

Figura 5.3 BER x $\theta_{\text {offset }}$ para $R_{\text {offset }}=12.5 \mu \mathrm{m}$.

dos para uma condição de lançamento sobre o eixo X. Isso ocorre para esse deslocamento do $R_{\text {offset }}$, pois nesse caso, mais campos de propagação da fibra multimodo possuem componentes no eixo $\mathrm{X}$, consequentemente, um maior número de modos excitados, e uma dispersão modal maior.

Finalizando a análise de desempenho em relação à variação do $\theta_{\text {offset }}$, fixamos o $R_{\text {offset }}=$ $25 \mu \mathrm{m}$. Na Figura 5.4 tem-se que o melhor desempenho em termos de BER foi obtido quando posicionamos o feixe de lançamento sobre o eixo Y, excitando uma quantidade menor de modos e consequentemente levando a uma BER menor.

Através das Figuras 5.1, 5.3 e 5.4, pudemos perceber que o desempenho tem dependência direta com a condição de lançamento, como era esperado, e todos dependentes da caracterização da fibra, ou seja, de como os campos de propagação da fibra se comportam. Dentre as condições simuladas, o melhor desempenho alcançado foi para um condição de lançamento para $R_{\text {offset }}=2.5 \mu \mathrm{m}$ e $\theta_{\text {offset }}=5 \pi / 4$ radianos, em que obtivemos a menor BER, na faixa de $5 \times 10^{-5}$.

Nas simulações do transmissor OFDM, utilizou-se 1024 sub-portadoras, espaçadas entre si de $4 \mathrm{MHz}$, sendo as 512 sub-portadoras negativas o complexo conjugado das 512 subportadoras positivas, totalizando uma banda de $2.048 \mathrm{GHz}$ para o sinal OFDM. Utilizando 66 sub-portadoras piloto, espaçadas entre si de $48 \mathrm{MHz}$, e definindo $G=\frac{1}{2^{4}}$ (prefixo cíclico), obteve-se um símbolo OFDM com duração de 531.25 ns. O formato de modulação das subportadoras de dados é QPSK. Geraram-se 16 símbolos OFDM por simulação e fixou-se o índice de modulação em 2\%. Quando utilizou-se Monte Carlo e EVM o simulador foi executado várias vezes até atingir o número mínimo de bits gerados para uma análise de desempenho precisa.

Após a transmissão do sinal OFDM por 500 m de fibra multimodo, com uma condição de lançamento em que a fibra monomodo está no centro da fibra multimodo, obteve-se o espectro de amplitude do sinal na saída do diodo PIN, conforme visto na Figura 5.5. Nota-se que o sinal 


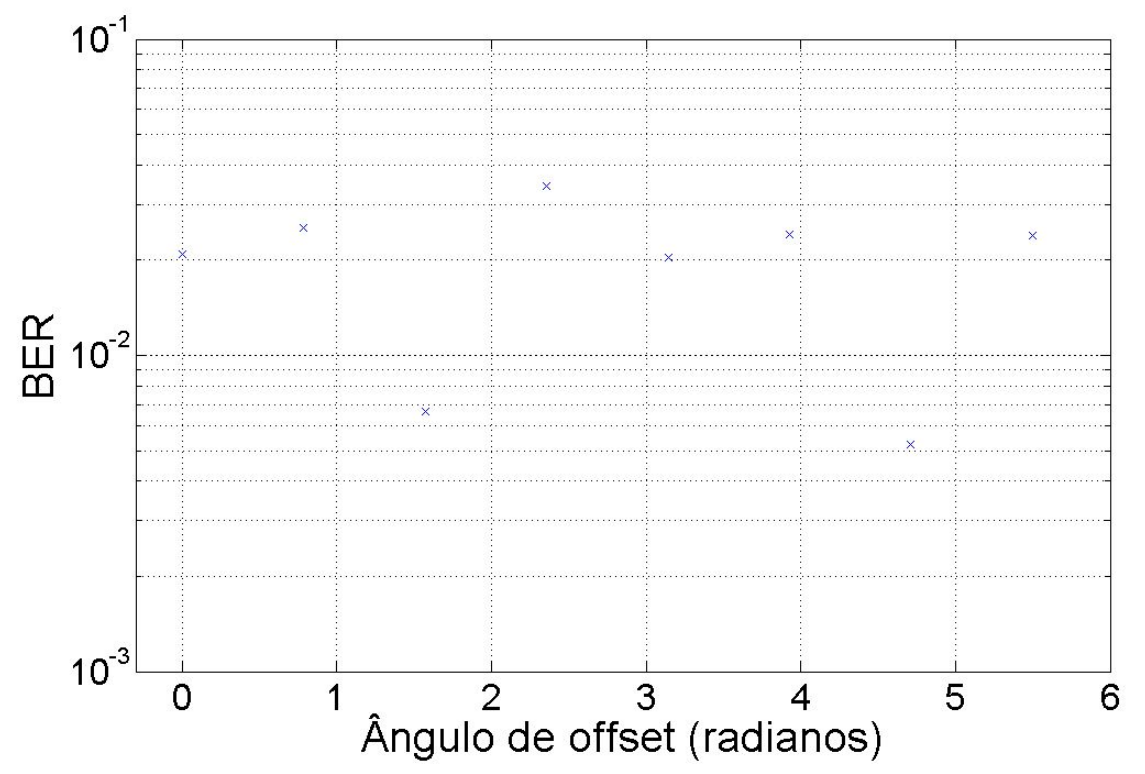

Figura 5.4 BER x $\theta_{\text {offset }}$ para $R_{\text {offset }}=25 \mu \mathrm{m}$.

sofreu uma atenuação considerável em algumas faixas de frequência. Isso era de se esperar, de acordo com a função de transferência da fibra multimodo para esses parâmetros e condição de lançamento, exposta no Capítulo 4. Com uma $\frac{E_{b}}{N_{0}}$ de $5 \mathrm{~dB}$, pode-se avaliar o comportamento do espectro de amplitude perante a adição do ruído térmico imposto pelo circuito, como pode ser visto na Figura 5.6. O ruído se estende além da banda do sinal. Utilizou-se um filtro passabaixa de Butterworth de sexta ordem com frequência de corte igual a $2.048 \mathrm{GHz}$ no receptor para eliminar qualquer ruído além da banda do sinal transmitido, como pode ser visto na Figura 5.7. Com isso, consegue-se amenizar o efeito do ruído fora da banda do sinal OFDM, mas não dentro da banda.

Para utilizar a simulação de Monte Carlo, é necessário decidir quantos erros por subportadora são necessários para que a BER seja calculada de forma precisa. Com uma relação $\frac{E_{b}}{N 0}$ de $2 \mathrm{~dB}$, construiu-se um gráfico de BER versus número de erros na pior sub-portadora, com a BER calculada pelo método de MC, como se pode ver na Figura 5.8. Como era de se esperar, percebe-se que à medida que se aumenta o número de simulações realizadas, mais erros ocorrem, as flutuações da BER diminuem consideravelmente e esta converge para um certo valor. É possível perceber que com mais de 100 erros na pior sub-portadora a BER não varia expressivamente, logo o critério de parada para a simulação de MC que foi utilizado neste trabalho é de 100 erros na pior sub-portadora. Assim, após essa condição ser atendida, calculou-se a BER de acordo com as equações 5.7 e 5.8 .

Como o EVM mede a variância de um conjunto de pontos em torno de um ponto central, para que essa estimativa seja coerente com o real é necessário que haja um número mínimo de amostras para realizar este cálculo com precisão. No caso do sistema OFDM modelado neste trabalho, uma amostra é um símbolo QPSK em uma sub-portadora. Com o intuito de verificar quantas amostras por sub-portadora são necessárias na equação 5.10 para que a estimativa da 


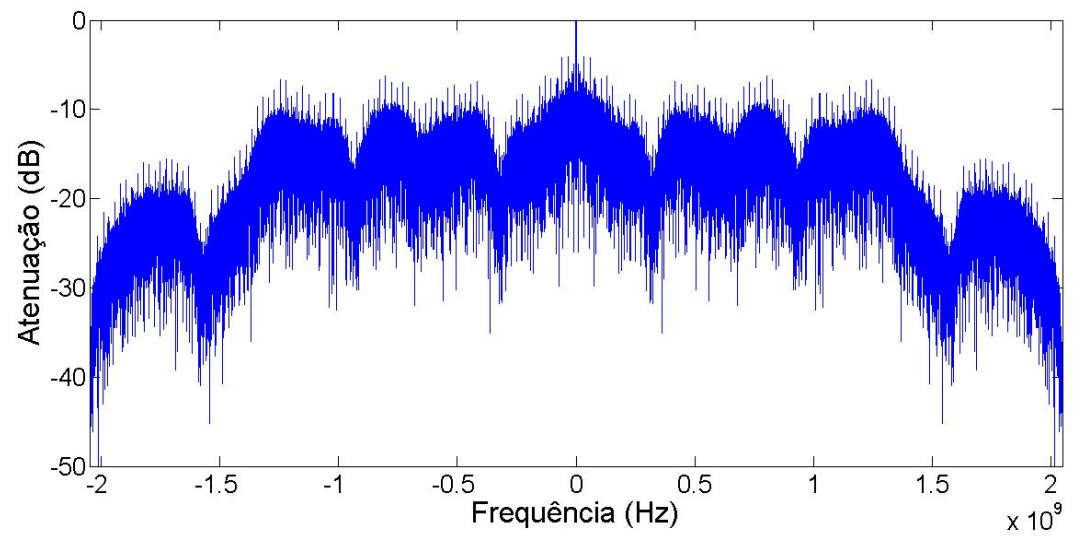

Figura 5.5 Espectro de amplitude do sinal OFDM após diodo PIN.

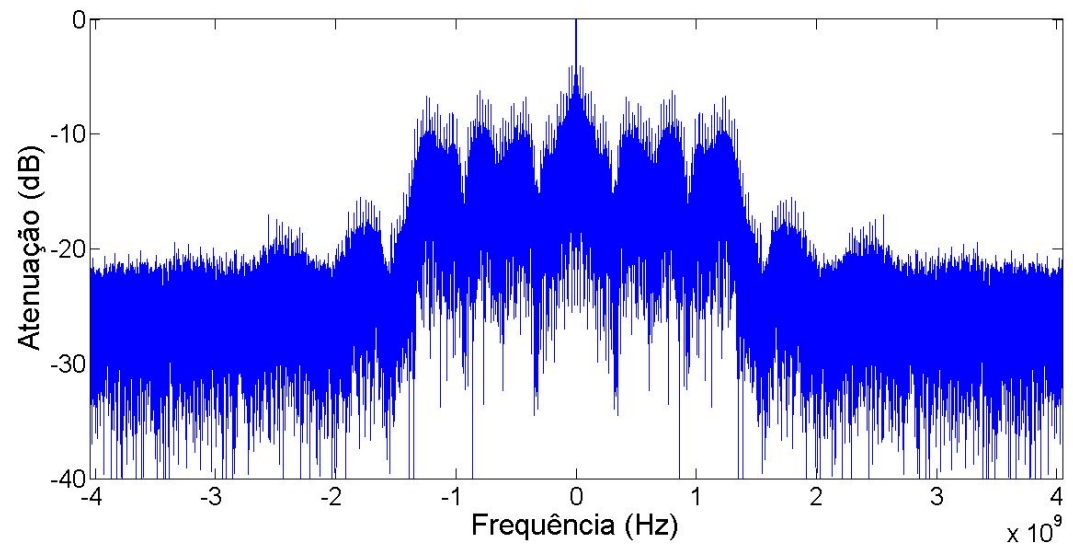

Figura 5.6 Espectro de amplitude do sinal OFDM após diodo PIN com adição de ruído. 


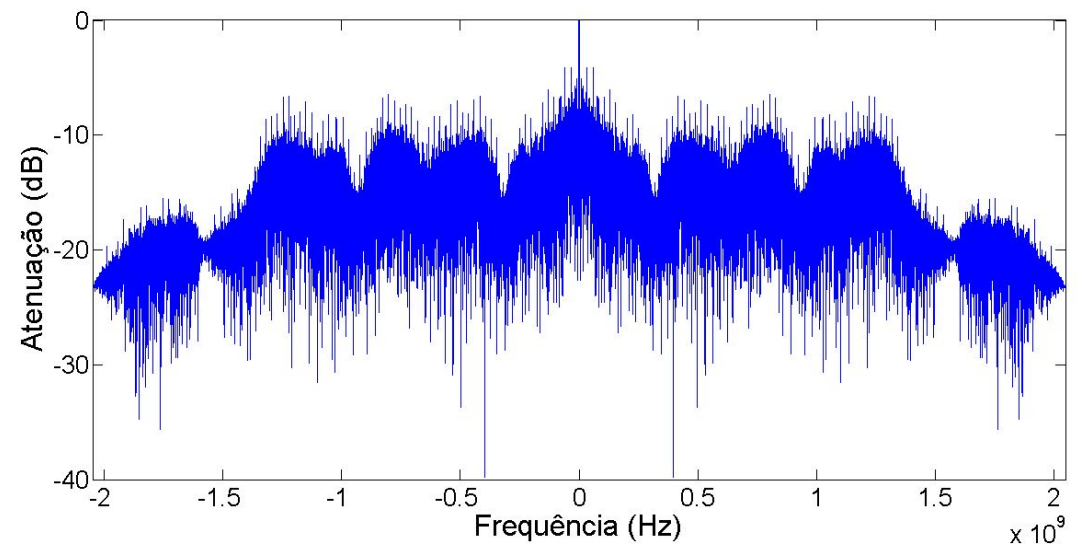

Figura 5.7 Espectro de amplitude do sinal OFDM filtrado após diodo PIN com adição de ruído e após filtragem.

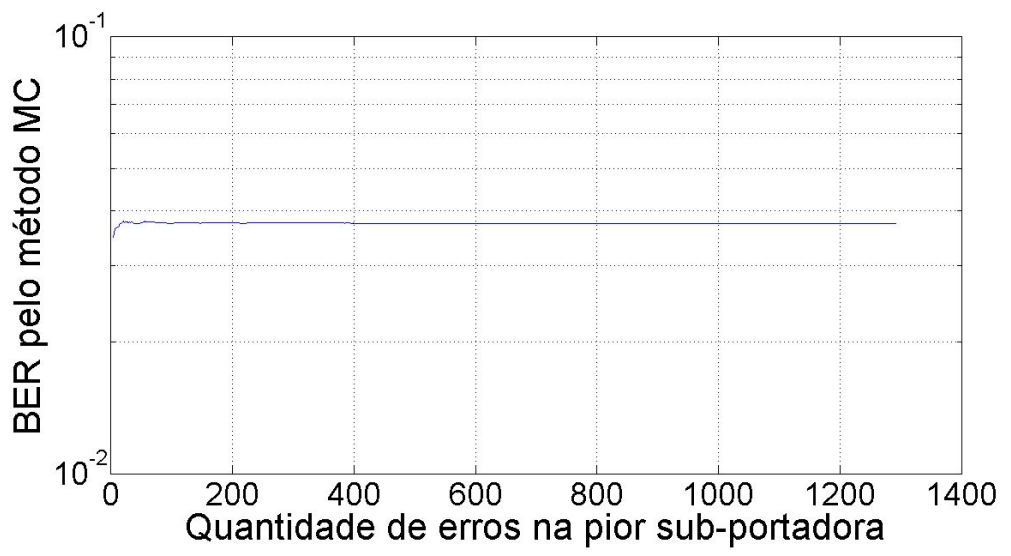

Figura 5.8 BER por MC versus erros na pior sub-portadora. 


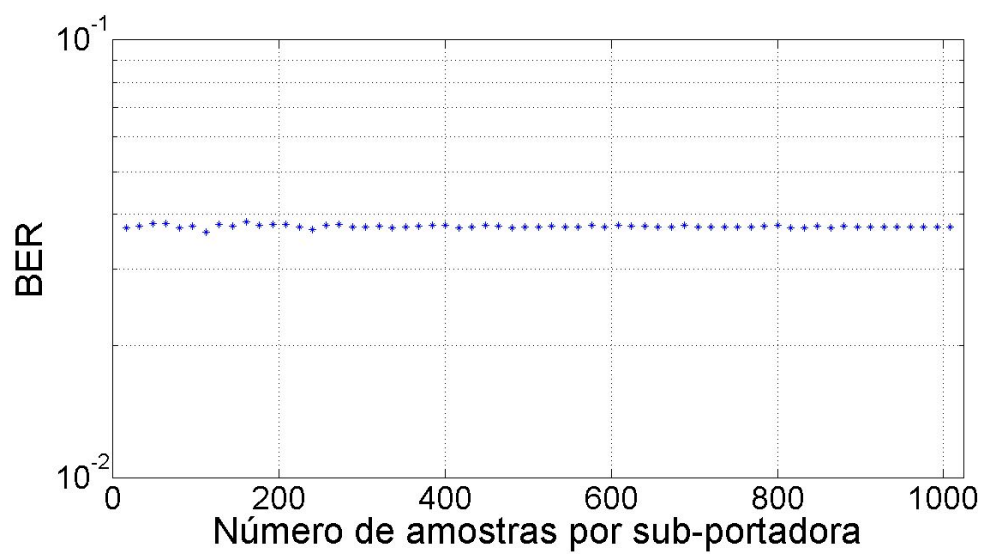

Figura 5.9 BER versus número de amostras por sub-portadora para $\frac{E_{b}}{N 0}=2 \mathrm{~dB}$.

BER pelo EVM não seja imprecisa, geraram-se gráficos da BER estimada por EVM versus número de amostras por sub-portadora, mostrados nas Figuras 5.9 e 5.10 , para $\frac{E_{b}}{N 0}$ igual a $2 \mathrm{~dB}$ e $6 \mathrm{~dB}$, respectivamente. Como é possível perceber, a BER varia muito pouco acima de 200 amostras por sub-portadora, logo este foi o número de amostras utilizado neste trabalho. A variação relativa da BER foi calculada pela expressão:

$$
\Delta R_{B E R}=\frac{\max (B E R[k])-\min (B E R[k])}{\overline{B E R[k]}},
$$

em que $\max (B E R[k])$ e $\min (B E R[k])$ são os valores máximo e mínimo, respectivamente, de $B E R[k]$ e $\overline{B E R[k]}$ é a sua média. Geraram-se gráficos para a variação relativa da BER versus número de amostras por sub-portadora, dadas pelas Figuras 5.11 e 5.12, para dois casos de $\frac{E_{b}}{N 0}$. Como pode-se perceber, para 200 amostras por sub-portadora a variação relativa da BER é consideravelmente pequena para resultar em erros de estimativa desta. Para reduzir ainda mais de forma significativa a variação relativa é necessário aumentar muito o número de amostras. Logo, mantém-se a conclusão anterior de que 200 amostras por sub-portadora são suficientes para um cálculo preciso da BER pelo EVM.

Para avaliar a degradação do sistema para diferentes intensidades de ruído, gerou-se um gráfico de BER versus $\frac{E_{b}}{N 0}$, com a BER calculada por simulação de MC e pelo método EVM, conforme pode-se observar na Figura 5.13. Para avaliar somente a distorção causada pelo ruído, removeram-se ou diminuiram-se consideravelmente as outras fontes de distorção. Dessa forma, fixou-se o índice de modulação em $2 \%$ e o sistema é back-to-back, minimizando a distorção causada pelo modulador Mach-Zehnder e removendo a distorção causada pela fibra multimodo. Conforme pode-se observar, tanto a simulação de MC quanto o método EVM deram resultados muito próximos, o que mostra que o EVM foi capaz de estimar de forma eficiente a BER, provando ser uma técnica rápida e eficaz quando a fonte dominante de distorção é o ruído Gaussiano.

Apresenta-se a taxa de transmissão alcançada no sistema na Figura 5.14, para várias quantidades de sub-portadoras piloto. O sinal foi transmitido em banda base em uma largura de 


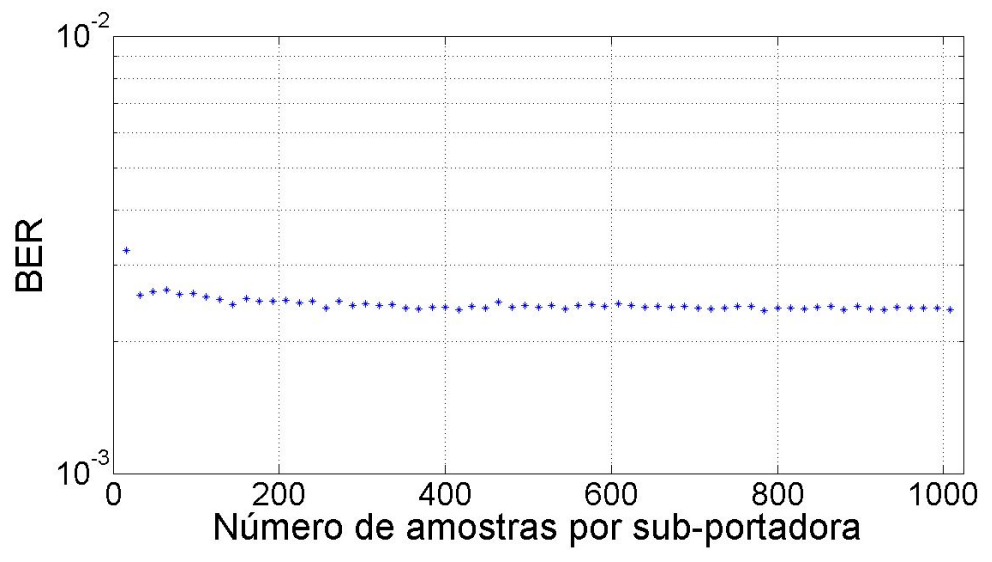

Figura 5.10 BER versus número de amostras por sub-portadora para $\frac{E_{b}}{N 0}=6 \mathrm{~dB}$.

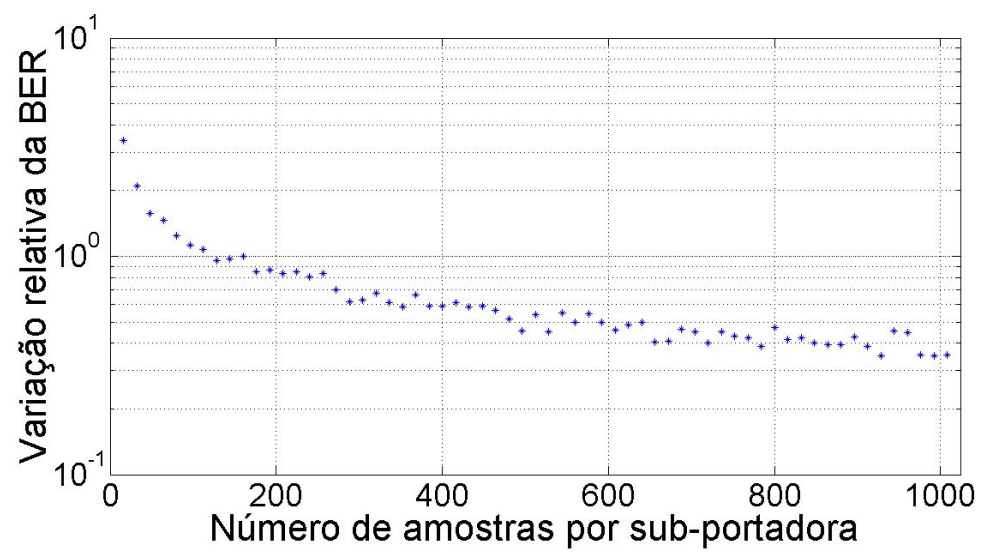

Figura 5.11 Variação relativa da BER versus número de amostras por sub-portadora para $\frac{E_{b}}{N 0}=2 \mathrm{~dB}$.

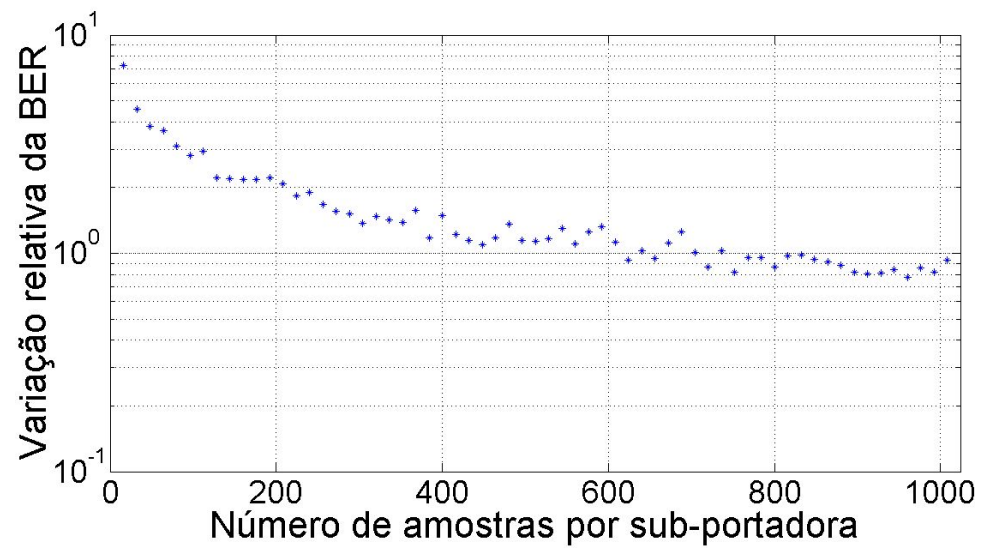

Figura 5.12 Variação relativa da BER versus número de amostras por sub-portadora para $\frac{E_{b}}{N 0}=6 \mathrm{~dB}$. 


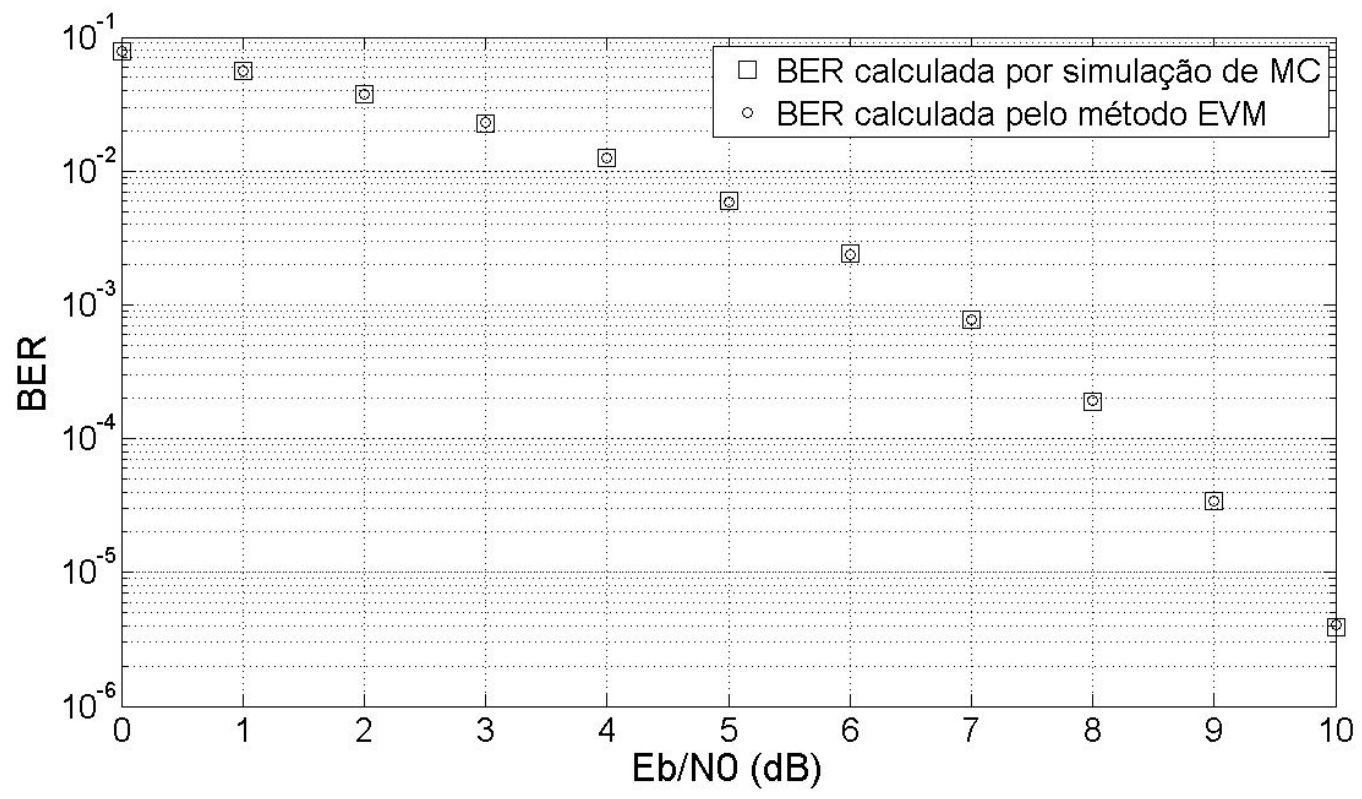

Figura 5.13 BER versus $\frac{E_{b}}{N 0}$.

banda de $2.048 \mathrm{GHz}$. Utilizou-se $\frac{1}{16}$ do símbolo OFDM para compor o prefixo cíclico. É possível perceber que a eficiência espectral é sempre menor do que um, o que era esperado, visto que metade da capacidade de transmissão é perdida para que o sinal seja real na saída do transmissor e também por causa da utilização de sub-portadoras piloto e do prefixo cíclico.

A Figura 5.15 mostra a BER para diferentes comprimentos de fibra multimodo. O sistema nesse caso está livre de ruído, foram utilizadas 66 sub-portadoras piloto e calculou-se a BER pelo método EVM e por simulação de MC. Como pode ser observado, a BER tende a aumentar à medida que o comprimento da fibra aumenta. Isso ocorre pois a dispersão modal é cada vez mais intensa para maiores comprimentos de fibra. Porém, há alguns pontos que fogem a essa tendência, apresentando valores de BER altos para comprimentos baixos ou valores baixos para comprimentos altos. Apresentam-se a resposta de amplitude, resposta ao atraso e resposta ao impulso para uma MMF de comprimento igual a $280 \mathrm{~m}$ nas Figuras 5.16, $5.17 \mathrm{e}$ 5.18, respectivamente. É possível perceber que a função de transferência varia muito rápido perto de $1 \mathrm{GHz}$ e o estimador de canal não consegue acompanhar uma variação tão brusca. É por esse motivo que existem pontos na Figura 5.15 que possuem uma BER muito alta, mesmo quando seus vizinhos apresentam uma BER relativamente baixa. Para alcançar um desempenho satisfatório para esses pontos com BER alta é necessário utilizar mais sub-portadoras piloto.

Se o comprimento da fibra aumentar para $300 \mathrm{~m}$ o estimador de canal já é capaz de reproduzir eficientemente a função de transferência para esse número de sub-portadoras piloto, conforme pode-se observar nas Figuras 5.19 e 5.20. Percebe-se que a função de transferência para esse comprimento não possui variações tão rápidas. Apresenta-se a resposta ao impulso para esse caso na Figura 5.21.

Percebe-se ainda pela Figura 5.15 que apesar da distorção causada sobre o sinal pela dis- 


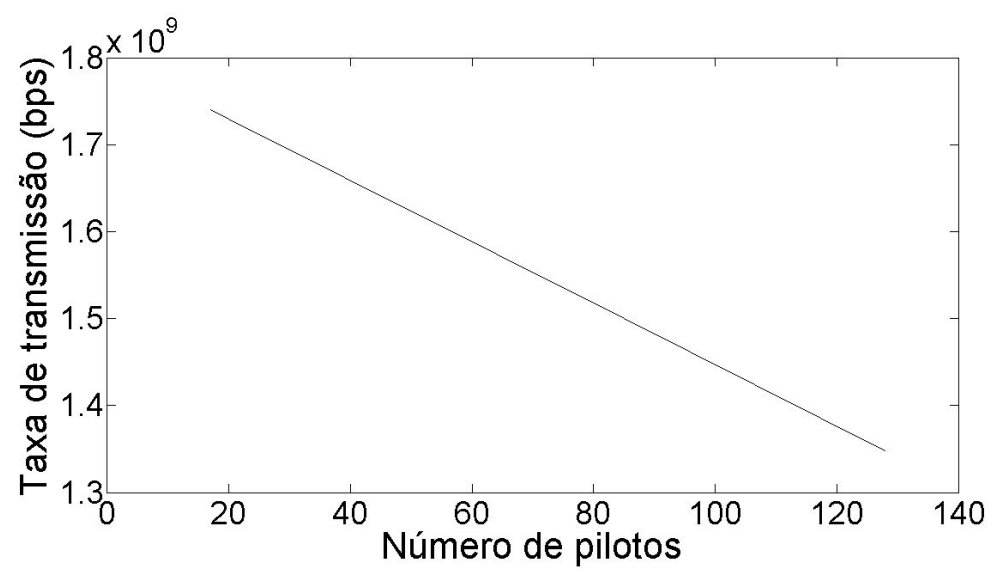

Figura 5.14 Taxa de transmissão versus número de sub-portadoras piloto

persão modal não ter uma distribuição Gaussiana, o EVM ainda foi capaz de estimar a BER sem muita perda de precisão. A discrepância em relação à BER calculada por simulação de MC foi de aproximadamente meia ordem de grandeza, o que pode ser suficiente se a análise de desempenho do sistema não requisitar uma precisão muito alta para a BER.

Para comprimentos de fibra maiores que $500 \mathrm{~m}, 66 \mathrm{sub}$-portadoras piloto se tornam insuficientes para estimar o canal de forma satisfatória, o que faz com que a BER seja inaceitavelmente alta para um desempenho satisfatório do sistema, conforme visto na Figura 5.15.

Para continuar a avaliação de desempenho do sistema, calculou-se o $E V M_{R M S}$ para diferentes valores de comprimento de fibra multimodo, número de sub-portadoras piloto e grau do polinômio interpolador.

Apresenta-se a influência do número de pilotos na função de transferência do equalizador nas Figuras 5.22, 5.23, 5.24 e 5.25. Pode-se observar que para um número maior de pilotos estima-se melhor a função de transferência do sistema, conforme esperado. Para 128 pilotos, a função de transferência do sistema e a função de transferência do equalizador estão praticamente sobrepostas, mostrando que estimou-se o canal de forma satisfatória.

Apresenta-se a função de transferência do equalizador para um polinômio interpolador de primeira ordem nas Figuras 5.26 e 5.27. É possível notar que, em comparação com a Figura 5.22, um polinômio de grau quatro estima melhor o canal neste caso.

Para um nível mais baixo de distorção, o número de pilotos requeridos para uma estimativa satisfatória da função de transferência do sistema é menor, como mostrado nas Figuras 5.28 e 5.29. É possível perceber que somente 26 pilotos foram necessários para uma boa estimativa neste cenário.

A Figura 5.30 apresenta o $E V M_{R M S}$ do sistema em função do grau do polinômio interpolador para diferentes números de sub-portadoras piloto e comprimentos de fibra multimodo. É possível observar que para um comprimento da MMF de $500 \mathrm{~m}$ e 66 pilotos um grau de polinômio de pelo menos quatro pode ser necessário para uma boa estimativa da função de transferência do sistema. Para um grau menor do que quatro, o polinômio pode não se ajustar satisfatoriamente à função de transferência do canal, levando a uma estimativa precária. Entre- 


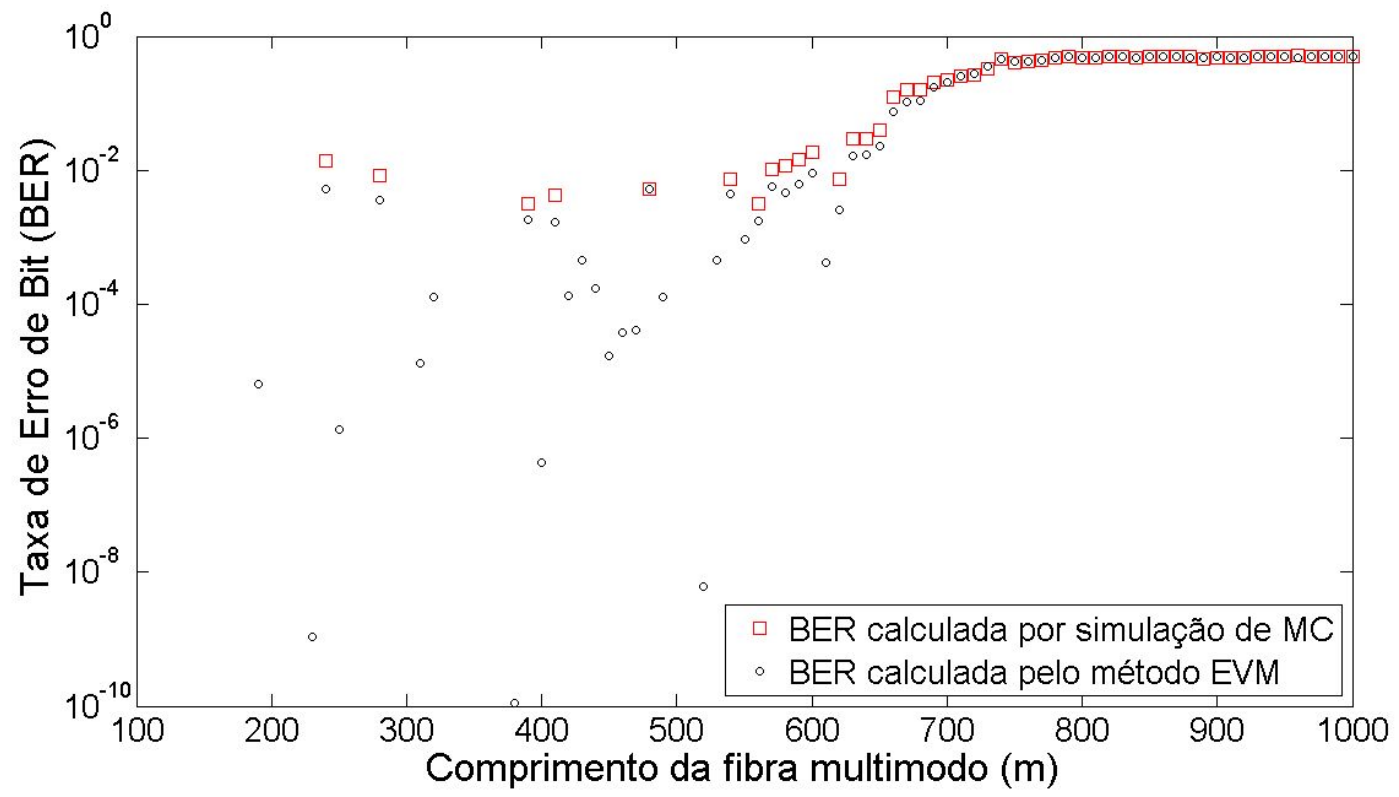

Figura 5.15 BER em função do comprimento da fibra multimodo.

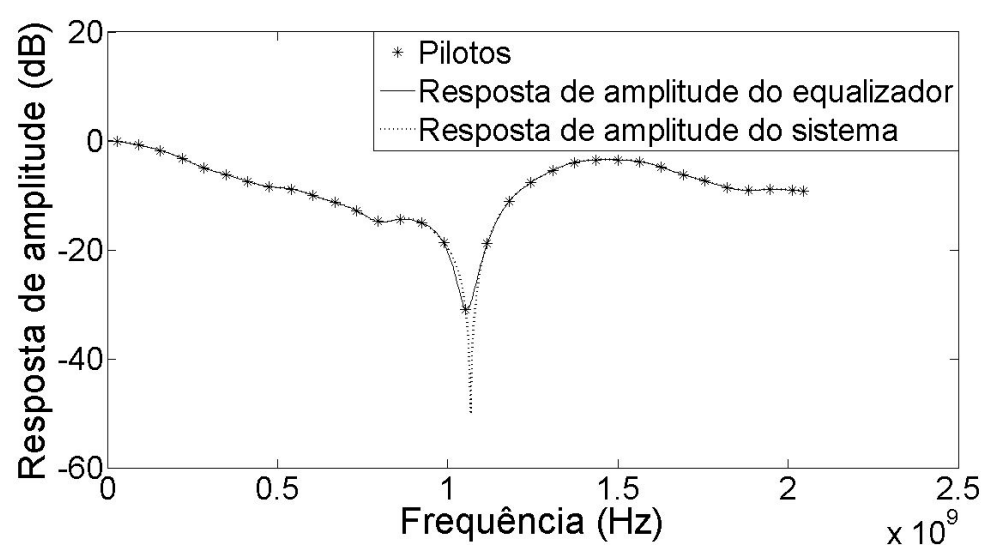

Figura 5.16 Resposta de amplitude do sistema e do equalizador para $280 \mathrm{~m}$ de fibra multimodo. 


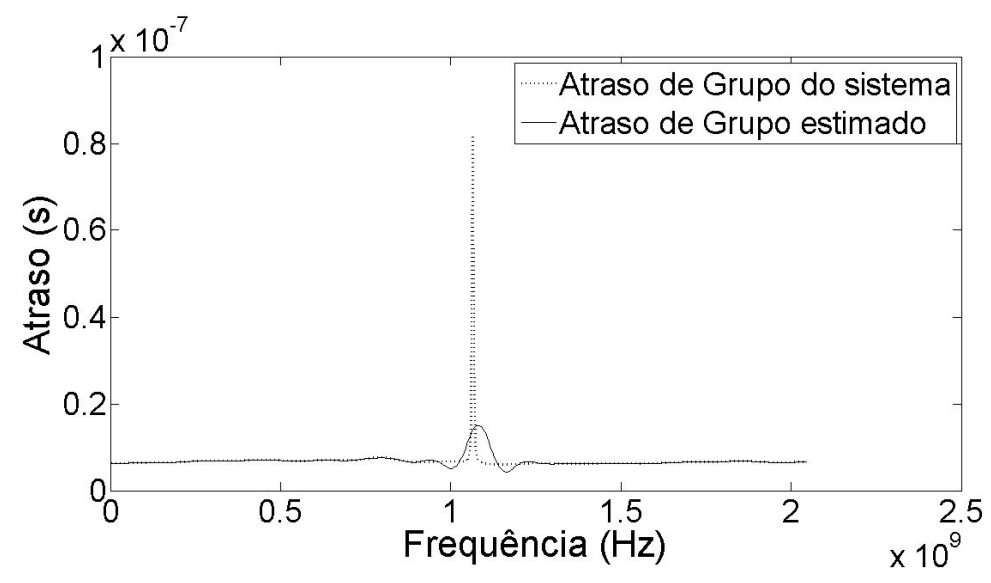

Figura 5.17 Resposta ao atraso do sistema e do equalizador para $280 \mathrm{~m}$ de fibra multimodo.

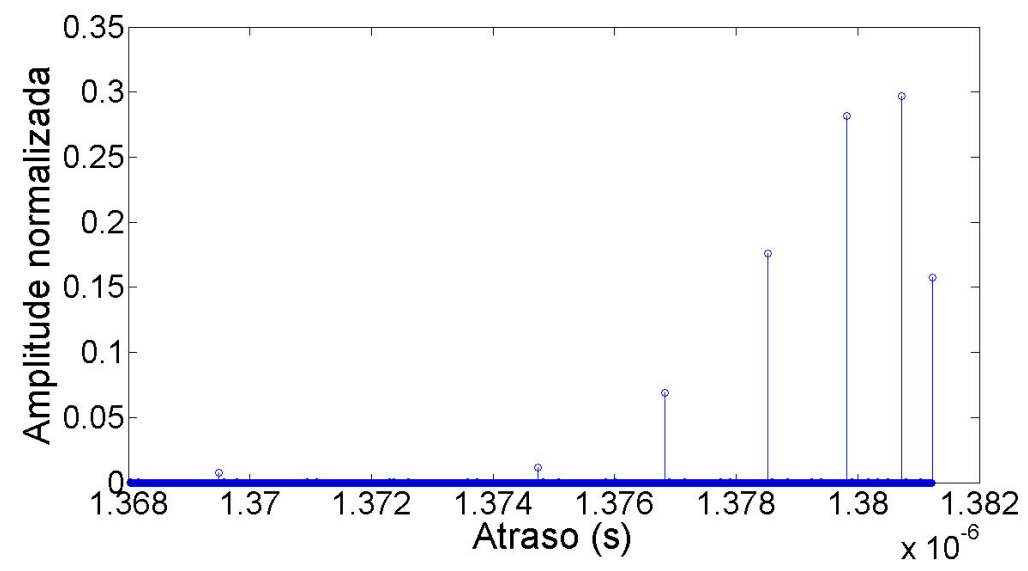

Figura 5.18 Resposta ao impulso do sistema para $280 \mathrm{~m}$ de fibra multimodo.

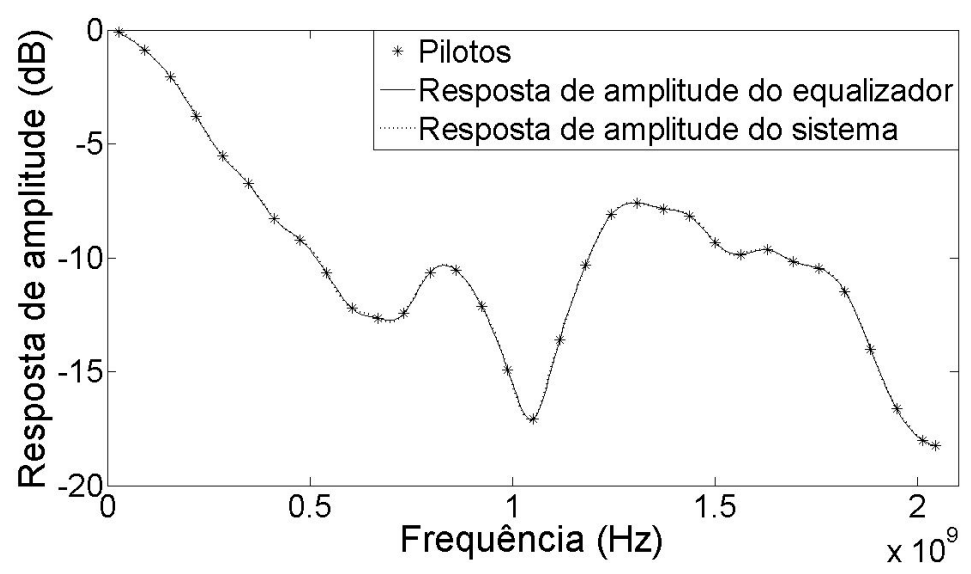

Figura 5.19 Resposta de amplitude do sistema e do equalizador para $300 \mathrm{~m}$ de fibra multimodo. 


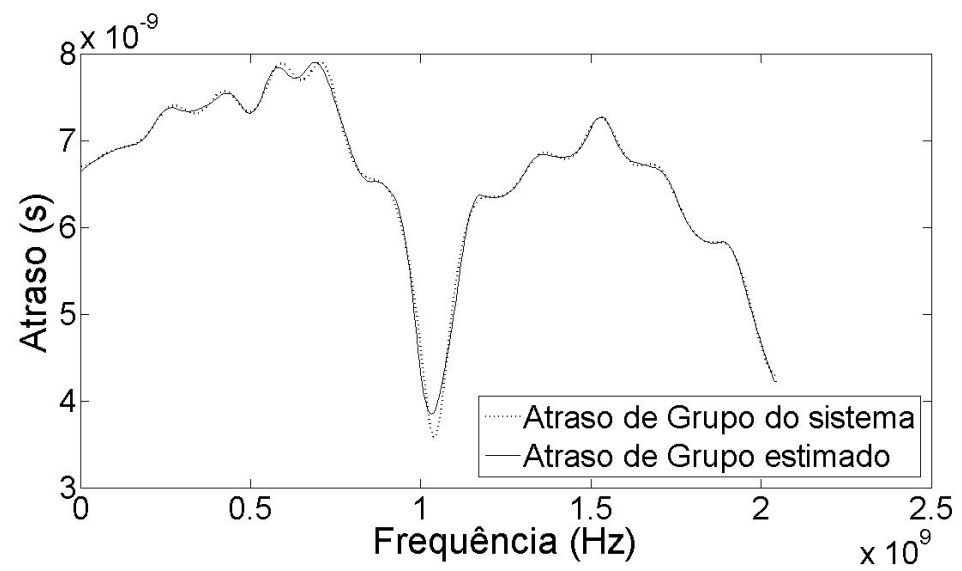

Figura 5.20 Resposta ao atraso do sistema e do equalizador para $300 \mathrm{~m}$ de fibra multimodo.

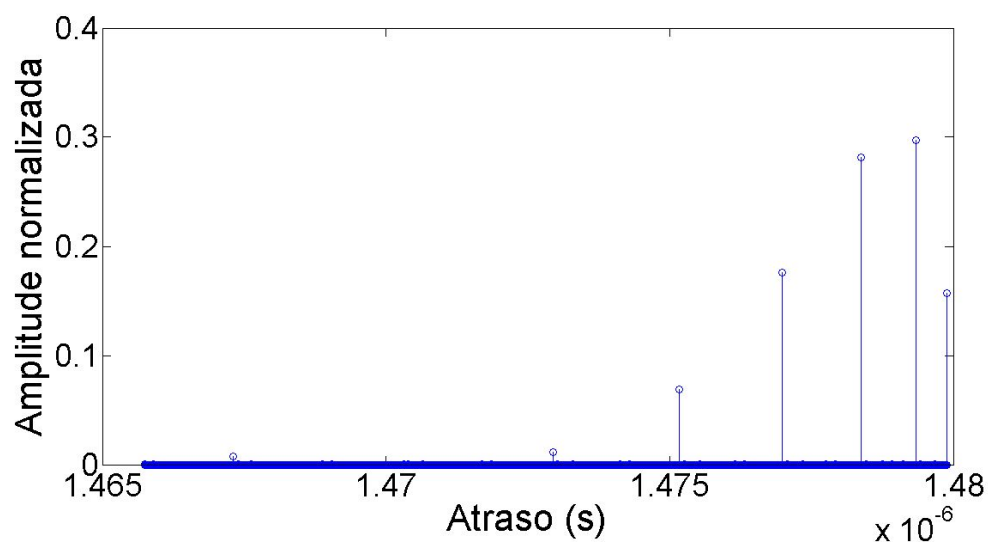

Figura 5.21 Resposta ao impulso do sistema para $300 \mathrm{~m}$ de fibra multimodo. 


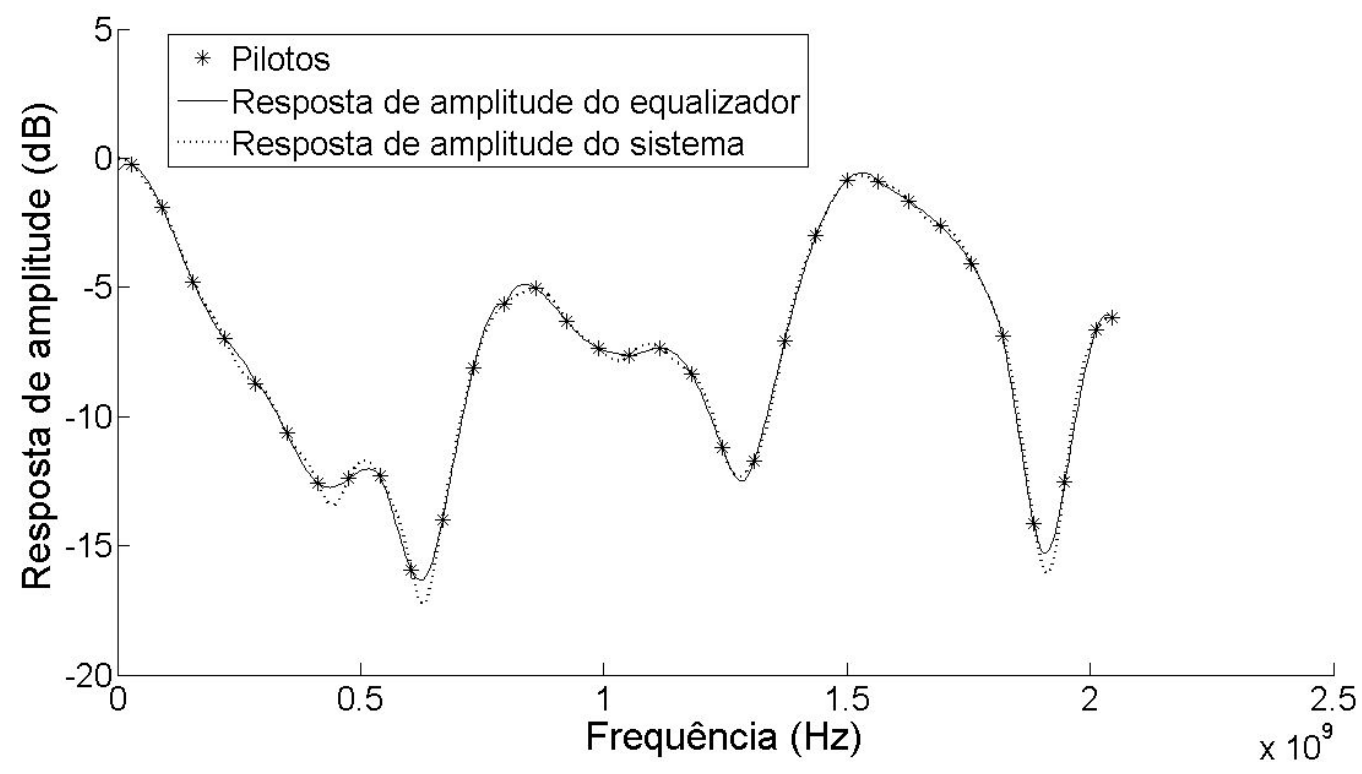

Figura 5.22 Resposta de amplitude do sistema e do equalizador para 66 sub-portadoras piloto, $500 \mathrm{~m}$ de fibra multimodo e polinômio interpolador de ordem 4 .

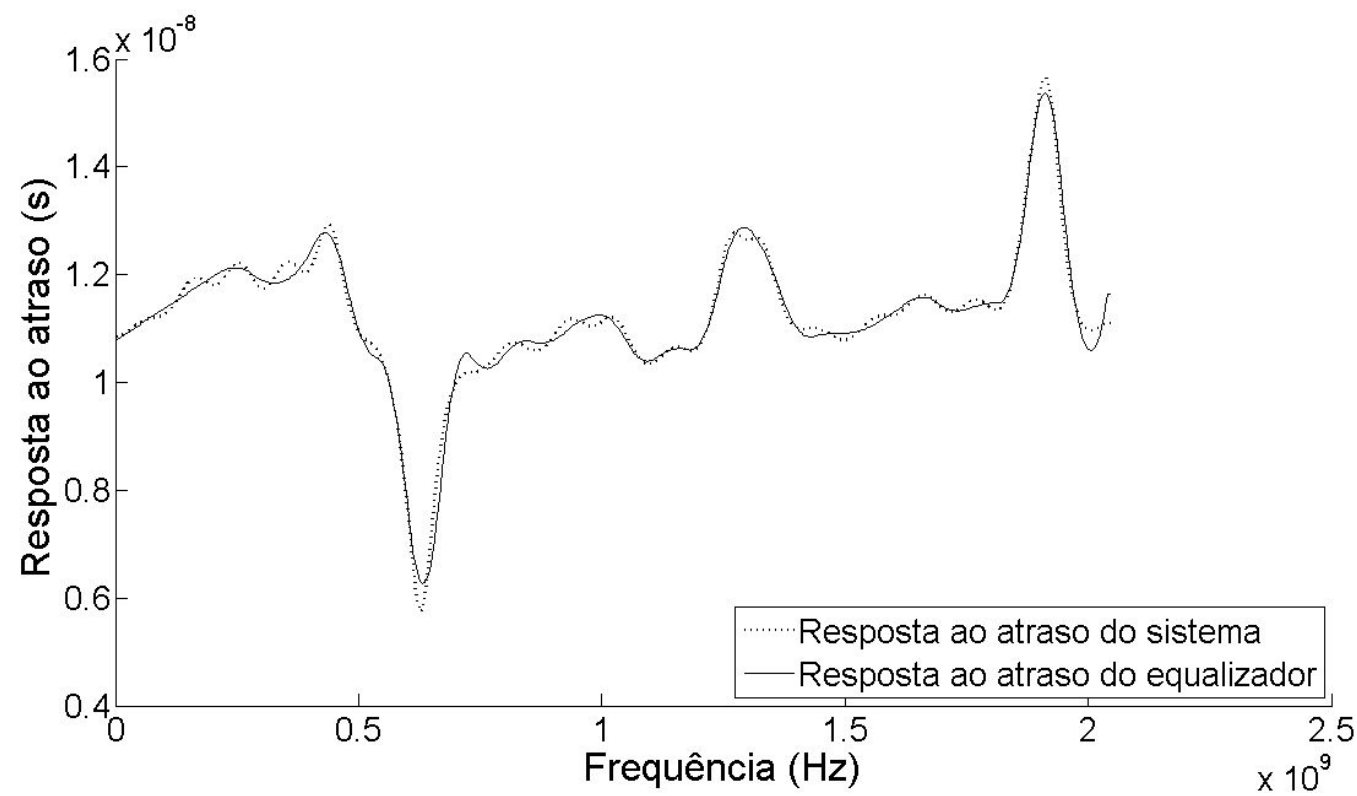

Figura 5.23 Resposta ao atraso do sistema e do equalizador para 66 sub-portadoras piloto, $500 \mathrm{~m}$ de fibra multimodo e polinômio interpolador de ordem 4. 


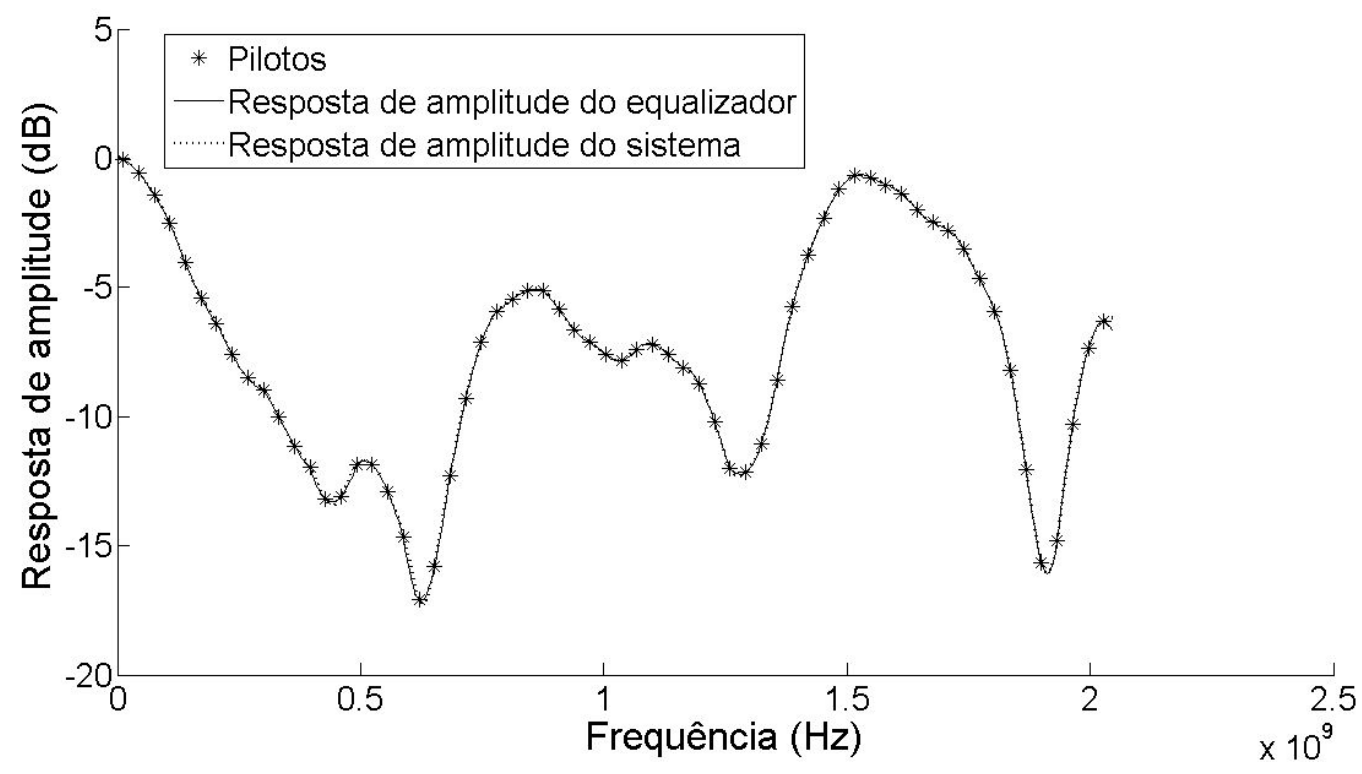

Figura 5.24 Resposta de amplitude do sistema e do equalizador para 128 sub-portadoras piloto, $500 \mathrm{~m}$ de fibra multimodo e polinômio interpolador de ordem 4 .

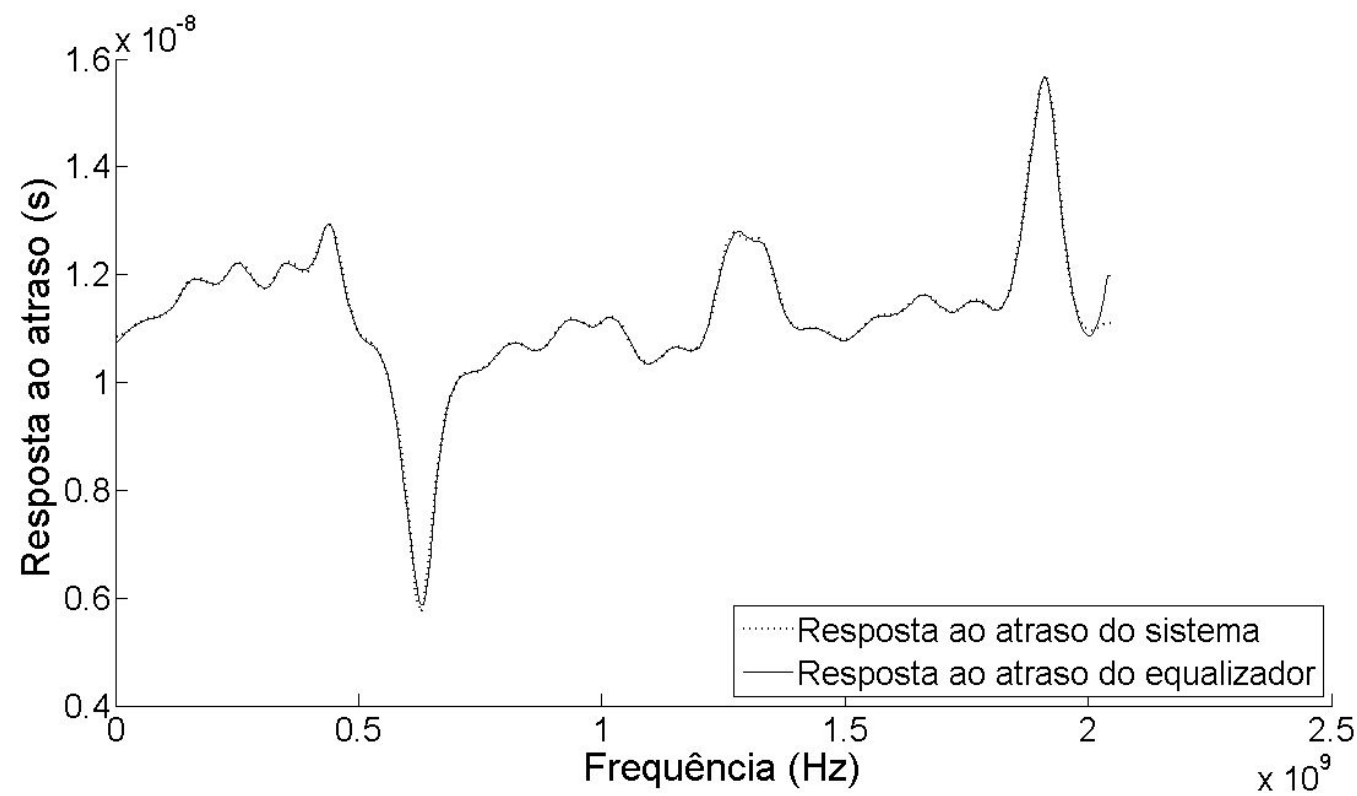

Figura 5.25 Resposta ao atraso do sistema e do equalizador para 128 sub-portadoras piloto, $500 \mathrm{~m}$ de fibra multimodo e polinômio interpolador de ordem 4. 


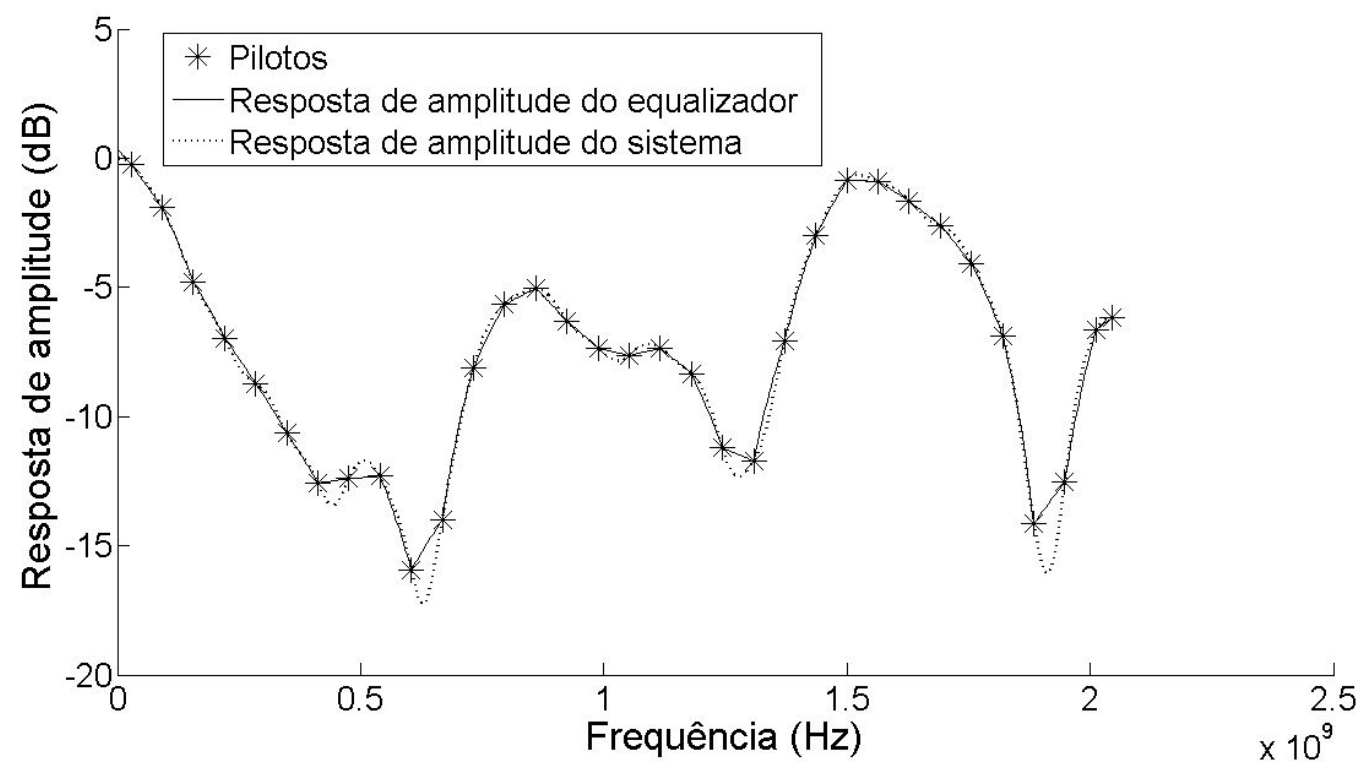

Figura 5.26 Resposta de amplitude do sistema e do equalizador para 66 sub-portadoras piloto, $500 \mathrm{~m}$ de fibra multimodo e polinômio interpolador de ordem 1.

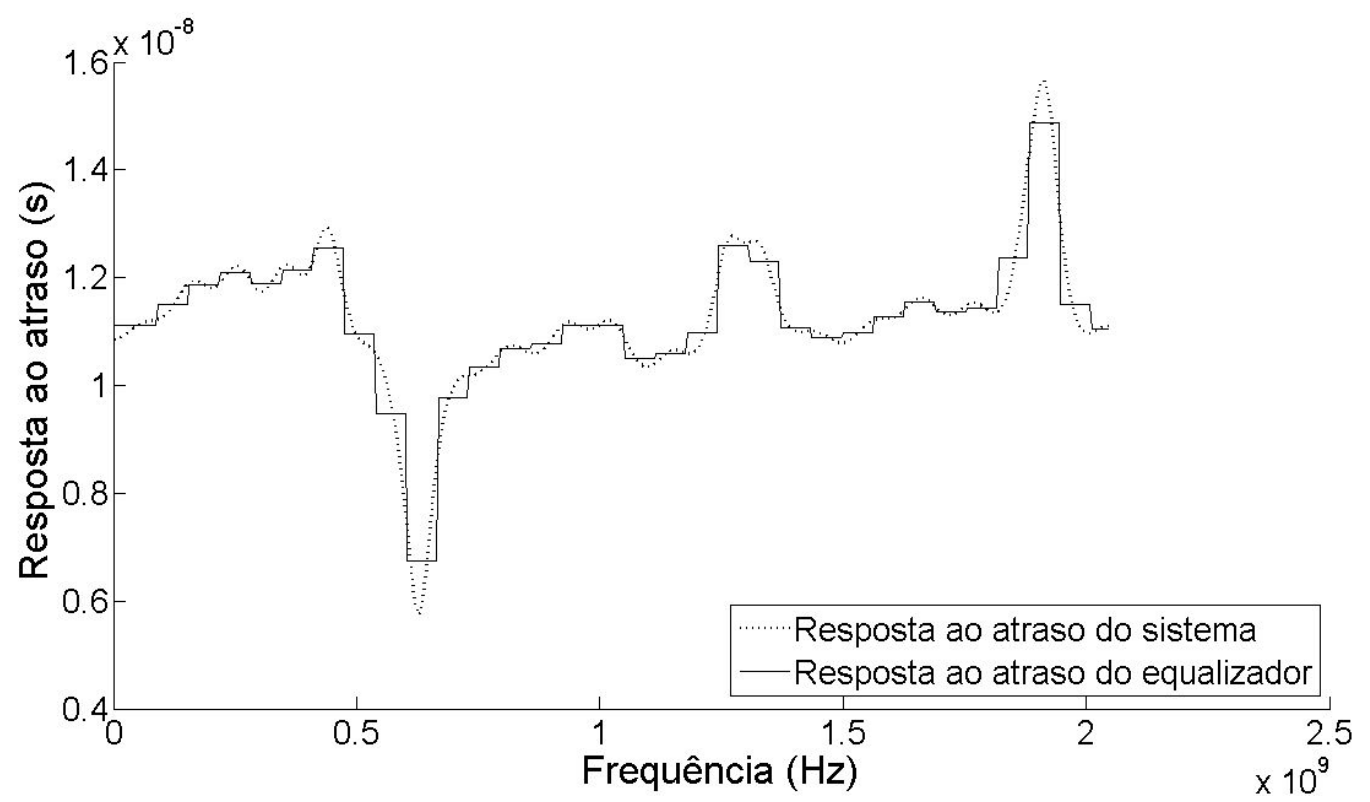

Figura 5.27 Resposta ao atraso do sistema e do equalizador para 66 sub-portadoras piloto, $500 \mathrm{~m}$ de fibra multimodo e polinômio interpolador de ordem 1. 


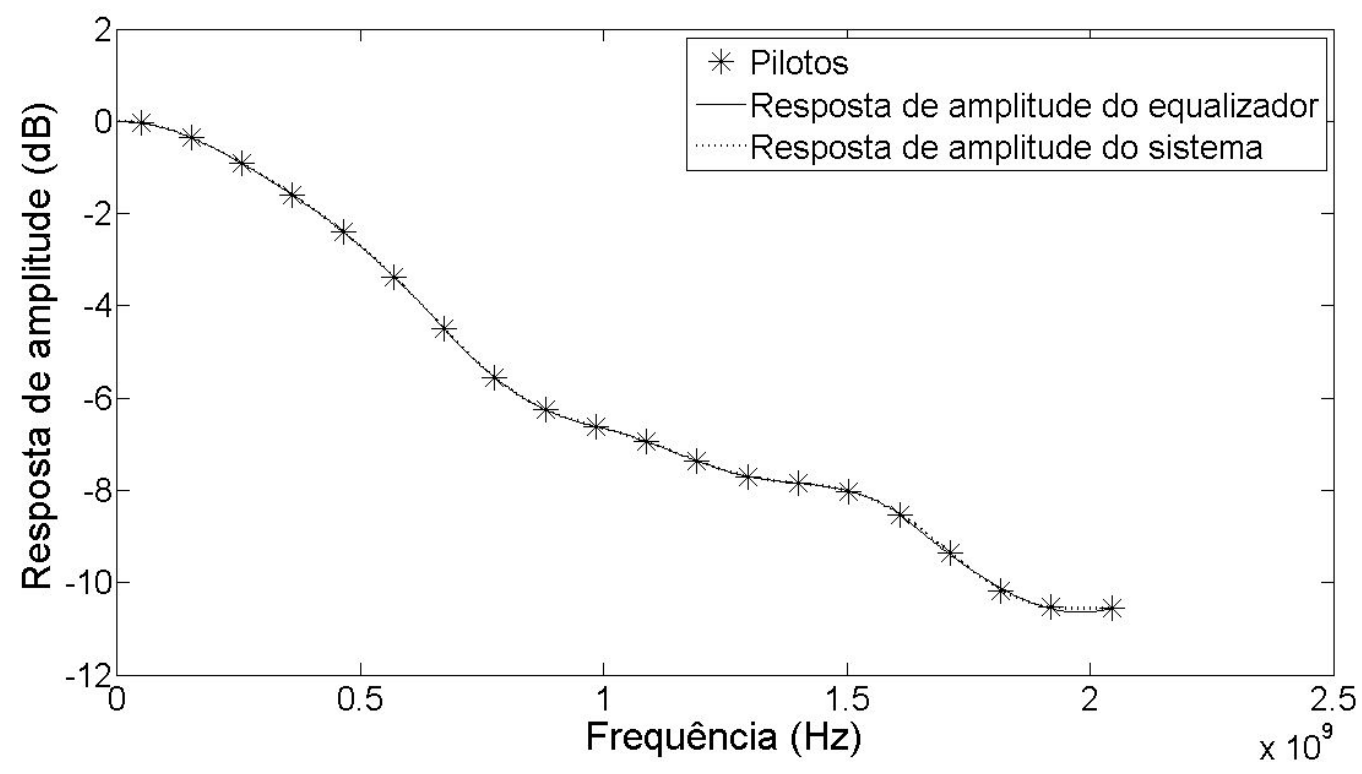

Figura 5.28 Resposta de amplitude do sistema e do equalizador para 26 sub-portadoras piloto, $100 \mathrm{~m}$ de fibra multimodo e polinômio interpolador de ordem 3 .

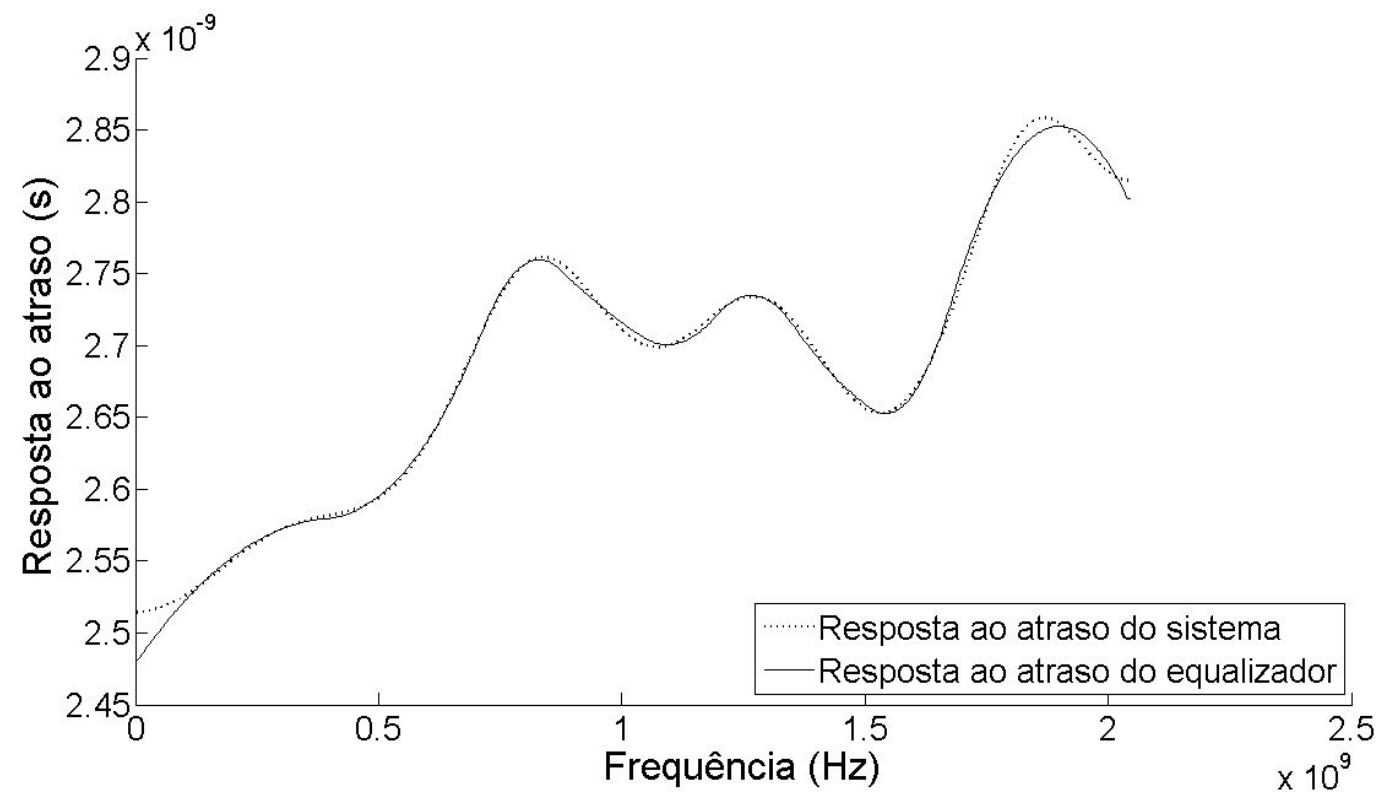

Figura 5.29 Resposta ao atraso do sistema e do equalizador para 26 sub-portadoras piloto, $100 \mathrm{~m}$ de fibra multimodo e polinômio interpolador de ordem 3 . 


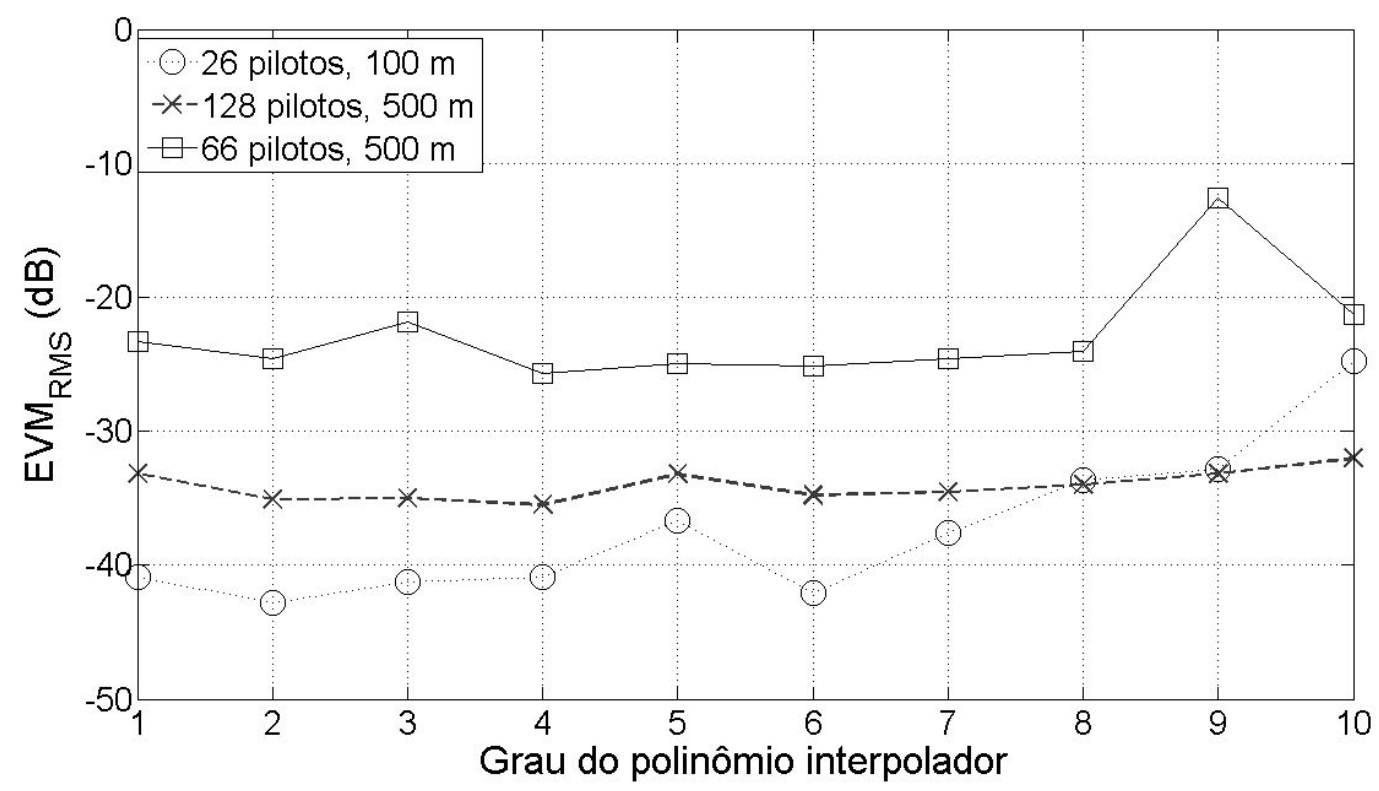

Figura 5.30 $E V M_{R M S}$ versus grau do polinômio interpolador para diferentes números de sub-portadoras piloto e comprimento de MMF.

tanto, o grau deve ser mantido abaixo de nove para prevenir degradação de desempenho. Isso acontece porque quanto maior o grau do polinômio, mais pilotos precisam ser utilizados em cada estimativa, assim abrangendo uma maior faixa de frequências e diminuindo a probabilidade de que exista um polinômio que se ajuste de forma satisfatória à função de transferência do sistema.

Para investigar o grau do polinômio interpolador requerido para um número maior de pilotos, calculou-se também o $E V M_{R M S}$ para $500 \mathrm{~m}$ de MMF e 128 pilotos. A Figura 5.30 apresenta os resultados obtidos para esta situação. Pode ser observado que qualquer grau menor do que nove leva a uma boa estimativa, embora valores iguais ou maiores do que nove não estão muito distante dos demais. Assim, quanto maior o número de pilotos sendo utilizados, menor é a ordem do polinômio requerida para o mesmo valor de $E V M_{R M S}$ e ainda polinômios de alta ordem também podem levar a um desempenho satisfatório.

A Figura 5.30 mostra ainda o $E V M_{R M S}$ obtido para um cenário de baixa distorção (comprimento da MMF de $100 \mathrm{~m}$ ) e apenas 26 pilotos. É possível perceber que por causa da distorção reduzida, polinômios de ordem baixa se ajustam melhor à função de transferência do sistema. Neste caso, o grau que leva ao menor valor de $E V M_{R M S}$ é dois.

Podem-se observar as constelações recebidas, antes e após equalização, para três casos de comprimento de MMF e de sub-portadoras piloto, nas Figuras 5.31 a 5.36. Pode parecer que as constelações após equalização estão piores do que realmente são, mas isso é porque um total de 7648 símbolos recebidos são considerados em cada figura e apenas algumas sub-portadoras sofrem alto nível de distorção.

Apresenta-se um resumo dos resultados obtidos na Tabela 5.1. Pelos valores apresentados 


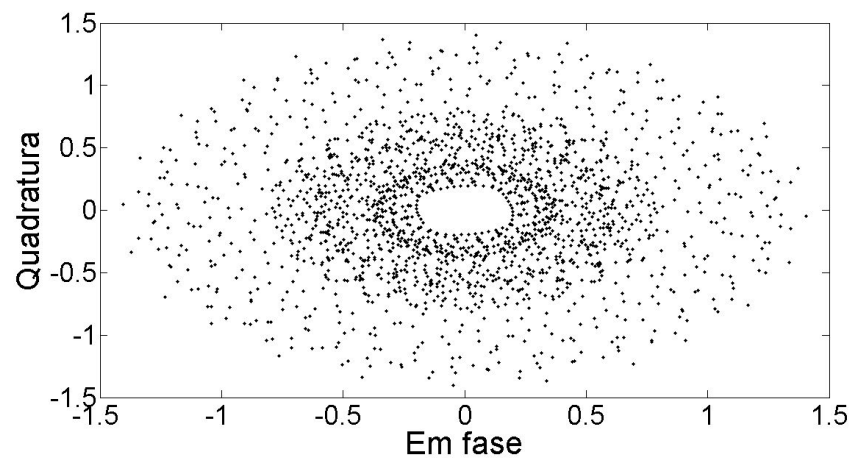

Figura 5.31 Constelação recebida antes da equalização para 500 m de MMF, 66 sub-portadoras piloto e polinômio interpolador de grau 4.

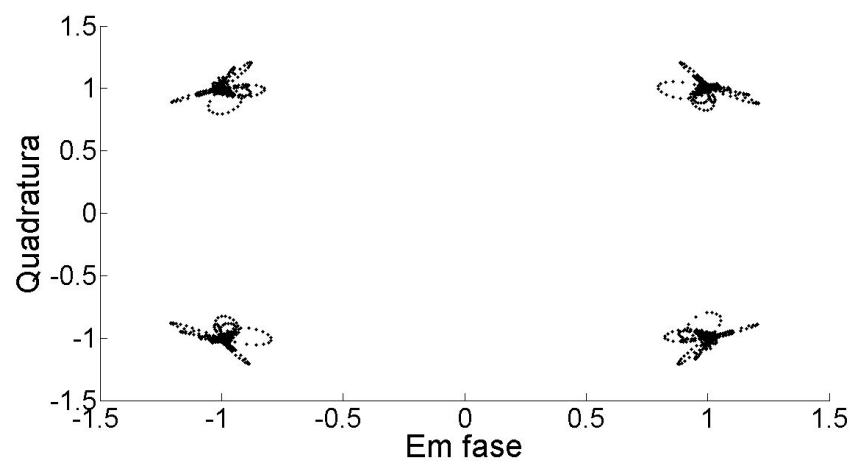

Figura 5.32 Constelação recebida após equalização para 500 m de MMF, 66 sub-portadoras piloto e polinômio interpolador de grau 4.

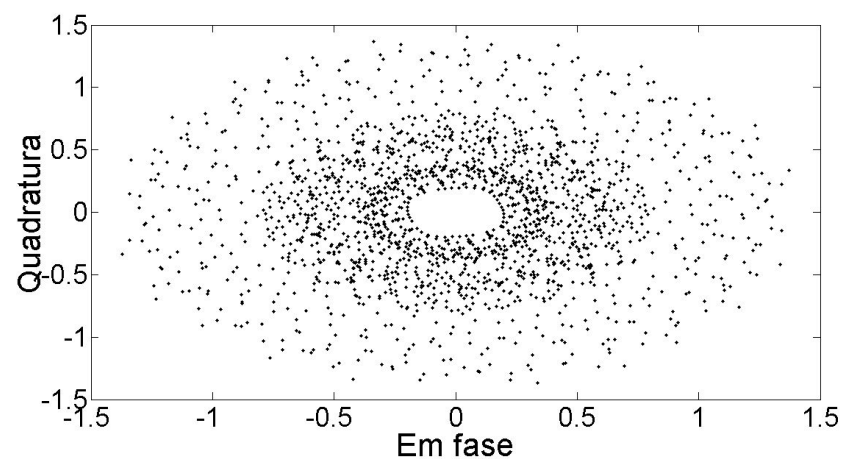

Figura 5.33 Constelação recebida antes da equalização para $500 \mathrm{~m}$ de MMF, 128 sub-portadoras piloto e polinômio interpolador de grau 4. 


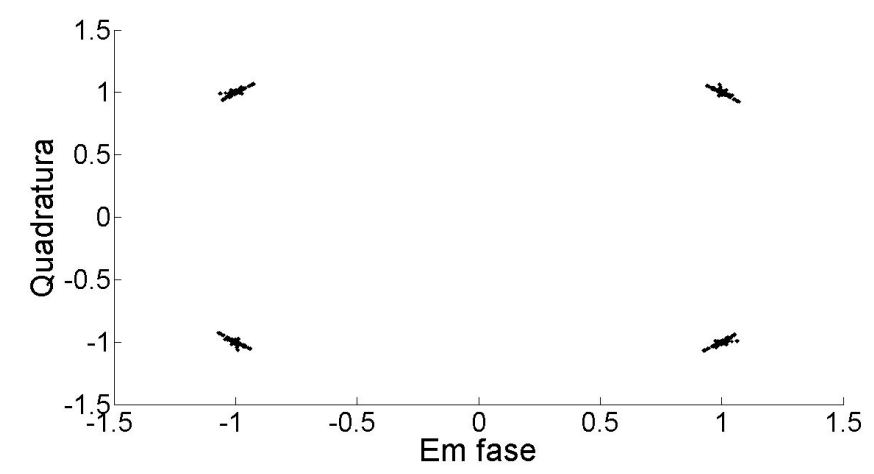

Figura 5.34 Constelação recebida após equalização para 500 m de MMF, 128 sub-portadoras piloto e polinômio interpolador de grau 4.

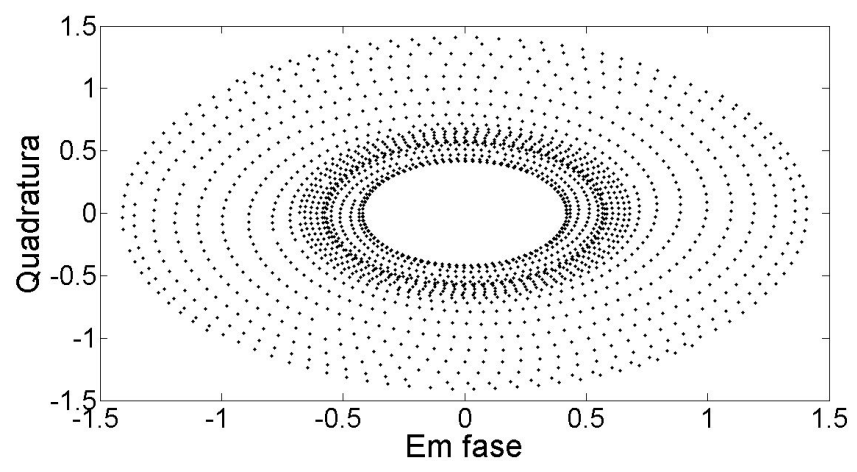

Figura 5.35 Constelação recebida antes da equalização para 100 m de MMF, 26 sub-portadoras piloto e polinômio interpolador de grau 3.

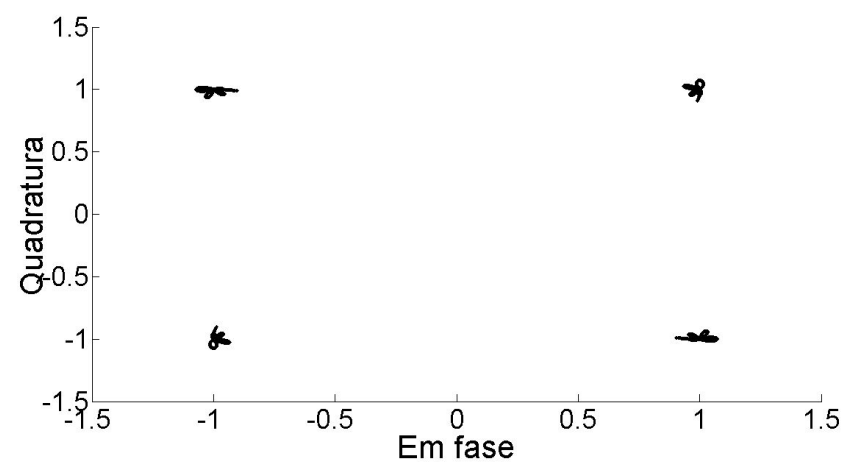

Figura 5.36 Constelação recebida após equalização para $100 \mathrm{~m}$ de MMF, 26 sub-portadoras piloto e polinômio interpolador de grau 3. 
para o $E V M_{R M S}$, pode-se observar que a distorção remanescente após a equalização é muito baixa para todos os casos, indicando que o equalizador foi capaz de compensá-la satisfatoriamente.

\begin{tabular}{|c|c|c|c|}
\hline Comprimento da MMF (m) & Número de pilotos & Grau polinomial ótimo & EVM $_{\text {RMS }}(\mathrm{dB})$ \\
\hline 500 & 66 & 4 & -25.7 \\
\hline 500 & 128 & 4 & -35.5 \\
\hline 100 & 26 & 2 & -42.8 \\
\hline
\end{tabular}

Tabela 5.1 Resumo dos resultados.

Demonstrou-se pelos desenvolvimentos anteriores que dividir a banda do sinal em várias sub-bandas menores simplifica o processo de equalização, visto que um polinômio de menor ordem é suficiente para estimar bem o canal do que se esta divisão não fosse efetuada. Isso torna possível estimar de forma eficiente um canal com vários desvanecimentos profundos, como o canal da fibra multimodo.

Mostrou-se também que quanto maior o número de pilotos sendo utilizados, menor é a ordem requerida do polinômio para que o mesmo desempenho seja alcançado. A utilização de polinômios de ordem mais baixa também pode ser possível quando uma distorção de nível mais baixo é aplicada ao sinal OFDM, como quando o comprimento da fibra é menor. 


\section{CAPÍtulo 6 \\ Conclusões}

Através de uma prévia modelagem matemática da fibra multimodo, criamos um software em Matlab bastante genérico e versátil. Por meio desse software fomos capazes de observar os campos de propagação que definem a fibra multimodo, bem como os respectivos modos excitados para diversas condições de lançamento e comprimentos de fibra. No caso apresentado, tem-se uma fibra multimodo de raio de núcleo igual a $25 \mu \mathrm{m}$ de perfil degrau, com uma fibra monomodo acoplada de raio de núcleo igual a $4 \mu \mathrm{m}$, funcionando como um "pig-tail". Dessa forma, mostramos por meio de simulações que a condição de lançamento é um fator fundamental no desempenho de sistemas ópticos que utilizam fibras multimodo, e assim, definimos a melhor condição de lançamento para o nosso sistema. A dispersão modal, principal fator limitante do produto BxL em fibras multimodo, pode ser amenizada para condições de lançamento específicas.

O software também modela um sistema OFDM completo, em que cada sub-portadora foi modulada em QPSK. Utilizou-se um equalizador "one-tap", que obtém informações do canal por meio de sub-portadoras piloto, que se mostrou bastante eficiente em compensar as distorções causadas pela dispersão modal. Mostrou-se a influência da quantidade de subportadoras piloto utilizadas e da ordem do polinômio interpolador sobre a função de transferência do equalizador. Concluiu-se também que pode ser vantajoso para a equalização dividir a banda do sinal em diversas sub-bandas.

Implementou-se dois métodos de análise de desempenho, o de simulação de Monte-Carlo e o EVM. Mostrou-se que para o Monte Carlo um critério de parada de 100 erros na pior subportadora é suficiente para uma estimativa acurada da BER. Da mesma forma, demonstrou-se que 200 amostras por sub-portadora são suficientes para o EVM estimar de forma satisfatória a BER. Concluiu-se também que o EVM é uma técnica eficiente para calcular a BER quando a distorção é predominantemente Gaussiana.

Mesmo com toda a base e padrões de sistemas OFDM para redes sem fio e cabeadas sendo definidos nos anos 90, apenas recentemente o OFDM tem sido utilizado visando amenizar os efeitos da dispersão modal nas fibras multimodo. Dessa forma, com o software desenvolvido, foi possível realizar uma análise da transmissão de sinais OFDM em banda base sobre fibras multimodo de perfil degrau. 



\section{APÊNDICE A \\ Sistema de Coordenadas}

Implementou-se a mudança do sistema de coordenadas em Matlab. Realizou-se o procedimento mapeando primeiramente o sistema de coordenadas desejado em uma matriz que abrange toda a área a ser coberta pela seção transversal da fibra multimodo. Uma vez que o raio da fibra multimodo seja definido $\left(r_{m m}\right)$, determinou-se então como período de análise, ou seja, período de integração, um valor de 3 vezes o raio do núcleo da fibra multimodo. Assim, definiu-se o raio da casca da fibra multimodo com um valor de $2 r_{m m}$. Chamamos a matriz que armazena o valor do campo na seção transversal da fibra de $A_{m m}$. Tal mapeamento está representado na Figura A.1, em que o quadrado externo representa a matriz e os círculos interno e externo representam o núcleo e a casca da fibra multimodo respectivamente. Dessa forma, mapeou-se o valor do campo, discretizado em cada ponto da matriz, nas posições de $A_{m m}$.

Definiu-se a fonte de luz como uma fibra monomodo. Dessa forma, uma vez definida a matriz que armazena os valores dos campos da fibra multimodo ao longo do raio e do ângulo, definiu-se uma nova matriz, com os mesmos procedimentos citados acima, mas agora para a fibra monomodo. Chamou-se o raio da fibra monomodo de $r_{s m}$ e o período de integração foi igual a $3 r_{s m}$, para um raio da casca igual a $2 r_{s m}$. Essa nova matriz armazena os valores do campo referentes ao modo fundamental para a fibra monomodo ao longo do raio e do ângulo. Chamamos essa matriz de $B_{s m}$. Necessariamente, as dimensões de $B_{s m}$, para uma mesma resolução de mapeamento, serão menores que $A_{m m}$, uma vez que $r_{s m}<r_{m m}$.

Com ambas as matrizes mapeadas, representando as fibras multimodo e monomodo, e definindo as condições de lançamento $r_{\text {offset }}$ para o deslocamento ao longo do eixo do raio e $\theta_{\text {offset }}$ ao longo do eixo angular, determinou-se quais posições da matriz $A_{m m}$ devem ser multiplicadas pelos respectivos valores da fonte (fibra monomodo - matriz $B_{s m}$ ), na determinação das amplitudes modais $a_{l m}$ em 2.47. Com o sistema de coordenadas discretizado e mapeado corretamente, bastou fazer uma multiplicação ponto a ponto das matrizes. Representa-se nas Figuras A.2 e A.3 duas possibilidades de sobreposição de matrizes, sendo no primeiro caso um lançamento centralizado e, no segundo caso, um lançamento com offset no raio e no ângulo.

Assim, os modos excitados foram aqueles que possuíam componentes na intersecção das duas matrizes (dois quadrados nas figuras), pois zerou-se todas as outras posições da matriz que não estão na intersecção, visto que a fonte possui valor nulo nesses pontos. 


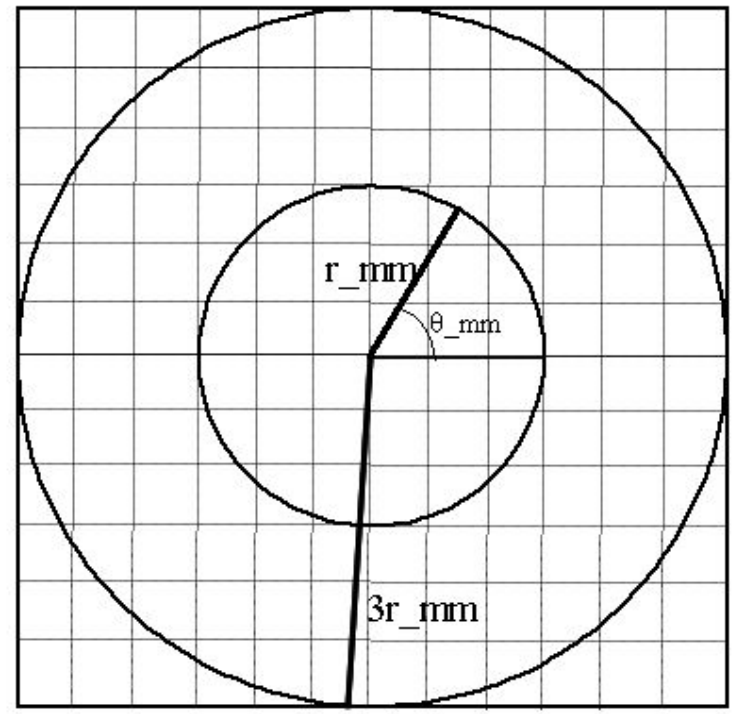

Figura A.1 Mapeamento do eixo de coordenadas em matriz.

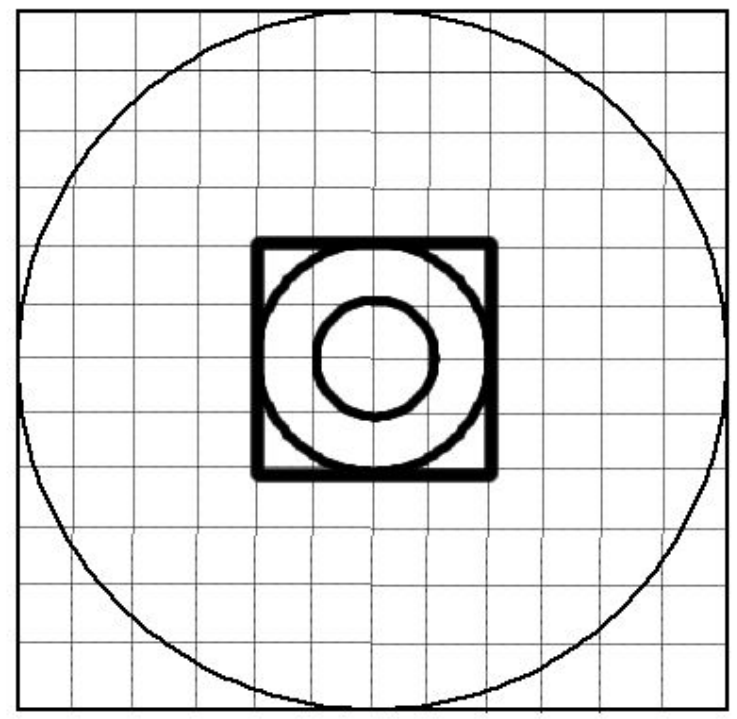

Figura A.2 Matrizes sobrepostas com lançamento centralizado. O quadrado externo representa a matriz $A_{m m}$ para a fibra multimodo e o quadrado menor representa a matriz $B_{s m}$ para a fibra monomodo. 


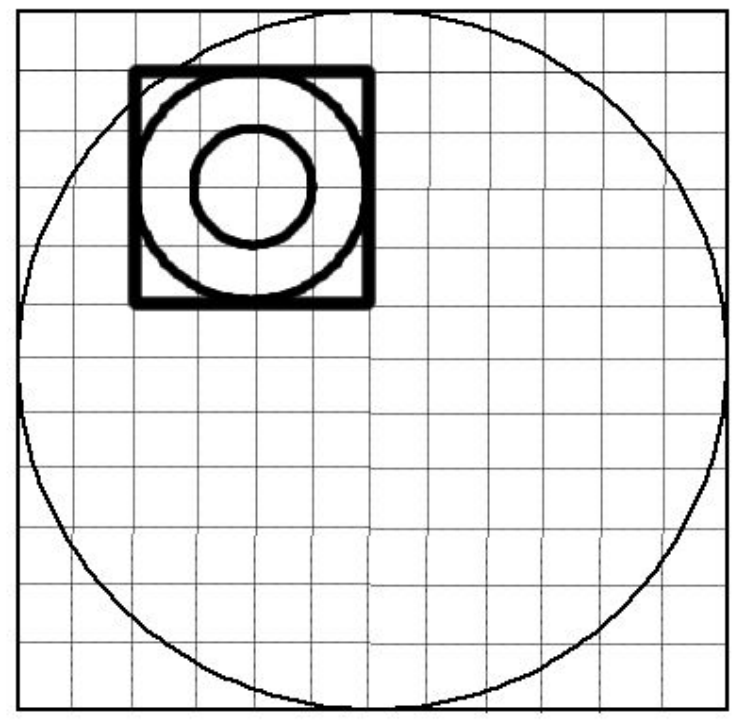

Figura A.3 Matrizes sobrepostas com lançamento deslocado no raio e ângulo. O quadrado externo representa a matriz $A_{m m}$ para a fibra multimodo e o quadrado menor representa a matriz $B_{s m}$ para a fibra monomodo. 



\section{APÊNDICE B \\ Implementação}

O Software possui uma função principal, na qual se definem todos os parâmetros da fibra a serem utilizados, as condições de lançamento e os parâmetros do sinal OFDM a ser enviado.

Dessa forma, a partir do código principal "Principal.m", chamam-se as diversas funções que agregam funcionalidades ao software. Primeiramente, usa-se a função 2 para gerar a sequência binária a ser transmitida, que é passada para a função 3, devolvendo já o sinal OFDM real, com os quadrantes mapeados para uma futura análise na deteção. Em seguida, sobre amostra-se o sinal utilizando a função 4, para então passar pelo modulador Mach-Zehnder (função 5).

Logo após, o sinal passa pela função da fibra multimodo (função 1), que calcula a resposta ao impulso da fibra, e então pela função 6 para fazer a convolução do sinal OFDM com a resposta impulsional.

No receptor, primeiramente detecta-se o sinal pelo diodo PIN, representado na função 11. Em seguida, adiciona-se o ruído ao sinal detectado (função 12). Novamente filtra-se o sinal que então passa pelo conversor A/D, descrito pela função 13. Decodifica-se e equaliza-se então o sinal na função 9. Finalmente, chama-se a função 14 para calcular a BER do sistema, de modo a analisar o seu desempenho.

A seguir, listam-se os parâmetros de entrada e saída das funções:

\section{Função de cálculo da resposta ao impulso da fibra multimodo. (mmFiber.m)}

\section{Entradas:}

- raio da fibra monomodo utilizada para lançamento da luz na fibra.

- excentricidade no lançamento.

- comprimento da fibra.

- resolução desejada da resposta ao impulso

\section{Saídas:}

- resposta ao impulso.

Com os valores das constantes de propagação já previamente definidos de acordo com os parâmetros da fibra propostos pelo livro [14], e com as condições de lançamento definidas, calculam-se os campos transversais da fibra para o núcleo e para a casca, como podemos ver em 2.20 a 2.23. Com isso, calculam-se as parcelas de potência que cada modo carrega, bem como os seus respectivos atrasos, determinando assim a função de transferência da fibra. 
2. Função geradora de sequências pseudoaleatórias binárias a serem inseridas no sistema. (bits_generator.m)

\section{Entradas:}

- comprimento da sequência binária.

\section{Saídas:}

- sequência binária.

Esta função utiliza o gerador de números aleatórios do Matlab (random.m) para gerar uma sequência pseudoaleatória binária a ser inserida no sistema.

3. Função de geração do sinal OFDM (real_OFDM_generator.m)

\section{Entradas:}

- sequência binária.

- número de sub-portadoras.

- duração do prefixo cíclico (Fração do símbolo OFDM).

-formato de modulação.

\section{Saídas:}

- sinal OFDM.

Esta função trata a geração de um sinal OFDM real, em que realiza-se o processo de paralelização e codificação do sinal de acordo com a modulação das sub-portadoras. Realizam-se também a IFFT e a adição do prefixo cíclico nessa função e, posteriormente, a serialização. Para efeitos de simplificação do transmissor e receptor, usa-se da simetria Hermitiana do sinal, antes da IFFT, para que na saída desta tenha-se apenas um sinal real.

4. Função de sampling and holding, conversor D/A (sample_hold.m)

\section{Entradas:}

-sinal OFDM.

-espaçamento entre amostras do sinal no domínio do tempo

-banda de observação desejada

\section{Saída:}

-sinal OFDM sobre amostrado.

5. Função de filtragem do sinal (filter.m)

\section{Entradas:}

-Numerador referente à frequência de corte definido pelo tipo do filtro.

-Denominador referente à frequência de corte definido pelo tipo do filtro

-Sinal a ser filtrado 


\section{Saída:}

-sinal filtrado.

Esta função é responsável por fazer a filtragem do sinal de entrada (LPF).

\section{Função modulador Mach-Zehnder (machzehnder.m)}

\section{Entradas:}

-sinal OFDM sobre amostrado.

-índice de modulação desejado.

-potência de bombeio do modulador MZ.

\section{Saída:}

-sinal OFDM sobre amostrado após função de transferência do modulador MZ.

Nesta função, faz-se o sinal passar pelo modulador Mach-Zehnder.

\section{Função de Suavização de espectro (signal_smoothing.m)}

\section{Entradas:}

-sinal a ser suavizado.

-fator de suavização.

\section{Saída:}

-sinal suavizado.

Esta função é responsável por usar técnicas de simulação para suavizar o espectro do sinal, tendo assim uma melhor visualização do mesmo, sem grandes oscilações.

8. Função de multiplicação do sinal OFDM sobre amostrado com a função de transferência da fibra (channel_conv.m)

\section{Entradas:}

-sinal a ser transmitido pela fibra.

-resposta ao impulso da fibra.

-espaçamento entre amostras do canal no domínio do tempo.

-banda de observação desejada

\section{Saída:}

-sinal após transmissão.

Esta função faz a multiplicação no domínio da frequência dos dois sinais de entrada: o sinal a ser transmitido pela fibra e a resposta ao impulso da fibra. 
9. Função que passa o sinal recebido pelo receptor OFDM(OFDM_receiver.m)

\section{Entradas:}

-sinal OFDM detectado pelo fotodiodo PIN.

- formato de modulação.

- número de sub-portadoras.

\section{Saída:}

-sinal após receptor OFDM.

Nessa função tem-se o processo reverso do transmissor, dessa forma, faz-se a paralelização do sinal e a remoção do prefixo cíclico. Faz-se então a FFT, para em seguida decodificar-se o sinal. Enfim, faz-se a serialização do sinal.

10. Função de sub-amostragem do sinal OFDM transmitido (downsample.m)

\section{Entradas:}

-sinal OFDM transmitido pela fibra.

-fator de sub-amostragem.

\section{Saída:}

-sinal OFDM transmitido pela fibra sub-amostrado.

Uma função que retorna o sinal à taxa de amostragem inicial, para futura análise e recepção.

11. Função do fotodiodo PIN (photodiodepin.m)

\section{Entradas:}

-sinal OFDM transmitido pela fibra sub-amostrado.

-responsividade do fotodiodo.

\section{Saída:}

-sinal detectado pelo fotodiodo.

Função responsável por caracterizar o fotodiodo PIN. Faz-se uma simples multiplicação do módulo do sinal pela responsividade do diodo.

12. Função de adição do ruído (add_noise.m)

\section{Entradas:}

-sinal detectado pelo diodo PIN.

-valor em $\mathrm{dB}$ de $E_{b} / N 0$.

-quantidade de símbolos OFDM gerados.

-duração do símbolo OFDM.

-quantidade de bits por sub-portadora. 
-resolução do sinal analógico no tempo.

-impulso.

\section{Saída:}

-sinal de entrada com ruído adicionado.

-ruído.

Essa função é responsável pela geração e adição do ruído térmico do circuito ao sinal de entrada.

13. Função que representa o conversor $A / D$ (downsample.m)

\section{Entradas:}

-sinal OFDM detectado com ruído.

-fator de sub-amostragem.

\section{Saída:}

-sinal digital.

Essa função é responsável por sub-amostrar o sinal analógico, tomando amostras desse sinal, igualmente espaçadas entre si, ou seja, simulando a digitalização do sinal.

14. Função de cálculo da BER (BER_calc.m)

\section{Entradas:}

-sequência binária transmitida.

-sequência binária recebida.

\section{Saída:}

-BER.

Função que avalia a taxa de erro de bit, por uma simples divisão da quantidade dos bits que foram detectados com erro pelo total de bits transmitidos. 



\section{Referências Bibliográficas}

[1] CAMERA, M. 100GbE optical transport, appropriate modulation formats, and impact on deployed transport networks. OFC/NFOEC, $p$ p. 1-3, 2010. 1

[2] CHAMBERLAin B. L. DANIELSON, G. W. D. D. L. F. R. L. G. E. M. K. G. E.; YOUNG, M. Optical fiber characterization. NBS Special Publication 637. Gaithersburg, MD: Nat. Bureau Standards, 1982. 1.1

[3] ALVES, T.; CARTAXO, A. Characterizing multimode fiber bandwidth for gigabit ethernet applications. Corning White Paper n. WP4062, 1988. 1.1

[4] AMPHAWAN FRANK PAYNE, D. B. A.; SHAH, N. Derivation of an analytical expression for the power coupling coefficient for offser launch into multimode fiber. Journal of Lightwave Technology, vol. 28, No. 6, March 15, pp. 861-869, 2010. 1.1, 1.3

[5] BIKHAZI N.W., J. M. A. A. MIMO signaling over the MMF optical broadcast channel with square-law detection. Communications, IEEE Transactions, march 10, pp. 614-617, 2009. 1.1

[6] D. H. SIM, Y. T.; CHUNG, Y. C. High-speed multimode fiber transmission by using modefield matched center-launching technique. Journal of Lightwave Technology, Vol. 27, $N^{o} 8$, April 15, pp. 1018-1026, 2009. 1.3

[7] FANG JUNWEN ZHANG, Y. S. B. H. N. C. W. The improvement of transmission properties for multi-mode fiber based on launching optical field shaping and feedback equalization. Communications and Photonics Conference and Exhibition (ACP), pp. 1-2, 2009. 1.3

[8] FREUND CHRISTIAN-A. BUNGE, N. N. L. D. M. R. E.; CASPAR, C. High-speed transmission in multimode fibers. Journal of Lightwave Technology, Vol. 28, $N^{o}$ 4, February 15, pp. 569-586, 2010. 1.3

[9] MA, Y. T. Y.; SHIEH, W. 107 Gbit/s transmission over multimode fibre with coherent optical OFDM using centre launching technique. Electronics Letters, 30th July, Vol. 45, No. 16, pp. 848-849, 2009. 1.3

[10] ALVES, T.; CARTAXO, A. Performance degradation due to OFDM-UWB radio signal transmission along dispersive single-mode fiber. Photonics Technology Letters, IEEE, vol. 21, No. 3, February 1, pp. 158-160, 2009. 1.3 
[11] YEE Y.X. GUO, L. O. J. Z. J. H. M. Performance evaluation of bidirectional MB-OFDM UWB over cable, MMF and SMF. Microwave Symposium Digest. MTT '09. IEEE MTT-S International, pp. 357-360, 2009. 1.3

[12] RENWEI TONG ZHENGRONG, X. X. Y. X. W. Research on adaptive modulation algorithm of multimode fiber communication system using coherent optical OFDM. International Conference on Communications and Mobile Computing, vol. 2, pp. 26-29, 2010. 1.3

[13] MARCUSE, D. Theory of dieletric optical waveguides. 2. ed. [S.1.]: Academic Press. 2.1, $2.1,2.1,2.1$

[14] BOTTACCHI, S. Multi-Gigabit trasmission over multimode optical fibre. 1. ed. [S.1.]: Wiley, 2006. 2.1, 1

[15] ARMSTRONG, J. OFDM for optical communications. Journal of Lightwave Technology, vol. 27, No. 3, February 1, 2009. 3.1, 3.1, 3.2 